Leonardo de Oliveira Martins

\title{
Estimativas de Atributos Volumétricos de Curvatura em Dados Sísmicos
}

Tese apresentada ao Programa de Pós-graduação em Informática do Departamento de Informática da PUC-Rio como requisito parcial para obtenção do título de Doutor em Informática

Orientador: Prof. Marcelo Gattass 


\section{Leonardo de Oliveira Martins}

\section{Estimativas de Atributos Volumétricos de Curvatura em Dados Sísmicos}

Tese apresentada como requisito parcial para obtenção do grau de Doutor pelo Programa de Pós-graduação em Informática do Departamento de Informática do Centro Técnico Científico da PUCRio. Aprovada pela Comissão Examinadora abaixo assinada.

Prof. Marcelo Gattass

Orientador

Departamento de Informática - PUC-Rio

Prof. Pedro Mário Cruz e Silva

TECGRAF/PUC-Rio

Prof. Aristófanes Corrêa Silva

UFMA

Prof. Adelson Santos de Oliveira

PETROBRAS

Prof. Waldemar Celes

PUC-Rio

Prof. Hélio Côrtes Vieira Lopes

PUC-Rio

Prof. José Eugênio Leal

Coordenador Setorial do Centro Técnico Científico - PUC-Rio 
Todos os direitos reservados. É proibida a reprodução total ou parcial do trabalho sem autorização da universidade, do autor e do orientador.

\section{Leonardo de Oliveira Martins}

Leonardo de Oliveira Martins nasceu em São Luís, Maranhão, Brasil. Graduou-se bacharel em Ciência da Computação na UFMA (Universidade Federal do Maranhão) em 2005. Concluiu o mestrado em Engenharia de Eletricidade com ênfase em Processamento de Imagens Digitais também na UFMA em 2007. Desde 2008 faz parte do TECGRAF/PUC-Rio, onde participa do desenvolvimento de um sistema de visualização de dados sísmicos realizado em parceria com a gerência de Tecnologia em Geofísica da Petrobras.

Ficha Catalográfica

Martins, Leonardo

Estimativas de Atributos Volumétricos de Curvatura em Dados Sísmicos / Leonardo de Oliveira Martins; orientador: Marcelo Gattass. - Rio de Janeiro : PUC-Rio, Departamento de Informática, 2012.

v., 66 f: il. ; $29,7 \mathrm{~cm}$

1. Tese (doutorado) - Pontifícia Universidade Católica do Rio de Janeiro, Departamento de Informática.

Inclui referências bibliográficas.

1. Informática - Tese. 2. Curvatura. 3. Atributos Sísmicos. 4. Dados Sísmicos 3D. 5. Orientação Local. I. Gattass, Marcelo. II. Pontifícia Universidade Católica do Rio de Janeiro. Departamento de Informática. III. Título. 


\section{Agradecimentos}

Aos meus pais José de Ribamar Braga e Helena Maria pela educação recebida, por todo o carinho e apoio em todos os momentos de minha vida.

A minhas irmãs Maria Carolina e Cláudia Maria pelo companheirismo e amizade sempre constantes.

Ao meu orientador Marcelo Gattass pela confiança e paciência a mim dirigidas, pela oportunidade de participar deste trabalho de pesquisa.

Ao meu co-orientador Pedro Mário, pelos comentários, correções e sugestões sempre relevantes dentro do tema da pesquisa.

Aos meus ex-professores e colegas da UFMA, pela valiosa formação acadêmica recebida, assim como pela amizade, confiança e companheirismo recebidos ao longo de toda a minha trajetória.

A todos os professores e colegas do Departamento de Informática da PUC-Rio pelo ótimo ambiente acadêmico.

À coordenação do Tecgraf, pelo excelente ambiente de pesquisa e suporte tecnológico oferecido.

A todos os colegas da Petrobras que contribuíram com essa pesquisa, em especial a Fernando Barbosa, pelo acompanhamento e validação dos resultados obtidos com dados reais.

A todos os amigos e amigas que de alguma forma contribuíram para a realização deste trabalho.

Ao $\mathrm{CNPq}$, à Fundação Padre Leonel Franca e à PUC-Rio pelos auxílios concedidos, sem os quais este trabalho não poderia ter sido realizado. 


\section{Resumo}

Martins, Leonardo; Gattass, Marcelo. Estimativas de Atributos Volumétricos de Curvatura em Dados Sísmicos. Rio de Janeiro, 2012. 66p. Tese de Doutorado - Departamento de Informática, Pontifícia Universidade Católica do Rio de Janeiro.

Atributos de curvatura são uma importante ferramenta para visualização e interpretação de feições estruturais em dados sísmicos. Tais medidas podem realçar falhas e fraturas sutis que não estavam evidentes no dado de amplitude, fornecendo ao intérprete informações importantes para a construção do modelo geológico da área de interesse. Neste trabalho é apresentado um método para estimar atributos de curvatura volumérica em dados sísmicos empilhados. A partir do dado de amplitude, é computado um atributo identificador de horizonte, o qual permite que horizontes sísmicos sejam representados como superfícies de nível. Dessa maneira, o gradiente desse atributo fornece uma representação coerente do campo de normais do volume. Fórmulas para o cálculo de curvatura em superfícies implícitas são usadas para obter vários atributos de curvatura úteis na delineação e predição de importantes feições estratigráficas. Testes realizados com dados sintéticos e reais mostram que o método proposto é capaz de fornecer estimativas coerentes de atributos de curvatura a um baixo custo de processamento. São avaliados três atributos identificadores de horizontes: fase instantânea, derivada vertical e atributo de ridges.

\section{Palavras-chave}

Curvatura. Atributos Sísmicos. Dados Sísmicos 3D. Orientação Local. 


\section{Abstract}

Martins, Leonardo; Gattass, Marcelo (advisor) . Estimates of volumetric curvature attributes in seismic data. Rio de Janeiro, 2012. 66p. DSc Thesis — Departamento de Informática, Pontifícia Universidade Católica do Rio de Janeiro.

Curvature attributes are powerful tools for visualization and interpretation of structural features in seismic data. Such measures may highlight faults and subtle fractures that were not evident in amplitude data, providing important information to the interpreter to build the geological model of the area of interest. This paper presents a method for estimating volumetric curvature attributes in post-stack seismic data. Using amplitude volume, an horizon identifier attribute is computed, in order to represent seismic horizons as level surfaces. Thus, the gradient of this attribute provides a coherent estimate of volumetric normal field. Formulas for the calculation of curvature in implicit surfaces are used to compute several curvature attributes useful in the delineation and prediction of important stratigraphic features. Tests with synthetic and real data show that the proposed method is able to provide consistent estimates of attributes of curvature at low cost processing. Three horizon identifer attributes are evaluated: instantaneous phase, vertical derivative and ridge attribute.

\section{Keywords}

Curvature. Seismic Attributes. 3D Seismic Data. Local Orientation. 


\section{Sumário}

1 Introdução $\quad 15$

2 Trabalhos relacionados $\quad 18$

3 Conceitos básicos $\quad 22$

3.1 Curvatura 22

3.2 Atributos de curvatura 23

3.3 Relação entre feições sísmicas e curvatura 26

4 Método proposto $\quad 30$

4.1 Atributos identificadores de horizontes 31

4.2 Cálculo de curvatura em superfícies implícitas 36

4.3 Suavização da estimativa das derivadas 38

5 Resultados $\quad 41$

5.1 Resultados em dados sintéticos $\quad 41$

5.2 Resultados em um dado real 46

6 Conclusões e trabalhos futuros $\quad 60$ 


\section{Lista de figuras}

3.1 Convenção de sinais adotada para valores de curvatura. Adaptado de Roberts (2001)

3.2 Definição de curvatura. Adaptado de Donias et al. (1998) 23

3.3 Curvaturas principais $k_{1}$ e $k_{2}$ para um ponto em uma superfície. 24

3.4 Classificação da forma geométrica de acordo com as curvaturas principais $k_{1}$ e $k_{2}$. Através dessas duas medidas é possível inferir importantes informações acerca da morfologia local de uma superfície. Adaptado de Mynatt et al. (2007).

3.5 Classificação da forma geométrica de acordo com a curvatura gaussiana $k_{G}$ e a curvatura média $k_{M}$. Assim como no caso das curvaturas principais, através dessas duas medidas é possível inferir importantes informações acerca da morfologia local de uma superfície. Adaptado de Mynatt et al. (2007).

3.6 Exemplo de variação do atributo curvedness de acordo com a morfologia local. Fonte: Phillips e Todd (1996).

3.7 Classificação da forma geométrica de acordo com o índice de forma. Um valor intermédiário entre as classes representa uma figura gemétrica de transição entre as mesmas. Adaptado de Yoshida et al. (2002).

3.8 Horizonte com valores de tempo (a); atributo de coerência (b); curvatura principal $k_{1}(\mathrm{c})$; curvatura principal $k_{2}(\mathrm{~d})$. As setas indicam falhas e outras feições relevantes. Fonte: Chopra e Marfurt (2006).

3.9 Atributos $k_{1}$ e $k_{2}$, respectivamente, obtidos através da estimativa de curvatura volumétrica proposta por Al-Dossary e Marfurt (2006). As setas indicam a correspondência entre a sísmica original e a resposta dos atributos. Adaptado de Chopra e Marfurt (2007a).

4.1 Método proposto. A partir de um dado volumétrico de amplitude, é calculado um atributo identificador de horizontes cujo gradiente fornece uma representação coerente do campo de normais volumétrico. Tal campo de normais é usado como entrada para fórmulas de cálculo de curvatura em superfícies implícitas.

4.2 Relação entre a amplitude e a fase instantânea em um traço sísmico de um dado sintético.

4.3 Comparação entre a amplitude e a fase instantânea em um dado sintético.

4.4 Relação entre a amplitude e a derivada vertical em um traço sísmico de um dado sintético.

4.5 Comparação entre a amplitude e a derivada vertical em um dado sintético.

4.6 Relação entre a amplitude e o atributo de ridges em um traço sísmico de um dado sintético.

4.7 Comparação entre a amplitude e o atributo de ridges em um dado sintético. 
5.1 Modelo de convolução. Adaptado de Gerhardt (1998)

5.2 Seção vertical do dado sintético usado nos experimentos e um horizonte rastreado em formato de semi-esfera.

5.3 Seção vertical do dado sintético original e com acréscimo de ruído aleatório.

5.4 Atributos volumétricos $k_{1}$ e $k_{2}$ (curvaturas principais), obtidos tendo a fase instantânea (a), a derivada vertical (b) e o atributo de ridges (c) como atributos identificadores de horizontes. Os atributos estão sendo visualizados ao longo de um horizonte rastreado a partir do volume de amplitudes. O operador de derivada considera uma vizinhança de $5 \times 5 \times 5$ amostras e uma variância $\sigma^{2}=0,5$ para a derivada da função gaussiana.

5.5 Curvaturas volumétricas média $\left(k_{M}\right)$ e gaussiana $\left(k_{G}\right)$ computadas tendo a fase instantânea (a), a derivada vertical (b) e o atributo de ridges (c) como atributos identificadores de horizontes. Os atributos estão sendo visualizados ao longo de um horizonte rastreado a partir do volume de amplitudes. O operador de derivada considera uma vizinhança de $5 \times 5 \times 5$ amostras e uma variância $\sigma^{2}=0,5$ para a derivada da função gaussiana.

5.6 Atributos volumétricos de índice de forma e curvicidade, tendo a fase instantânea (a), a derivada vertical (b) e o atributo de ridges (c) como atributos identificadores de horizontes. Os atributos estão sendo visualizados ao longo de um horizonte rastreado a partir do volume de amplitudes. O operador de derivada considera uma vizinhança de $5 \times 5 \times 5$ amostras e uma variância $\sigma^{2}=0,5$ para a derivada da função gaussiana.

5.7 Comportamento dos atributos de curvatura em relação à sísmica original. Os atributos volumétricos de curvatura $k_{1}$ e $k_{2}$ estão sendo visualizados ao longo de um horizonte rastreado a partir do dado de amplitude e foram obtidos através do uso da fase instantânea $(a$ e $b$ ), derivada vertical ( $c$ e $d$ ) e atributo de ridges ( $e$ e $f$ ) como atributos identificadores de horizontes. As setas indicam que existe uma correspondência entre os picos e vales do horizonte na sísmica e a resposta dos atributos volumétricos de curvatura. $O$ operador de derivada considera uma vizinhaną de $5 \times 5 \times 5$ amostras e uma variância $\sigma^{2}=0,5$ para a derivada da função gaussiana.

5.8 Fatia de tempo da sísmica original e fatias correspondentes do atributo $k_{2}$ obtidas através da fase instantânea (a), derivada vertical (b) e atributo de ridges (c). O operador de derivada considera uma vizinhana de 9×9×9 amostras e uma variância $\sigma^{2}=0,9$.

5.9 Variação dos atributos de curvatura ocasionada pela pela mundança no tamanho do operador de derivada. Atributo de curvedness obtido a partir da derivada vertical, em uma fatia de tempo, considerando

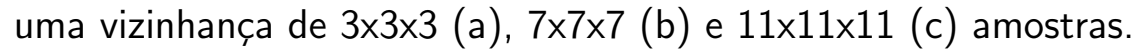


5.10 Influência da variância $\sigma^{2}$ no resultado do atributo de curvatura. São mostrados os atributos volumétricos $k_{1}$ e $k_{2}$, obtidos usando o atributo de derivada vertical, e visualizados ao longo de um horizonte rastreado. $O$ tamanho do operador de derivada é de $7 \times 7 \times 7$ amostras. Podemos ver que o aumento de $\sigma^{2}$ é capaz de reduzir o detalhamento do resultado final dos atributos.

5.11 Comparação entre o atributo de índice de forma gerado usando a fase instantânea (a), a derivada vertical (b) e o atributo de ridges (c) como atributos identificadores de horizontes, considerando uma vizinhança de $11 \times 11 \times 11$ amostras, para o operador de derivada. 0 valor da variância $\sigma^{2}$ da derivada da gaussiana é $\sigma^{2}=1,1$.

5.12 Comparação do método proposto com a abordagem proposta por Al-Dossary e Marfurt (2006). Em (a) temos o atributo volumétrico $k_{1}$ obtido através de uma implementação do trabalho de Al-Dossary e Marfurt (2006) sendo exibido ao longo de um horizonte rastreado. Em (b), (c) e (d) temos o mesmo atributo volumétrico obtido através da fase instantânea (b), derivada vertical (c) e atributo de ridges $(\mathrm{d})$, ao longo do mesmo horizonte. Considerou-se o tamanho do operador de derivada de $7 \times 7 \times 7$ amostras e a variância da derivada da gaussiana $\sigma^{2}=0,7$. Percebe-se nitidamente a presença das mesmas estr uturas principais nos atributos obtidos através das abordagens. Entretanto, na implementação do método de Al-Dossary e Marfurt (2006) as setas verdes indicam a presença de artefatos causados por ruído de aquisição, confirmados pelo intérprete, que não aparecem nos atributos obtidos de acordo com o método proposto.

5.13 Comparação do método proposto com a abordagem proposta por Al-Dossary e Marfurt (2006), mostrando a intersecção de uma seção vertical da sísmica original com um horizonte rastreado. Ao longo desse horizonte são exibidos os valores do atributo volumétrico $k_{1}$ obtido através da estimativa de Al-Dossary e Marfurt (2006) (a), e usando os atributos de fase instantânea (b), derivada vertical (c) e atributo de ridges (d) através do método proposto. Considerou-se o tamanho do operador de derivada de $5 \times 5 \times 5$ amostras e a variância da derivada da gaussiana $\sigma^{2}=0,5$. Uma inspeção visual mostra que os atributos obtidos através do método proposto apresentam menor sensibilidade a ruído de aquisição para o dado real usado nos experimentos. Além disso, as setas indicam que o método proposto é capaz de gerar maior continuidade no delineamento de falhas e fraturas confirmadas pelo intérprete. 
5.14 Comparação do método proposto com a abordagem proposta por Al-Dossary e Marfurt (2006). Em (a) temos a intersecção da sísmica original com uma fatia de tempo (horizontal) do atributo volumétrico $k_{1}$ obtido através do método de Al-Dossary e Marfurt (2006). Em (b), (c) e (d) temos o mesmo resultado usando os atributos de fase instantânea, derivada vertical e atributo de ridges, respectivamente, através do método proposto. Considerou-se o tamanho do operador de derivada de $5 \times 5 \times 5$ amostras e a variância da derivada da gaussiana $\sigma^{2}=0,5$. Os resultados mostram que os atributos obtidos através do método proposto apresentam menor sensibilidade a ruído de aquisição para o dado real usado nos experimentos e maior continuidade no delineamento de falhas e fraturas confirmadas pelo intérprete. As setas roxas indicam uma falha geológica capturada pelo método proposto mas ausente no atributo obtido através da implementação da abordagem de AlDossary e Marfurt (2006) 


\section{Lista de tabelas}

5.1 Curvatura média ao longo de um horizonte rastreado obtida através dos atributos propostos

5.2 Comparação entre o método proposto e o método de (AL-DOSSARY; MARFURT, 2006)

5.3 Curvatura média ao longo de um horizonte rastreado (dado com ruído)

5.4 Comparação entre o método proposto e o método de Al-Dossary e Marfurt (2006) (dado com ruído)

5.5 Tempo de processamento do método proposto variando o tamanho do operador de derivada

5.6 Comparação entre o tempo de processamento do método proposto e o da abordagem de (AL-DOSSARY; MARFURT, 2006) 
Agir, eis a inteligência verdadeira. Serei o que quiser. Mas tenho que querer o que for. $O$ êxito está em ter êxito, e não em ter condições de êxito. Condições de palácio tem qualquer terra larga, mas onde estará o palácio se não o fizerem ali?

Fernando Pessoa, Livro do Desassossego. 


\section{Introdução}

Atributos sísmicos podem prover ao intérprete importantes informações a respeito da geometria e das propriedades físicas das sub-superfícies em estudo, realçando feições estruturais e estratigráficas que não estavam evidentes no levantamento original. Assim, tais medidas desempenham um importante papel na caracterização e geração de modelos geológicos das áreas de interesse.

Nos últimos anos, atributos volumétricos de curvatura vêm destacando-se como importantes ferramentas para visualização e predição de fraturas sutis, falhas, canais, dentre outras feições estruturais e estratigráficas. Tais atributos provêem, para cada amostra do dado volumétrico de entrada, uma medida do quão curva a superfície local está, em relação a um plano. Assim, a análise de atributos volumétricos de curvatura pode ser usada como uma poderosa ferramenta de interpretação estrutural e estratigráfica (CHOPRA; MARFURT, 2006).

Inicialmente, atributos de curvatura em dados sísmicos eram obtidos a partir de horizontes interpretados manualmente. O mapeamento dos horizontes, ou refletores sísmicos, do conjunto de dados é uma das tarefas mais importantes da interpretação sísmica (FIGUEIREDO, 2007).

Essa abordagem, entretanto, traz algumas limitações. A interpretação manual de horizontes é uma tarefa bastante difícil, trabalhosa e dependente das habilidades do intérprete. Dessa forma, as estimativas de curvatura realizadas a partir de horizontes interpretados podem estar sujeitas a artefatos indesejáveis e propagação de ruído gerados pelo processo de interpretação. Além disso, nem todas as feições geológicas relevantes estão localizadas ao longo dos refletores (CHOPRA; MARFURT, 2007a).

Um importante avanço no campo de atributos sísmicos ocorreu com o surgimento dos atributos volumétricos de curvatura (AL-DOSSARY; MARFURT, 2006), os quais associam, para cada amostra do dado volumétrico de entrada, um valor de curvatura, sem a necessidade da amostra estar em um horizonte. Desse modo, as estimativas de curvatura pode ser visualizadas ao longo de superfícies, fatias, horizontes, ou qualquer outro objeto sísmico.

O objetivo principal desta tese é propor um método para estimar atributos volumétricos de curvatura em dados sísmicos de amplitude pós-empilhados, usando o suporte matemático provido pela geometria diferencial, e que forneça atributos de curvatura capazes de auxiliar os intérpretes no delineamento de 
falhas, fraturas e outras feições estruturais e estratigráficas relevantes.

Para tanto, é necessário levar em conta a natureza particular do dado sísmico de amplitudes. Os experimentos realizados em trabalhos anteriores (SILVA et al., 2003); (SILVA, 2004) indicam que o gradiente da amplitude não provê uma estimativa coerente do campo de normais, pois além de sua natureza oscilatória, a amplitude pode apresentar uma grande variação lateral ao longo do horizonte sísmico, mesmo localmente. Em outras palavras, horizonte sísmicos não podem ser considerados iso-superfícies em dados de amplitude.

Dessa forma, faz-se necessário, a partir do dado de entrada, a computação de um atributo identificador de horizontes, o qual permita representar adequadamente os refletores sísmicos como superfícies de nível. Dessa maneira, o gradiente desse atributo é capaz de fornecer uma estimativa mais coerente do campo de normais do volume sísmico. A partir desse ponto, o campo de normais obtido pode ser usado para obter atributos de curvatura volumétrica a partir de equações matemáticas para o cálculo de curvatura em superfícies implícitas.

Neste trabalho são examinados três atributos identificadores de horizonte: fase instantânea, derivada vertical e atributo de ridges.

O uso do gradiente da fase instantânea para a obtenção do campo de normais em dados sísmicos foi proposto por Silva (2004). Nesse trabalho, o autor realiza uma comparação entre o gradiente da amplitude e o gradiente da fase instantânea para fins de iluminação, demostrando a superioridade deste último. A fase instantânea é um atributo que assume valores próximos de zero nos picos de amplitude, o que favorece a representação de refletores como superfícies de nível.

A derivada vertical fornece uma medida simples de variação local de amplitude no traço sísmico. Nesse caso, os máximos e mínimos locais iriam a zero, e consequentemente, as amostras do volume correspondentes a refletores sísmicos também.

A detecção de cristas (ridges) e vales (valleys) é uma importante tarefa em processamento de imagens e visão computacional. Nesses contextos, cristas correspondem a regiões de máximos locais da imagem, e vales correspondem a mínimos locais. Assim, um detector de cristas e vales é capaz de capturar o interior de objetos no domínio da imagem, sendo bastante útil em aplicações de segmentação. Neste trabalho, parte-se da hipótese de que horizontes sísmicos correspondem a máximos ou mínimos locais no dado de amplitude. Assim, investiga-se o uso de um atributo identificador de ridges/valleys em fatias do volume de amplitude para representar horizontes sísmicos como superfícies de nível. 
Uma vez que os refletores sísmicos estão adequadamente representados como superfícies de nível, é possível a aplicação de equações para cálculo de curvatura voltadas para superfíces implícitas (MARTINS et al., 2012). Neste trabalho foram usadas adaptações das fórmulas fechadas de curvatura propostas por Goldman (2005), as quais são derivadas das equações clássicas de geometria diferencial para curvas e superfícies paramétricas.

Dentre as contribuições apresentadas por este trabalho pode-se citar uma nova abordagem para a computação de atributos volumétricos de curvatura em dados sísmicos, a qual, levando em conta a natureza particular do dado sísmico, e fundamentada inteiramente na teoria da geometria diferencial, é capaz de prover uma estimativa razoável dos principais atributos de curvaturas usados na interpretação e predição de diversas feições estruturais e estratigráficas, a um tempo de processamento aceitável em relação ao tamanho do dado de entrada.

Este trabalho está organizado da seguinte maneira. No Capítulo 2 é feita uma lista de alguns trabalhos relacionados ao tema abordado, mostrando desde as primeiras experiências conhecidas de uso de curvatura em dados sísmicos até o estado atual do tema na literatura. O Capítulo 3 apresenta alguns conceitos necessários para a compreensão do presente trabalho, enquanto que o método proposto para estimar os atributos de curvatura é apresentada no Capítulo 4. O Capítulo 5 apresenta os resultados dos atributos de curvatura obtidos com a abordagem proposta, aplicada em dados sintéticos e reais. Finalmente, o Capítulo 6 apresenta algumas conclusões obtidas a partir da análise dos resultados, bem como sugestões de trabalhos futuros, com a finalidade de dar continuidade à linha de pesquisa adotada neste trabalho. 


\section{2}

\section{Trabalhos relacionados}

As primeiras aplicações de curvatura em dados sísmicos datam do final da década de 80. Ericsson et al. (1988) demonstraram a existência de uma relação entre produção e curvatura em reservatórios.

Donias et al. (1998) propõem um método para estimar as curvaturas principais em dados sísmicos 2D e 3D em diferentes escalas. As curvaturas são então obtidas pela aplicação de fórmulas de geometria diferencial. O método foi capaz de detectar estruturas de domo que não estavam evidentes no dado original de amplitude. Apesar de coerente do ponto de vista matemático, a abordagem usada pelos autores assume que as estruturas geológicas podem ser localmente definidas como iso-superfícies implícitas do campo escalar de amplitudes, o que pode levar a resultados equivocados. Além disso, para o caso 3D, as curvaturas principais são obtidas indiretamente, através de uma busca pelas direções que fornecem valores extremos de curvaturas normais para cada amostra.

Roberts (2001) apresenta uma introdução aos principais atributos de curvatura e uma série de aplicações desses atributos voltadas para horizontes interpretados. O autor também apresenta fórmulas para a estimativa de tais atributos em horizontes. São também realizadas comparações entre atributos de curvatura e outras técnicas usadas por intérpretes para identificação de falhas. Apesar de fornecerem resultados satisfatórios, essa abordagem faz uso de atributos obtidos a partir de horizontes interpretados, não contemplando o volume sísmico como um todo.

Sigismondi e Soldo (2003) usam diferentes tamanhos de janelas de análise para obter medidas de curvatura máxima em diferentes escalas. A partir de horizontes interpretados, os autores podem extrair feições sutis que não estavam evidentes no mapeamento original. Os autores também realizam uma comparação entre atributos de curvatura e atributos de mergulho na tarefa de discriminar falhas e outras feições. Novamente, apenas atributos obtidos a partir de horizontes mapeados por intérpretes são considerados nessa abordagem.

Funções de transferência multi-dimensionais baseadas em curvatura para fins de visualização volumétrica foram propostas por Kindlmann et al. (2003). Os autores apresentam um método para a estimativa de medidas de curvatura, com ênfase na escolha de filtros que aumentem a precisão do cálculo de 
derivadas e convoluções. É demostrado que a visualização de propriedades de curvatura é capaz de acrescentar informação em aplicações de visualização volumétrica, em pelo menos três áreas: renderização volumétrica não fotorealística, suavização de superfícies via difusão anisotrópica e visualização de incerteza em iso-superfícies.

Marfurt (2006) propõe estimativas de dip e azimuth realizando buscas discretas por máxima correlação em volumes de coerência. São usadas múltiplas janelas de análise com o objetivo de evitar descontinuidades que são encontradas em mudanças bruscas de dip e azimuth e garantir maior precisão no delineamento de falhas sutis. O autor demonstra que estimativas mais precisas de dip e azimuth fornecem medidas mais precisas de coerência e curvatura.

Atributos de curvatura volumétrica em dados sísmicos foram propostos por Al-Dossary e Marfurt (2006). Os autores demonstram que medidas de curvatura volumétrica podem ser obtidas através das derivadas dos volumes de dip e azimuth, estimados de acordo com a abordagem de Marfurt (2006). O uso de operadores de derivadas fracionárias permite uma abordagem multiespectral para a estimativa de curvatura, realçando as feições sísmicas em diferentes escalas. Tal enfoque ajuda na extração de informações sutis do dado sísmico de amplitude. Entretanto, apesar de apresentar considerável grau de robustez na estimativa dos volumes de dip e azimuth, percebe-se na prática que esse é um passo bastante custoso computacionalmente. Além disso, os volumes de dip e azimuth são obtidos de forma semi-automática, através da definição dos ângulos mínimo e máximo usados na busca do ângulo (mergulho) que fornece a maior coerência; uma maior faixa de busca pode aumentar ainda mais o tempo de processamento.

Chopra e Marfurt (2007b) examinam diversas aplicações de curvatura em dados sísmicos, realizando comparações entre a curvatura obtida de forma volumétrica, através da abordagem de Al-Dossary e Marfurt (2006), e a curvatura obtida a partir de horizontes interpretados. Os autores examinam estratégias para minimizar o ruído dos dados em ambas as abordagens. A partir de exemplos, os autores demonstram que a curvatura volumétrica possui diversas vantagens sobre a curvatura obtida com base em horizontes interpretados.

Klein et al. (2008) propõem uma outra abordagem para a obtenção de curvaturas volumétricas em dados sísmicos, sem a necessidade de obtenção prévia dos volumes de dip e azimuth. Inicialmente, é realizada a construção de pequenas superfícies locais no redor de cada amostra do volume, através de correlação cruzada, interpolação e ajuste de uma superfície quadrática. A seguir, os atributos de curvatura são obtidos usando os coeficientes da 
superfície ajustada em fórmulas de geometria diferencial apresentadas por Roberts (2001). São apresentados diversos atributos de curvatura úteis na visualização de diversas feições estratigráficas e também uma comparação entre o atributo de coerência e os atributos de curvatura. Os autores demonstram através de exemplos que a curvatura pode demonstrar a existência de fraturas mesmo quando estas se encontram fracamente iluminadas no dado original.

Dessa maneira, Klein et al. (2008) propõem uma extensão do trabalho de Roberts (2001) para volumes sísmicos, usando as mesmas equações desse autor, em superfícies quadráticas locais ajustadas via correlação cruzada, interpolação e método de mínimos quadrados. Uma crítica a esse método encontra-se no fato de que nem toda superfície sísmica pode ser ajustada dessa maneira; certamente haverá ocasiões em que não será possível o ajuste, em áreas em que a orientação local não está muito bem definida. Além disso, a abordagem originalmente contempla apenas uma vizinhança de 3x3x3 amostras, sendo necessário a adaptação das equações para vizinhanças maiores, se quisermos, por exemplo, gerar resultados mais suaves de curvatura.

No trabalho de Mai et al. (2009), atributos de curvatura obtidos através da abordagem de Al-Dossary e Marfurt (2006) são visualizados simultaneamente com o intuito de delinear os diversos componententes de um sistema de fraturas. É proposto um método para geração de diagramas de rosa para mostrar os lineamentos das falhas e fraturas da Bacia de Cuu Long, Vietnam.

Chopra et al. (2011a) examinam os diversos tipos de ruído aos quais os dados sísmicos estão sujeitos e enfatizam a necessidade de pré-condicionamento dos mesmos, com o intuito de gerar atributos sísmicos sem a presença de artefatos. Após uma etapa de limpeza (filtros orientados) é realizada um passo de realce de frequências no dado de entrada. Os autores ilustram através de exemplos o impacto das etapas de pré-condicionamento dos dados de entrada na computação de atributos de curvatura e coerência em dados volumétricos de Alberta, Canadá.

O trabalho de Chopra e Marfurt (2011) examina a estimativa de curvatura através do gradiente da amplitude sísmica ao longo de horizontes. Os autores fazem uma distinção entre curvatura estrutural, obtida através de volumes de dip e azimuth (AL-DOSSARY; MARFURT, 2006) e a curvatura obtida usando unicamente o campo escalar de amplitudes. Alternativamente, outros atributos tais como impedância e RMS podem ser usados. É demonstrado que a curvatura gerada através da amplitude pode revelar maiores detalhes da sísmica de entrada, em comparação com a curvatura estrutural. Entretanto, podemos ponderar que nem sempre a amplitude sísmica irá ter o comportamento esperado de uma iso-superfície, levando a estimativas equivocadas de 
orientação local ao longo dos refletores.

A abordagem proposta nesta tese busca contornar os problemas listados nas abordagens anteriores propondo uma maneira mais simples e eficiente de estimar atributos volumétricos de curvatura. Para tanto, em primeiro lugar, a obtenção dos atributos se faz pela representação adequada de refletores como superfícies de nível, via computação de um atributo identificador de horizonte, e em seguida pela aplicação de fórmulas de geometria diferencial sobre o mesmo. A variação do tamanho do operador de derivada permite obter uma estimativa suavizada dos gradientes levando em conta diferentes tamanhos de vizinhança, fornecendo resultados mais detalhados (vizinhança menor) ou com menor nível de detalhamento (vizinhança maior). Dessa maneira, o presente trabalho propõe uma abordagem que, por levar em conta a natureza particular do dado sísmico de amplitude, faz uso do suporte provido pela teoria de geometria diferencial e obtém atributos volumétricos de curvatura de maneira simples e eficiente do ponto de vista computacional. 


\section{Conceitos básicos}

Este capítulo tem por objetivo apresentar alguns conceitos fundamentais para auxiliar no entendimento do presente trabalho e também fixar a nomenclatura usada nesta tese.

\section{1}

\section{Curvatura}

Curvatura pode ser entendida de maneira informal como uma medida que indica o quão "dobrada" uma curva 2D está, em um determinado ponto. Dessa maneira, a curvatura irá assumir valores mais altos em regiões de dobras e valores bem próximos de zero em linhas retas. Por convenção, na interpretação sísmica, o valor da curvatura é positivo em anticlinais (dobras convexas) e negativo em sinclinais (dobras côncavas). A Figura 3.1 mostra o relacionamento entre o comportamento da curva e o sinal da curvatura.

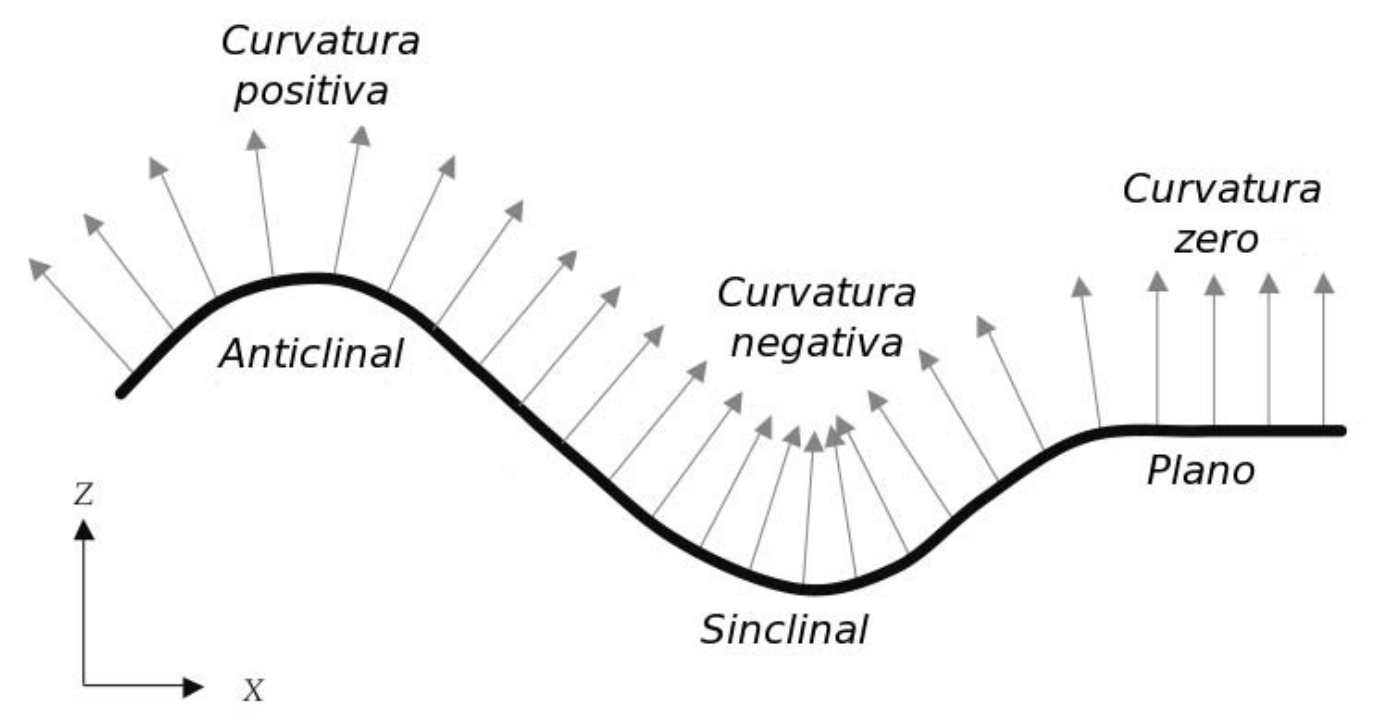

Figura 3.1: Convenção de sinais adotada para valores de curvatura. Adaptado de Roberts (2001)

Mais formalmente, a curvatura é definida como o inverso do raio $R$ do círculo osculador, o qual tangencia a curva em um ponto $P$ e tem o máximo de contato com a mesma (Figura 3.2). Ou seja, quanto menor for o valor de $R$, maior o valor de curvatura associado a $P$. No limite, quando $R$ tende a infinito (em uma região plana), a curvatura tenderá a zero. 


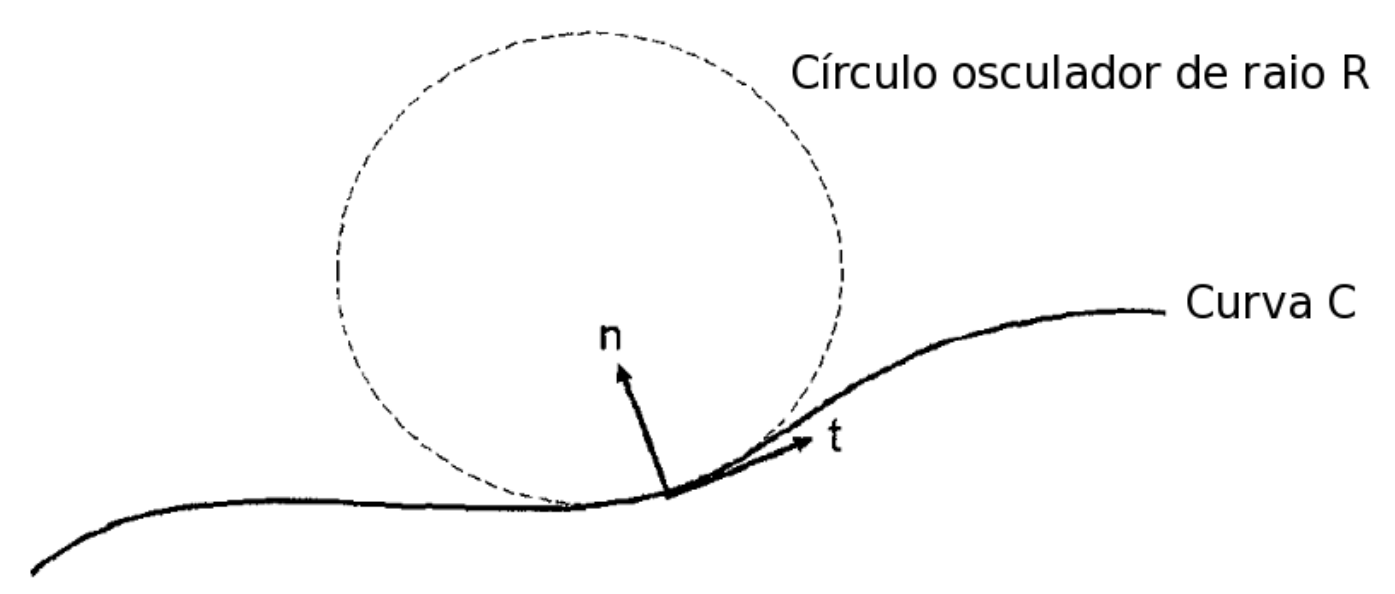

Figura 3.2: Definição de curvatura. Adaptado de Donias et al. (1998)

Este conceito pode ser convenientemente estendido para três dimensões, pois a intersecção entre uma superfície e um plano descreve uma curva. Como existem infinitos planos que interceptam uma superfície, existem infinitas curvas que podem ser geradas dessa maneira. Entretanto, uma classe especial de curva é obtida considerando apenas planos que são ortogonais à superfície. Curvaturas obtidas a partir de planos com essa característica são conhecidas como curvaturas normais.

\section{2}

\section{Atributos de curvatura}

Uma interessante propriedade das curvaturas normais é que, para qualquer par de curvaturas ortogonais (fornecidas por planos ortogonais entre si) em um determinado ponto da superfície, a média desse par é constante e definida como a curvatura média, $k_{M}$.

Para qualquer ponto da superfície, dentre os infinitos valores possíveis de curvatura normal, existe um que apresenta o maior valor. Tal medida de curvatura é conhecida como $k_{1}$. Além disso, a curvatura dada pelo plano ortogonal ao de $k_{1}$ sempre apresenta o menor valor e é chamada de $k_{2}$. Esses dois atributos são denotados por curvaturas principais e indicam os extremos das curvaturas normais. Consequentemente, para qualquer ponto da superfície, $k_{1} \geq k_{2}$ (Figura 3.3). Essas duas medidas podem fornecer importantes informações acerca da morfologia local de uma superfície, conforme pode ser visto na Figura 3.4.

Uma outra medida que pode ser útil na caracterização da geometria local de uma superfície é a curvatura gaussiana, denotada por $k_{G}$ e dada pelo 


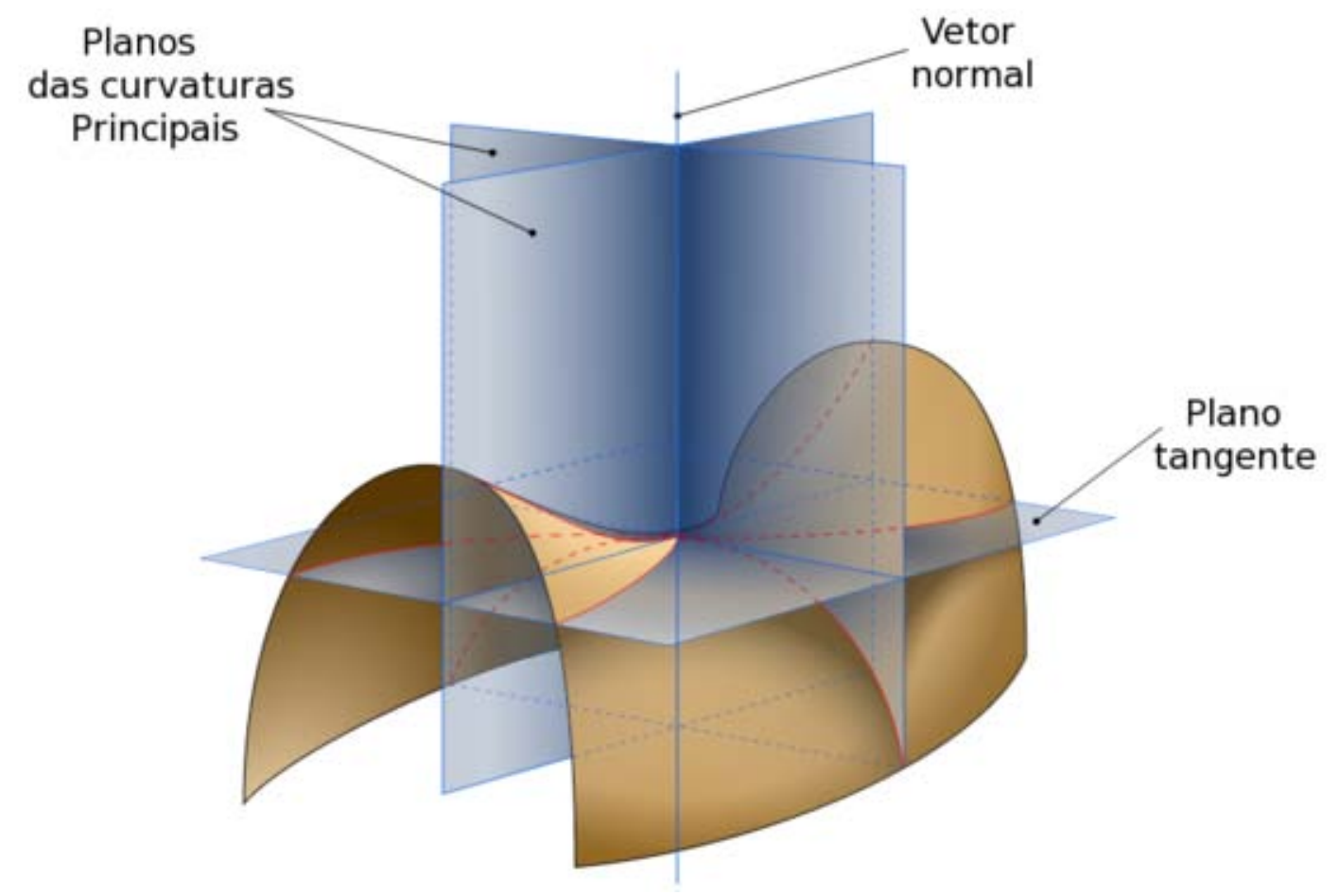

Figura 3.3: Curvaturas principais $k_{1}$ e $k_{2}$ para um ponto em uma superfície.

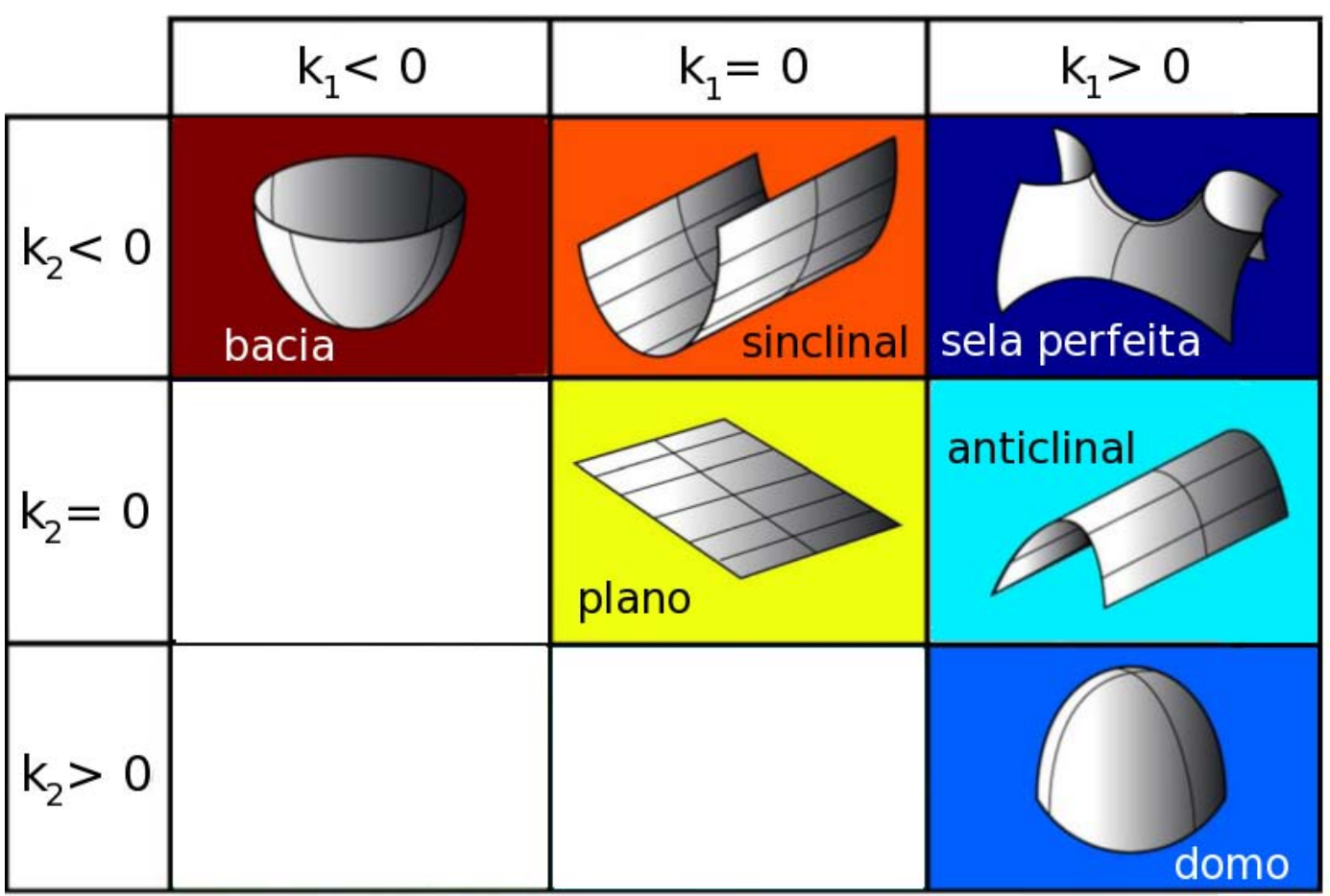

Figura 3.4: Classificação da forma geométrica de acordo com as curvaturas principais $k_{1}$ e $k_{2}$. Através dessas duas medidas é possível inferir importantes informações acerca da morfologia local de uma superfície. Adaptado de Mynatt et al. (2007).

produto das curvaturas principais $k_{1}$ e $k_{2}$. O nome curvatura gaussiana foi dado a partir do Teorema Egrégio de Gauss, o qual afirma que ao dobrarmos 
isometricamente uma superfície não alteramos a curvatura gaussiana dos pontos da mesma. Em outras palavras, se a superfície não for quebrada, esticada ou comprimida, a curvatura gaussiana $k_{G}$ permanecerá constante para qualquer ponto (GAUSS, 1828). Um exemplo clássico ocorre com a dobragem de um plano em um cilindro ou cone. Nessa transformação, apenas a maior curvatura $k_{1}$ é alterada, ao passo que $k_{2}$ permanece zero. Entretanto, uma consequência desse fato é que, na maioria das vezes, apenas a informação dada por $k_{G}$ não é suficiente para descrever a geometria local de uma superfície, sendo necessária a informação de curvatura média $k_{M}$ (Figura 3.5).

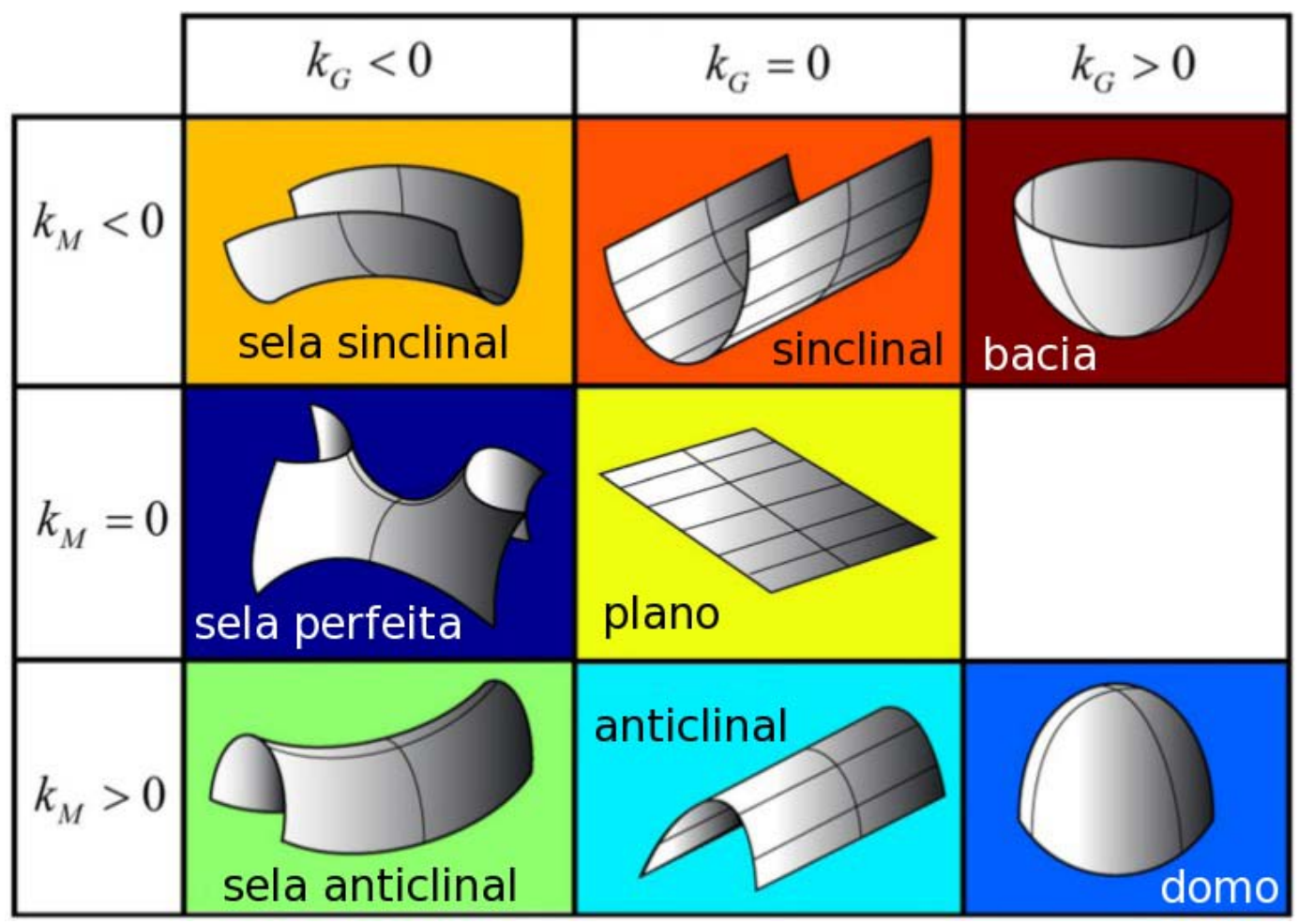

Figura 3.5: Classificação da forma geométrica de acordo com a curvatura gaussiana $k_{G}$ e a curvatura média $k_{M}$. Assim como no caso das curvaturas principais, através dessas duas medidas é possível inferir importantes informações acerca da morfologia local de uma superfície. Adaptado de Mynatt et al. (2007).

As curvaturas principais $k_{1}$ e $k_{2}$ podem ser usadas para derivar outros atributos, tais como curvicidade (curvedness) e índice de forma (shape index) (KOENDERINK; DOORN, 1992); (ROBERTS, 2001), os quais oferecem uma síntese da morfologia local em termos de magnitude e forma.

O atributo de curvicidade, ou curvedness, $(C)$ descreve a magnitude da curvatura independente de sua forma, fornecendo uma idéia da quantidade total de curvatura presente em um ponto de interesse. Esse atributo pode ser bastante útil quando não estamos interessados no formato geométrico da vizinhança em torno da amostra, mas apenas no quanto a mesma está 
"dobrada" em relação a um plano horizontal (Figura 3.6). É dado por:

$$
C=\frac{\sqrt{k_{1}^{2}+k_{2}^{2}}}{2}
$$

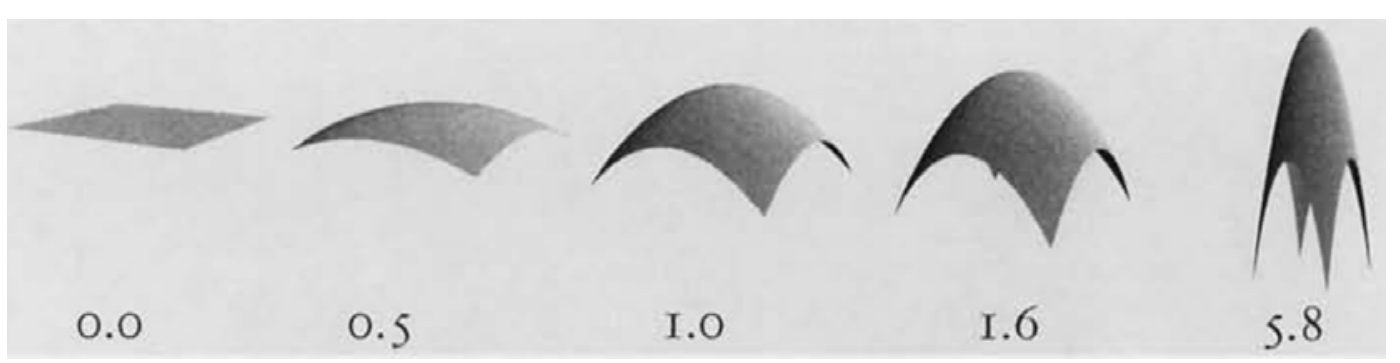

Figura 3.6: Exemplo de variação do atributo curvedness de acordo com a morfologia local. Fonte: Phillips e Todd (1996).

Por outro lado, o índice de forma ou shape index, como é mais conhecido na literatura, apresenta uma definição quantitativa de forma, descrevendo a morfologia local independente de escala. Um domo, por exemplo, poderá ser identificado como tal independente de seu tamanho. Para isso, esse atributo considera cinco classes de figuras geométricas, as quais possuem um único valor de índice de forma: bacia ou cavidade $(-1,0)$, sinclinal ou vale $(-0,5)$, sela $(0,0)$, anticlinal ou crista $(0,5)$ e domo $(1,0)$, conforme visto na (Figura 3.7). Assim, cada amostra do dado de entrada é classificada de acordo com a semelhança em relação a essas figuras.

Uma importante característica desse atributo é que o mesmo é contínuo. Por exemplo, um ponto que possui índice de forma igual a 0,85 representa uma figura que está entre um domo e uma crista, em termos de formato. Para efeito de visualização, é associado uma tabela de cores que associa uma cor a cada classe. Por exemplo, as cores das classes podem variar de azul escuro, para bacias, até vermelho, para domos, de acordo com a Figura 3.7.

O índice de forma $\left(S_{i}\right)$ é dado por:

$$
I_{f}=-\frac{2}{\pi} \tan ^{-1}\left[\frac{\left(k_{1}+k_{2}\right)}{\left(k_{1}-k_{2}\right)}\right]
$$

Segundo Roberts (2001), devido ao fato de que esse atributo é independente da magnitude absoluta da curvatura, o mesmo pode realçar falhas e fraturas bastante pequenas.

\section{3}

\section{Relação entre feições sísmicas e curvatura}

Apesar do atributo de curvatura média $k_{M}$ representar uma importante propriedade das superfícies, visualmente o mesmo pode não acrescentar muita informação, tendendo a ser dominado pelos valores de $k_{1}$. Por essa razão, a 

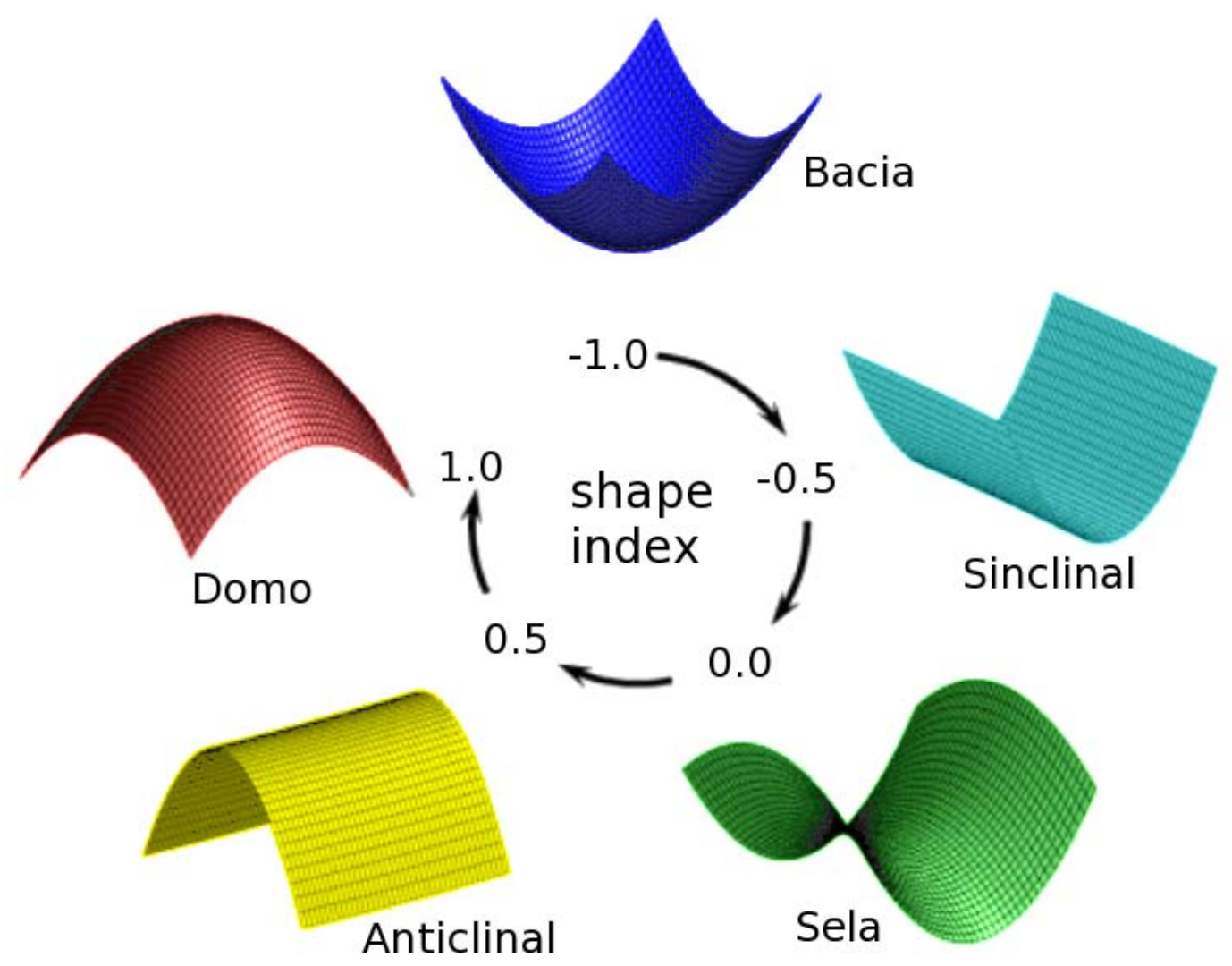

Figura 3.7: Classificação da forma geométrica de acordo com o índice de forma. Um valor intermédiário entre as classes representa uma figura gemétrica de transição entre as mesmas. Adaptado de Yoshida et al. (2002).

maior parte da importância de $k_{M}$ em dados sísmicos reside no fato de que é usado na derivação de outros atributos (CHOPRA; MARFURT, 2006). O mesmo ocorre com a curvatura gaussiana $k_{G}$. Embora os trabalhos de Lisle (1994) e Wen e Townsend (1997) tenham sugerido o uso de $k_{G}$ no delineamento de falhas, essa medida tradicionalmente fornece resultados insatisfatórios para esse tipo de operação, conforme visto nos exemplos de Roberts (2001) e Chopra e Marfurt (2006). Isso pode ser explicado pelo fato de que grande parte das feições sísmicas, como falhas, possuem formato linear, tendo uma das curvaturas principais próxima a zero. Consequentemente, sendo $k_{G} \mathrm{o}$ produto de $k_{1}$ e $k_{2}, k_{G}$ assumirá valores também próximos a zero (AL-DOSSARY; MARFURT, 2006).

Embora atributos de coerência (MARFURT et al., 1999) sejam ótimas ferramentas para visualização de falhas, os mesmos podem não prover bons resultados na presença de falhas com deslocamento pequeno demais ou simplesmente suprimido devido a erros de migração no dado sísmico de entrada. Atributos de curvatura, por outro lado, podem "enxergar" tais feições como dobras (CHO- 
PRA; MARFURT, 2007a). Além disso, em várias ocasiões, horizontes apresentam uma certa curvatura anterior à descontinuidade ocasionada pela falha (KLEIN et al., 2008), o que acaba permitindo o realce da descontinuidade, mesmo para uma falha com grande deslocamento.

Assim, diversos trabalhos demonstram que as curvaturas principais $k_{1} \mathrm{e}$ $k_{2}$ fornecem os melhores indicativos de falhas e fraturas, permitindo o realce das mesmas com elevado grau de continuidade (CHOPRA; MARFURT, 2007b) ; (CHOPRA; MARFURT, 2007a); (CHOPRA et al., 2008). Por essas razão, muitos intérpretes dão preferência aos atributos de curvatura principal, $k_{1}$ e $k_{2}$, no mapeamento dessas feições estruturais.

Além de falhas e fraturas, feições estratigráficas como canais e estruturas de colapsos também aparecem bem definidas em imagens obtidas a partir de atributos de curvatura (CHOPRA et al., 2011b).

A Figura 3.8 mostra o resultado obtido por Chopra e Marfurt (2006) para os atributos de coerência e para as curvaturas principais, $k_{1}$ e $k_{2}$. Os atributos foram obtidos tendo como entrada um horizonte interpretado manualmente, sendo exibidos ao longo do mesmo. Podemos observar que as curvaturas são capazes de delinear bem as falhas indicadas pelas setas amarelas, e também permitem o realce de outras feições indicadas pelas outras setas com uma boa continuidade e detalhamento.

$\mathrm{Na}$ prática, observa-se que valores positivos de $k_{1}$ evidenciam feições anticlinais e de domos, ao passo que valores negativos desse atributo mostram depressões e vales. Por outro lado, valores negativos de $k_{2}$ estão vinculados a feições sinclinais e depressões, enquanto que valores positivos são associados a domos (CHOPRA; MARFURT, 2006). Tal fato pode ser observado na Figura 3.9 , retirada de Chopra e Marfurt (2007a). Os atributos, $k_{1}$ e $k_{2}$ foram obtidos de acordo com a estimativa volumétrica de curvatura proposta por Al-Dossary e Marfurt (2006). As setas indicam que existe uma correspondência entre as feições observadas na sísmica de amplitudes (secção vertical) a resposta dos atributos. 

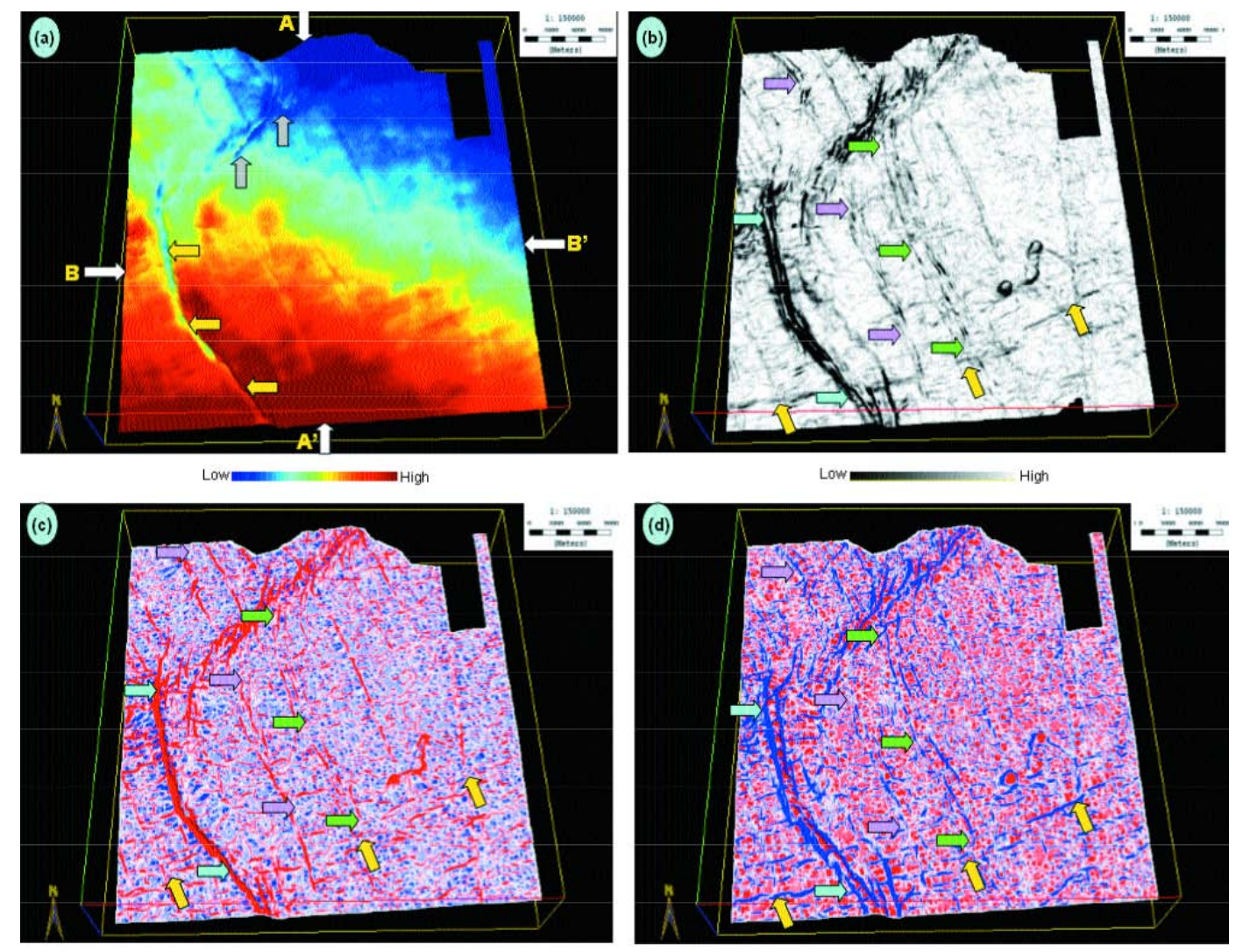

Low

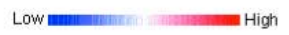

Figura 3.8: Horizonte com valores de tempo (a); atributo de coerência (b); curvatura principal $k_{1}(\mathrm{c})$; curvatura principal $k_{2}(\mathrm{~d})$. As setas indicam falhas e outras feições relevantes. Fonte: Chopra e Marfurt (2006).
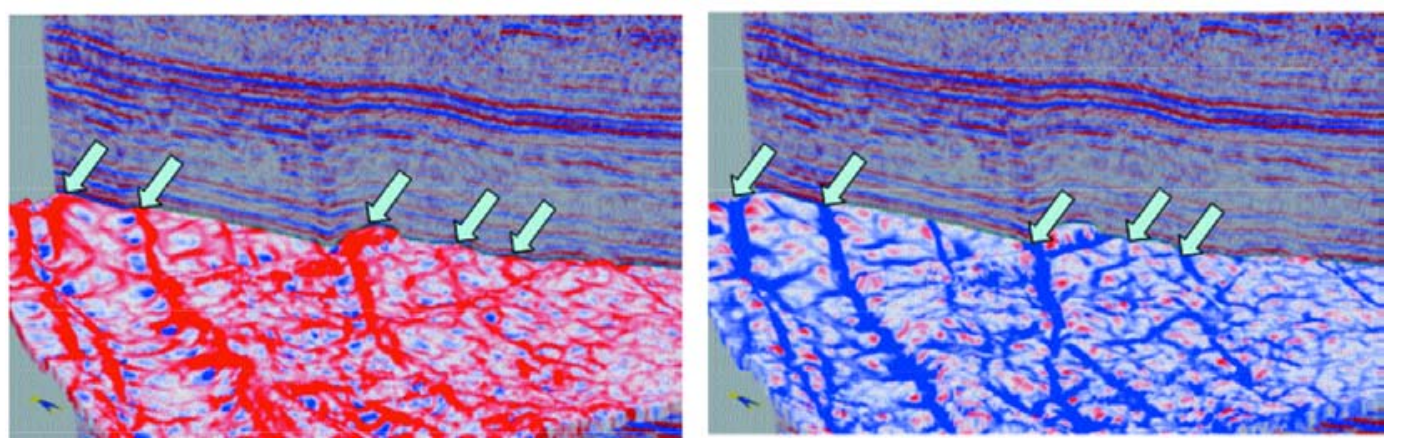

Figura 3.9: Atributos $k_{1}$ e $k_{2}$, respectivamente, obtidos através da estimativa de curvatura volumétrica proposta por Al-Dossary e Marfurt (2006). As setas indicam a correspondência entre a sísmica original e a resposta dos atributos. Adaptado de Chopra e Marfurt (2007a). 


\section{Método proposto}

A Figura 4.1 ilustra esquematicamente o método proposto no presente trabalho para estimar atributos volumétricos de curvatura em dados sísmicos.

Inicialmente, tendo como entrada um dado de amplitude pós-empilhado, um atributo identificador de horizontes é calculado. Tal atributo é capaz de fornecer uma representação aproximada de horizontes sísmicos como superfícies de nível. Neste trabalho, são avaliados os atributos de fase instantânea, derivada vertical e atributo de ridges.

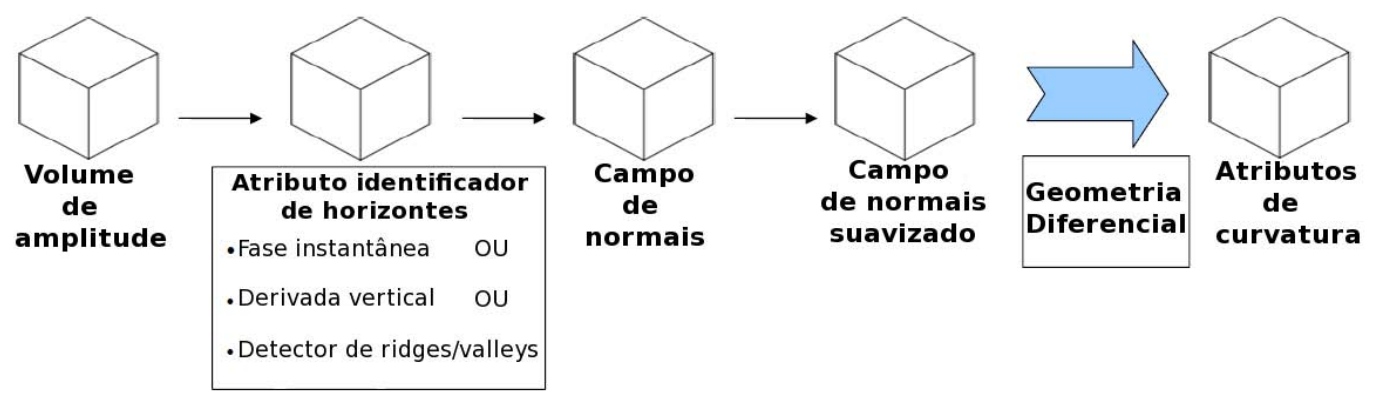

Figura 4.1: Método proposto. A partir de um dado volumétrico de amplitude, é calculado um atributo identificador de horizontes cujo gradiente fornece uma representação coerente do campo de normais volumétrico. Tal campo de normais é usado como entrada para fórmulas de cálculo de curvatura em superfícies implícitas.

O uso de um atributo identificador de horizontes faz-se necessário porque, tipicamente, devido a súbitas variações laterais em dados de amplitude, horizontes sísmicos não podem ser considerados iso-superfícies (SILVA et al., 2003). Dessa forma, o gradiente da amplitude fornece amiúde uma representação errônea do campo de normais do volume; tal fato foi demonstrado, através de experimentos com dados sintéticos e reais por Silva (2004), que usa o gradiente do atributo de fase instantânea como estimativa para as normais.

Para a obtenção do campo de normais do volume sísmico de forma mais consistente, faz-se necessário, portanto, o uso de um atributo que mantenhase aproximadamente constante ao longo dos horizontes sísmicos, de modo a representá-los como superfícies de nível. Essa representação pode ser expressa como

$$
\text { Horizontes }=\{(t, x, y): F(t, x, y)=c\}, c \in \mathbb{R}
$$


Sendo $F(t, x, y)$ chamado no presente trabalho de atributo identificador de horizontes. Portanto, o gradiente de um atributo desse tipo, por fornecer uma estimativa mais coerente do campo de normais, torna-se bastante útil em aplicações de iluminação e cálculo de atributos sísmicos que forneçam ou necessitem de orientação local, tais como mergulho ou curvatura.

Uma vez que o campo de normais do volume esteja estimado através do gradiente do atributo identificador de horizontes, o mesmo é usado como entrada para fórmulas de cálculo de curvaturas em superfícies implícitas. Nesse trabalho, foram adaptadas as fórmulas de curvatura propostas por Goldman (2005), as quais são derivadas das fórmulas clássicas de geometria diferencial para curvas e superfícies paramétricas.

\section{1}

\section{Atributos identificadores de horizontes}

Conforme mencionado na seção anterior, os refletores sísmicos não são necessariamente iso-superfícies do campo escalar da amplitude sísmica. Portanto, para a obtenção da orientação local de maneira mais consistente, faz-se necessário o uso do gradiente de um atributo, obtido a partir da amplitude, que se mantenha constante ao longo de um evento sísmico. Neste trabalho, três atributos são examinados nessa tarefa: fase instantânea, derivada vertical e atributo de ridges/valleys.

\subsection{1}

\section{Fase instantânea}

O atributo de fase instantânea é usado nos trabalhos de Barnes (1997) e Luo et al. (1996) como uma medida de continuidade e dispersão em dados sísmicos. Mudanças laterais bruscas na fase instantânea podem estar associadas a falhas, ao passo que amostras pertencentes ao mesmo evento sísmico possuem fase constante. Nesse contexto, esse atributo é particularmente útil na classificação de horizontes, podendo portanto ser usado como uma maneira de representar horizontes sísmicos como iso-superfícies (SILVA, 2004).

Seja a expressão analítica do traço sísmico dada por $Z(t)=X(t)+i Y(t)$, sendo $X(t)$ o próprio traço (parte real) e $Y(t)$ a parte complexa do sinal obtida através da sua transformada de Hilbert. Então, em termos matemáticos, a fase instantânea $\phi$ é calculada pelo argumento complexo do traço analítico, sendo dada por:

$$
\phi=\tan ^{-1}\left[\frac{Y(t)}{X(t)}\right]
$$


O comportamento da fase instantânea em relação à amplitude sísmica é mostrado na Figura 4.2, para um traço sísmico em um dado sintético. Através do gráfico podemos ver que os picos de amplitude no traço sísmico correspondem aproximadamente aos zeros da fase instantânea.

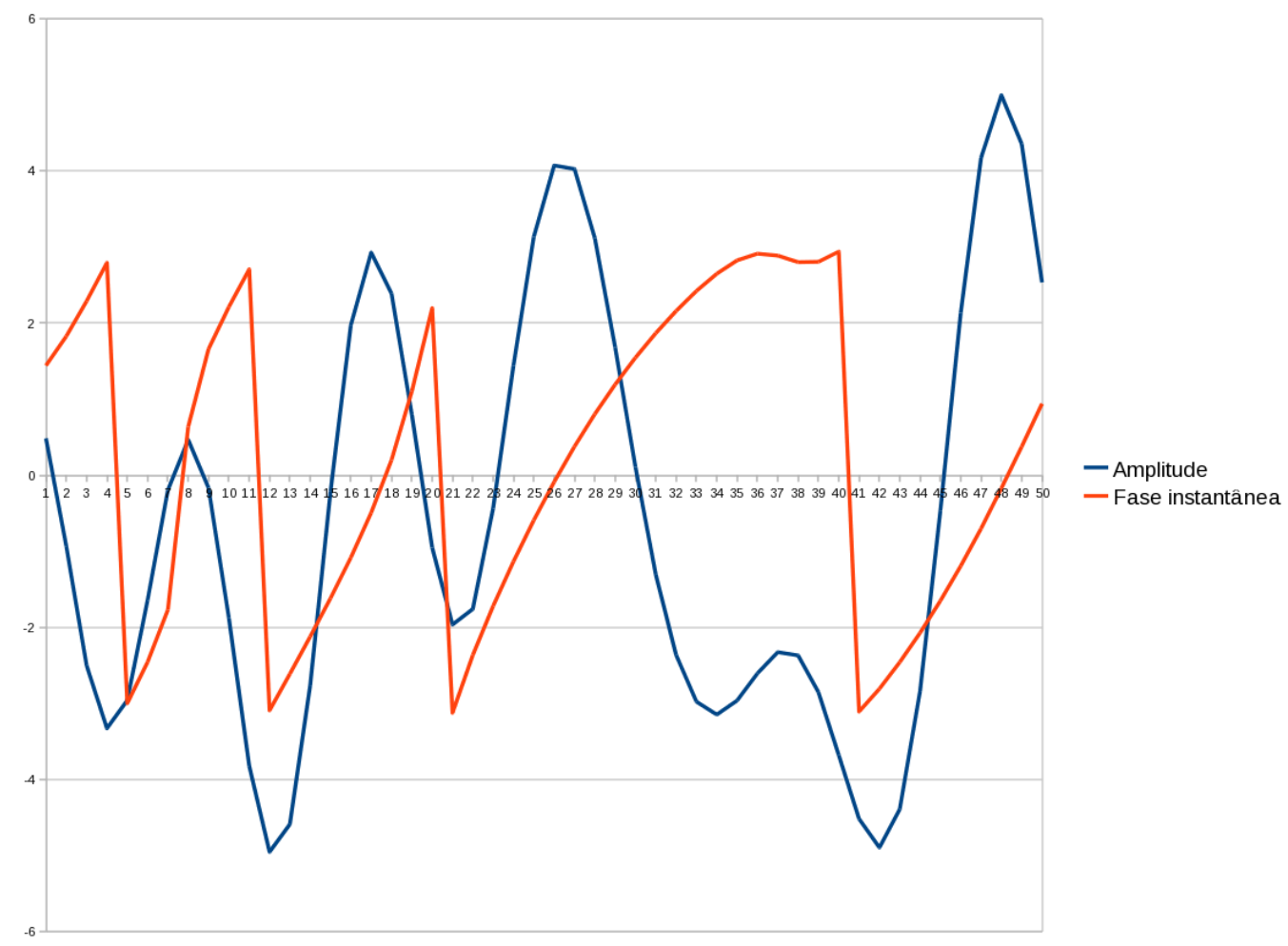

Figura 4.2: Relação entre a amplitude e a fase instantânea em um traço sísmico de um dado sintético.
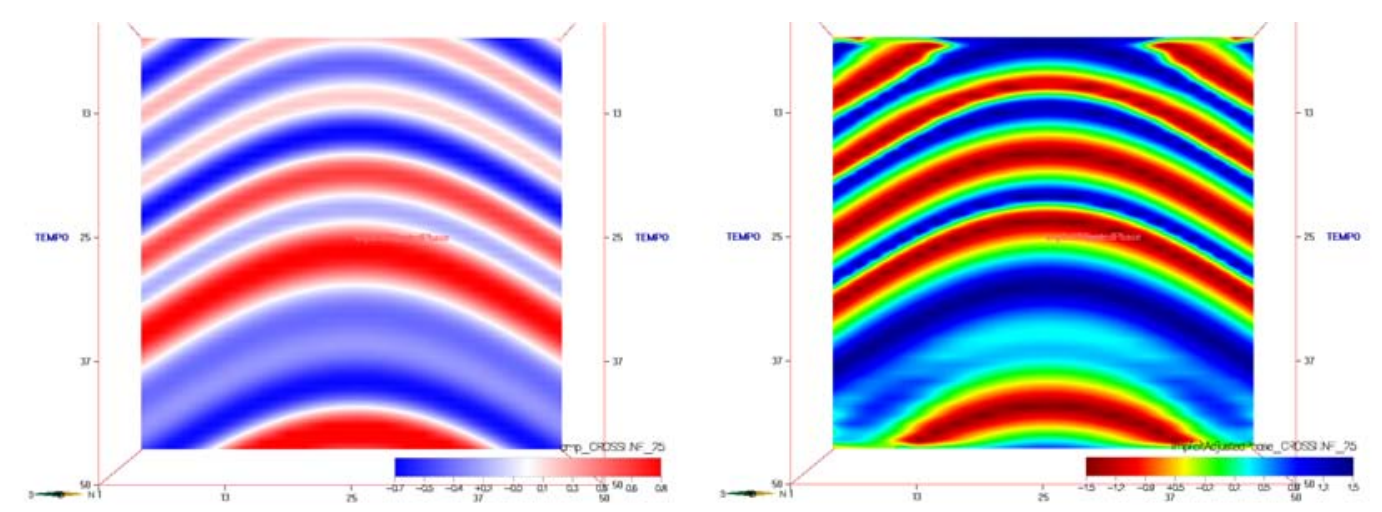

Figura 4.3: Comparação entre a amplitude e a fase instantânea em um dado sintético.

A Figura 4.3 mostra a aplicação do atributo de fase instantânea a uma seção de um volume de amplitudes do mesmo dado sintético. Da mesma maneira que no exemplo unidimensional, observa-se que os horizontes no 
dado de amplitude correspondem aproximadamente a valores de zero na fase instantânea.

\subsection{2}

\section{Derivada vertical}

A derivada vertical $D$ é uma medida simples que indica a variação de amplitude ao longo do traço sísmico, sendo dada por

$$
D=\frac{d X(t)}{d t}
$$

Este trabalho investiga o uso dessa medida como atributo identificador de horizontes. Por hipótese, horizontes sísmicos são os pontos de máximos e mínimos ao longo do traço. Dessa maneira, os mesmos corresponderiam aproximadamente aos zeros da derivada vertical. Assim, através desse atributo, horizontes sísmicos poderiam ser caracterizados adequadamente como superfícies de nível.

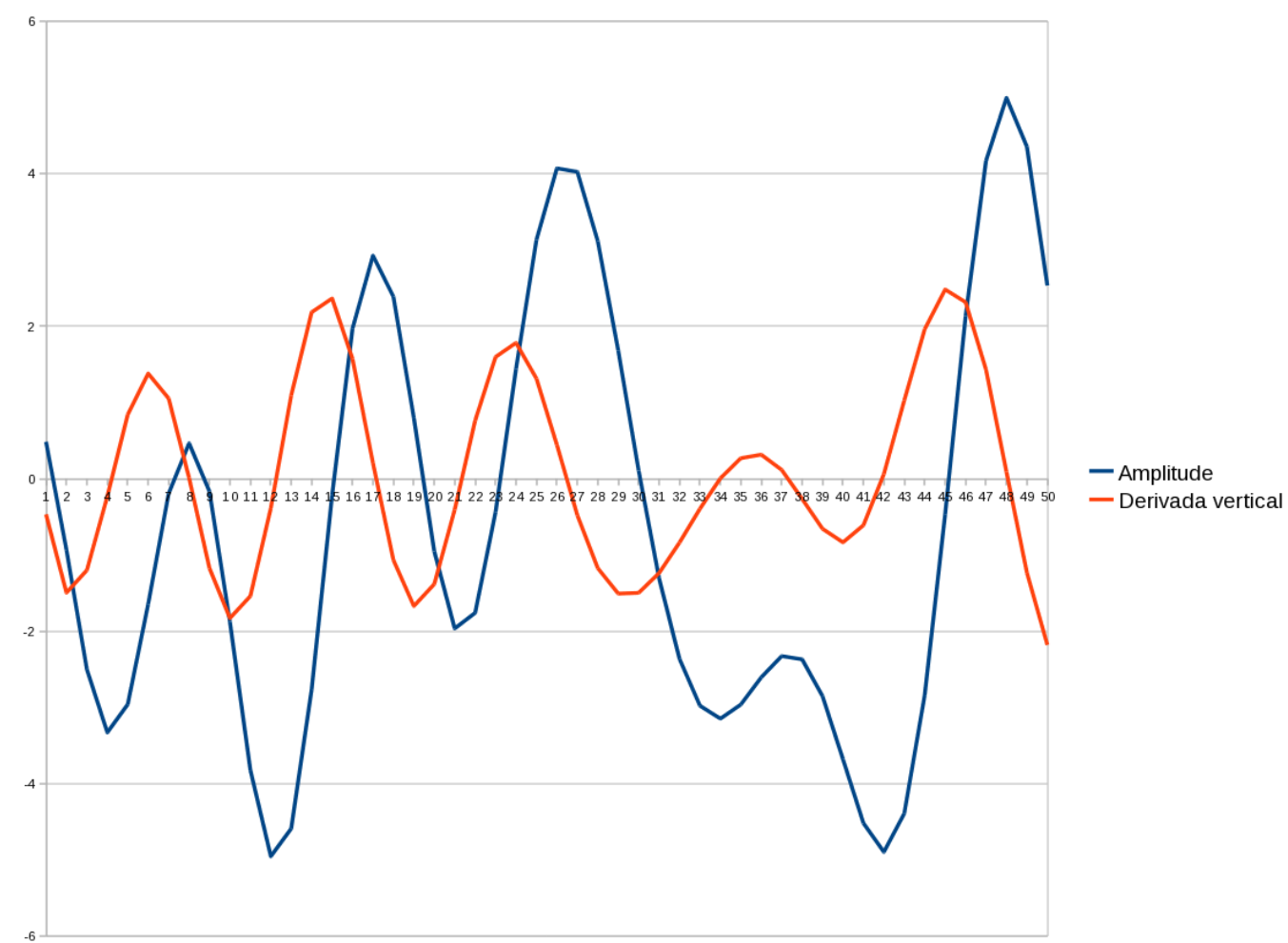

Figura 4.4: Relação entre a amplitude e a derivada vertical em um traço sísmico de um dado sintético.

Podemos ver a relação entre a derivada vertical e a amplitude sísmica na Figura 4.4, para um traço sísmico em um dado sintético. O gráfico aponta que os picos de amplitude no traço sísmico correspondem aproximadamente aos zeros da derivada vertical, o que corrobora a hipótese de que horizontes sísmicos podem ser identificados com o auxílio desse atributo. 


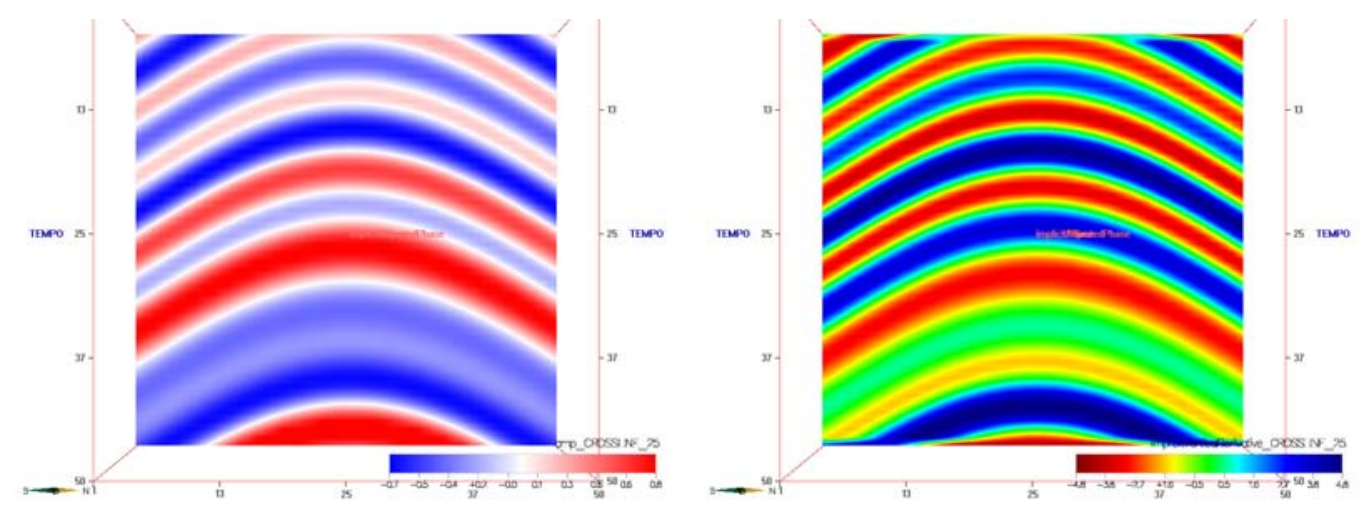

Figura 4.5: Comparação entre a amplitude e a derivada vertical em um dado sintético.

A Figura 4.5 mostra a aplicação do atributo da derivada vertical a uma seção do mesmo dado de amplitudes sintético. Novamente, percebe-se que existe uma correspondência aproximada entre valores de horizontes no dado de amplitude e valores de zero do atributo sísmico.

\subsection{3}

\section{Atributo de ridges}

A detecção de cristas (ridges) e vales (valleys) é uma importante tarefa em processamento de imagens e visão computacional. Cristas correspondem a regiões de máximos locais da imagem, e vales correspondem a mínimos locais. Dessa forma, um detector de ridges/valleys é capaz de capturar o interior de objetos no domínio da imagem. Como neste trabalho parte-se da hipótese de que horizontes sísmicos correspondem a máximos ou mínimos locais no dado de amplitude, é proposto o uso de um atributo capaz de identificar ridges e valleys em fatias do volume de amplitude, com o intuito de representá-los como superfícies de nível.

Seja $f(x, y)$ uma função de duas variáveis e $L$ uma representação de $f(x, y)$ suavizada pela convolução com uma função gaussiana. Em termos de um sistema ortonormal de coordenadas $(u, v)$, com a direção $v$ paralela ao gradiente da imagem, pode-se demonstrar que ridges e valleys podem ser definidos da seguinte maneira (LINDEBERG, 1994):

$$
L_{u v}=0, L_{u u}^{2}-L_{v v}^{2} \geq 0
$$

Sendo $L_{u v}$ a derivada mista de $u$ em relação a $v$, e $L_{u u}$ e $L_{v v}$ as derivadas segundas de $L$ nas direções $u$ e $v$, respectivamente. É possível estabelecer uma relação entre o sistema $(u, v)$ e o sistema cartesiano da imagem $(x, y)$ através das seguintes relações (LINDEBERG, 1994): 


$$
\begin{gathered}
L_{v}^{2} L_{u u}=L_{x}^{2} L_{y y}-2 L_{x} L_{y} L_{x y}+L_{y}^{2} L x x \\
L_{v}^{2} L_{u v}=L_{x} L_{y}\left(L_{x x}-L_{y y}\right)-\left(L_{x}^{2}-L_{y}^{2}\right) L_{x y} \\
L_{v}^{2} L_{u u}=L_{x}^{2} L_{x x}+2 L_{x} L_{y} L_{x y}+L_{y}^{2} L y y
\end{gathered}
$$

Sendo que o sinal de $L_{u u}$ determina o tipo de feição; $L_{u u}<0$ para cristas e $L_{u u}>0$ para vales. $L_{v}$ é a derivada direcional na direção normal $v$, paralela ao gradiente da imagem, ou seja:

$$
\begin{gathered}
L_{v}=\nabla L \cdot \vec{v} \\
L_{v}=\left(L_{x}, L_{y}\right) \cdot\left(\frac{L x}{\sqrt{L_{x}^{2}+L_{y}^{2}}}, \frac{L_{y}}{\sqrt{L_{x}^{2}+L_{y}^{2}}}\right) \\
L_{v}=\frac{\left(L_{x}^{2}+L_{y}^{2}\right)}{\sqrt{L_{x}^{2}+L_{y}^{2}}} \\
L_{v}=\sqrt{L_{x}^{2}+L_{y}^{2}}
\end{gathered}
$$

Podemos então combinar a definição de cristas e vales (Equação 4-4) com as equações 4-6 e 4-8 para encontrar uma expressão que ajude a identificar prováveis pontos de cristas e vales em uma imagem pela sua proximidade com uma constante $c$, onde $c \in \mathbb{R}$. Como, por definição, $L_{u v}=0$, podemos definir um atributo identificador de ridges e valleys da seguinte maneira:

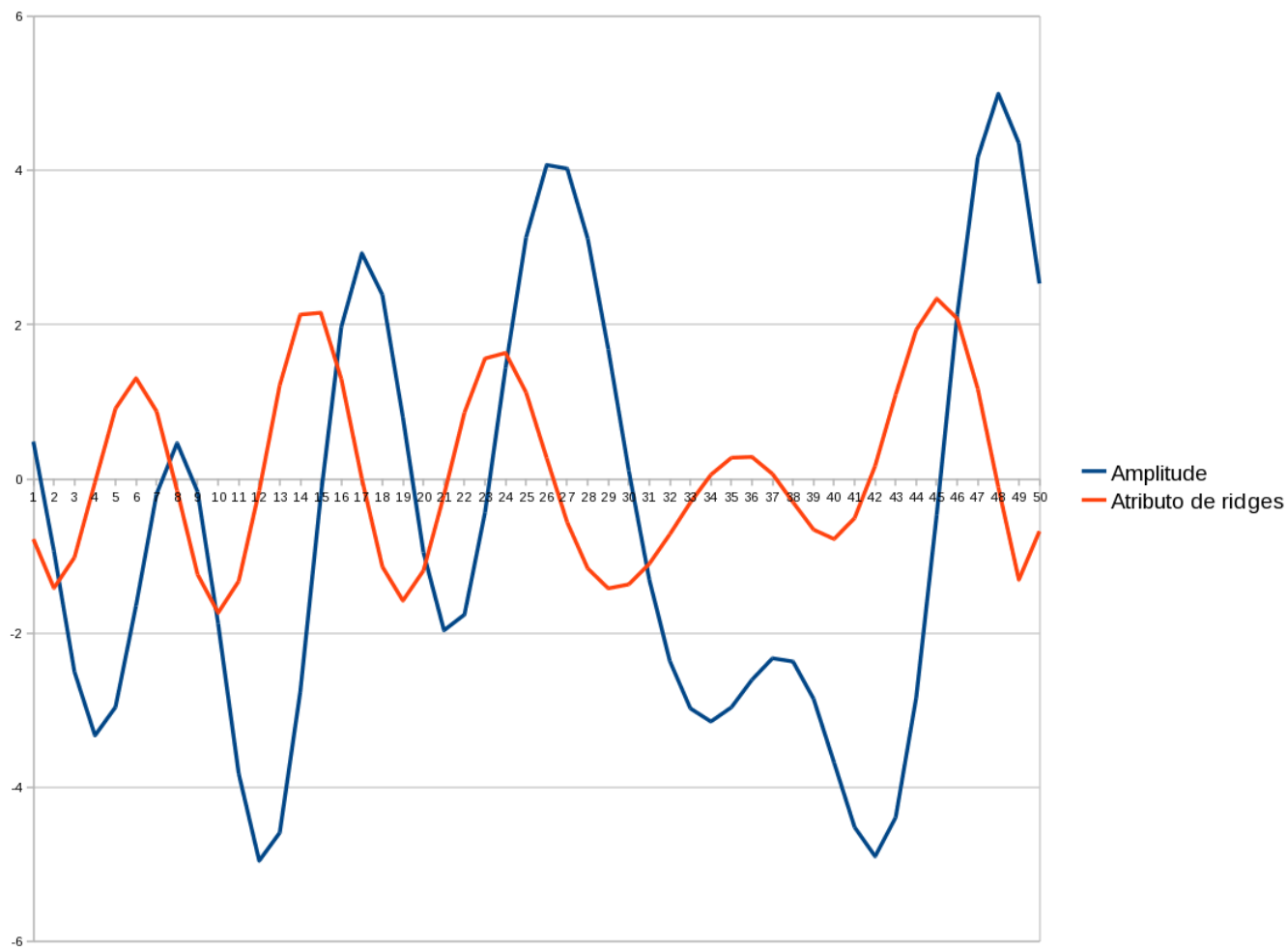

Figura 4.6: Relação entre a amplitude e o atributo de ridges em um traço sísmico de um dado sintético.

$$
L_{u v}=\frac{L_{x} L_{y}\left(L_{x x}-L_{y y}\right)-\left(L_{x}^{2}-L_{y}^{2}\right) L_{x y}}{\left(L_{x}^{2}+L_{y}^{2}\right)}=0
$$


Dessa forma, é proposto o uso deste atributo em fatias verticais do volume sísmico de amplitudes na tentativa de representar os máximos e mínimos locais (horizontes) como curvas de nível na imagem, e por conseguinte, como superfícies de nível no volume. Por ser um atributo bidimensional, nos experimentos realizados neste trabalho o atributo foi calculado fatia a fatia e foram usadas as fatias na direção inline como entrada.
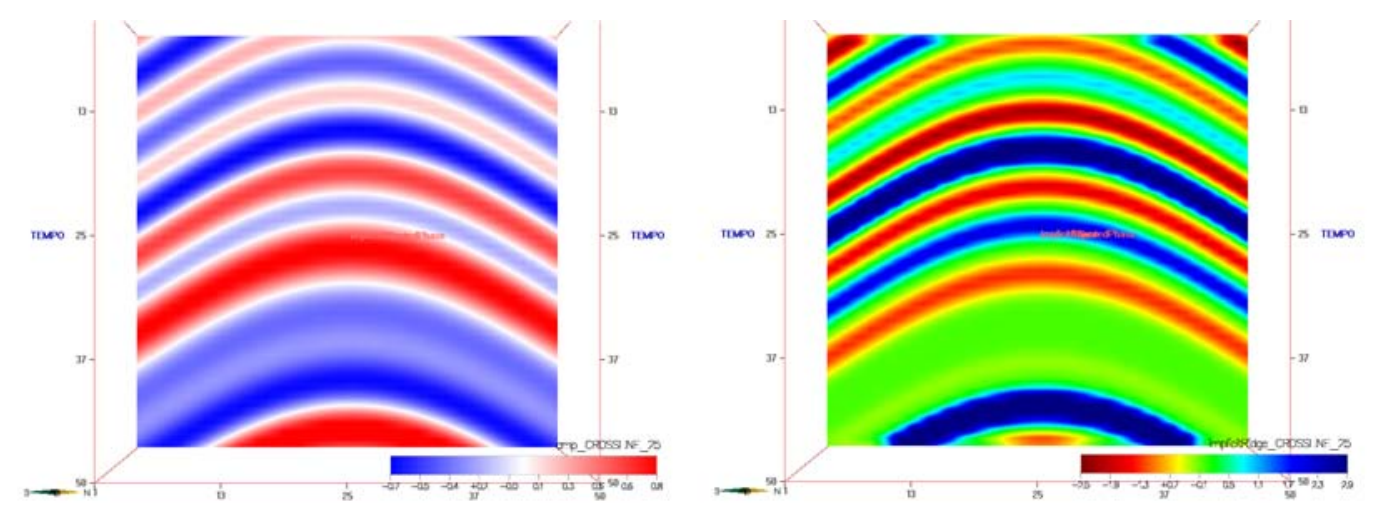

Figura 4.7: Comparação entre a amplitude e o atributo de ridges em um dado sintético.

A Figura 4.6 mostra o comportamento deste atributo em relação à amplitude sísmica, para um traço sísmico em um dado sintético. Através da análise do gráfico percebe-se que os picos de amplitude no traço sísmico correspondem aos zeros do atributo de ridges, o que indica que este atributo pode ser usado na representação dos refletores sísmicos como superfícies de nível.

Finalmente, a Figura 4.7 mostra a aplicação do atributo identificador de ridges a uma seção do mesmo dado sísmico de amplitudes sintético. Assim como no exemplo anterior, nota-se que existe uma correspondência entre valores de horizontes no dado de amplitude e valores de zero no atributo.

\section{2}

\section{Cálculo de curvatura em superfícies implícitas}

Uma vez que os horizontes do dado de entrada estão representados como superfícies implícitas, é possível a aplicação de equações para o cálculo de curvaturas voltadas para superfícies implícitas como forma de estimar os atributos de curvatura.

Para tanto, foi feita uma daptação das fórmulas listadas no trabalho de Goldman (2005) para a obtenção da curvatura gaussiana e da curvatura média em superfícies implícitas. Uma vez que essas duas medidas estejam disponíveis, podemos obter facilmente as curvaturas principais $k_{1}$ e $k_{2}$. 
Seja $F(x, y, z)=0$ uma superfície implícita, $\nabla F$ o vetor gradiente e $H(F)$ a matriz hessiana em um determinado ponto. Nesse caso, temos que:

$$
\begin{gathered}
\nabla F=\left(\frac{\partial F}{\partial x} \frac{\partial F}{\partial y} \frac{\partial F}{\partial z}\right)=\left(F_{x} F_{y} F_{z}\right) \\
H(F)=\left(\begin{array}{ccc}
\frac{\partial^{2} F}{\partial x^{2}} & \frac{\partial^{2} F}{\partial x \partial y} & \frac{\partial^{2} F}{\partial x \partial z} \\
\frac{\partial^{2} F}{\partial y \partial x} & \frac{\partial^{2} F}{\partial y^{2}} & \frac{\partial^{2} F}{\partial y \partial z} \\
\frac{\partial^{2} F}{\partial z \partial x} & \frac{\partial^{2} F}{\partial z \partial y} & \frac{\partial^{2} F}{\partial z^{2}}
\end{array}\right)=\left(\begin{array}{ccc}
F_{x x} & F_{x y} & F_{x z} \\
F_{y x} & F_{y y} & F_{y z} \\
F_{z x} & F_{z y} & F_{z z}
\end{array}\right)=\nabla(\nabla F)
\end{gathered}
$$

A fim de representar corretamente a orientação das feições ao longo das superfícies implícitas, e a convenção adotada para o sinal de curvatura (Figura 3.1), propõe-se a substituição do gradiente $\nabla F$ pelo vetor normal à superfície $N(F)$, definido da seguinte maneira:

$$
N(F)=\left\{\begin{array}{rll}
\nabla F, & \text { se } & F_{z} \geq 0 \\
-\nabla F, & \text { se } & F_{z}<0
\end{array}\right.
$$

Assim, substituímos, para cada ponto, a direção indicada pelo gradiente por uma orientação. Podemos então substituir na Equação 4-10 o gradiente $\nabla F$ e a matriz Hessiana $H(F)$ pelas expressões $N(F)$ e $H^{*}(F)$, da seguinte forma:

$$
\begin{gathered}
N(F)=\left(N_{x} N_{y} N_{z}\right) \\
H^{*}(F)=\left(\begin{array}{lll}
\frac{\partial N_{x}}{\partial x} & \frac{\partial N_{x}}{\partial y} & \frac{\partial N_{x}}{\partial z} \\
\frac{\partial N_{y}}{\partial x} & \frac{\partial N_{y}}{\partial y} & \frac{\partial N_{y}}{\partial z} \\
\frac{\partial N_{z}}{\partial x} & \frac{\partial N_{z}}{\partial y} & \frac{\partial N_{z}}{\partial z}
\end{array}\right)
\end{gathered}
$$

Podemos então adaptar as fórmulas presentes no trabalho de Goldman (2005) e apresentar a seguintes expressão para o cálculo da curvatura gaussiana $\left(k_{G}\right)$ :

$$
k_{G}=\frac{\left|\begin{array}{rr}
H^{*}(F) & N(F)^{T} \\
N(F) & 0
\end{array}\right|}{\left|N(F)^{4}\right|}
$$

A curvatura média $\left(k_{M}\right)$ pode ser obtida através da equação:

$$
k_{M}=\frac{N(F) * H^{*}(F) * N(F)^{T}-|N(F)|^{2} \operatorname{Trace}\left(H^{*}\right)}{2|N(F)|^{3}}
$$

Uma vez que as medidas de curvatura gaussiana e média estejam definidas, podemos obter as curvaturas principais $k_{1}$ e $k_{2}$ pela clássica equação

$$
k_{1}, k_{2}=k_{M} \pm \sqrt{k_{M}^{2}-k_{G}}
$$

Através dessas medidas de curvatura é possível determinar ainda outros 
atributos de curvatura, tais como índice de forma e curvicidade, discutidos na Seção 3.2 .

\section{3}

\section{Suavização da estimativa das derivadas}

Uma limitação da aplicação direta das fórmulas apresentadas na seção anterior é que, pelo fato de fazer uso de derivadas de segunda ordem, a estimativa da curvatura é frequentemente acompanhada de ruído. O uso de derivadas numéricas acentua o ruído e o problema aumenta à medida em que a ordem das derivadas cresce. Tal fato é especialmente importante no processamento de dados sísmicos, que comumente são extremamente ruidosos. Portanto, na estimativa computacional de atributos de curvatura através de fórmulas de geometria diferencial, a tarefa mais importante é obter medidas precisas e, ao mesmo tempo, suaves, das derivadas de primeira e segunda ordem (Equação 4-12).

Uma abordagem possível para contornar esse problema consiste em suavizar o campo de normais gerado a partir do gradiente do atributo identificador de horizonte. Nesse caso o gradiente pode ser estimado a partir de um método simples, como o método das diferenças centrais e suavizado através de filtros como média ou mediana vetorial. Dessa maneira, de posse de um campo de normais mais suavizado, é possível obter resultados bem mais suaves de curvatura. Outra abordagem consiste na convolução das amostras do atributo identificador de horizontes com um filtro que forneça as derivadas já suavizadas. É o caso da derivada da função gaussiana, por exemplo. Ambas as abordagens possuem a vantagem de permitir a variação do tamanho da janela de amostragem, o que permite gerar resultados mais ou menos detalhados de curvatura.

\subsection{1}

\section{Suavização do campo vetorial}

Uma maneira bastante conhecida de suavizar um campo vetorial consiste na aplicação do filtro de mediana vetorial. Neste caso, para uma janela de ordem $N$, a escolha da amostra é dada pelo ponto $P_{i}$ que minimiza o somatório de distâncias euclidianas entre o vetor deste ponto e os vetores das demais amostras da janela. Assim, o coeficiente de escolha $C_{i}$ de um ponto $P_{i}$ é dado por:

$$
C_{i}=\sum_{j=1}^{N} D\left(P_{i}, P_{j}\right)
$$


Sendo $D\left(P_{i}, P_{j}\right)=\left|P_{i}-P_{j}\right|$. Dessa maneira, é escolhido o ponto que possui o menor coeficiente de escolha.

O filtro da mediana vetorial é bastante útil em eliminar elementos espúrios presentes entre as amostras (outliers). Entretanto, pelo fato de que apenas um elemento da janela é preservado, existe a possibilidade de que amostras relevantes possam ser rejeitadas como ruído, assim como existe a possibilidade de inserção de descontinuidades nos dados suavizados.

Outra maneira de suavizar o campo de normais consiste no uso da média vetorial. Este filtro reduz os efeitos de ruído através da aplicação da média aritmética de todas as amostras do vetor:

$$
f\left(v_{1}, v_{2}, \ldots, v_{N}\right)=\frac{1}{N} \sum_{i=1}^{N} v_{i}
$$

Devido a simplicidade da operação de média aritmética, este filtro consegue melhores resultados de suavização em relação ao anterior. Entretanto, não existem garantias de que feições geoloógicas sutis não sejam borradas pelo processo de média, principalmente em janelas de análise maiores e se forem realizadas várias iterações do filtro.

Mais recentemente, surgiram outras abordagens que tentam suavizar os vetores e ao mesmo tempo preservar as bordas. Francis e Jager (2005) propõem um filtro que consiste em uma mediana ponderada, a qual estima os pesos de forma adaptativa. Wang et al. (2010) descrevem um filtro de suavização para volumes de dip e azimuth. Cada janela de análise é sub-dividida em janelas menores. A sub-janela que apresenta menor variação angular entre os vetores é escolhida como a mais centralizada. Tal sub-janela é filtrada pelo filtro de média e o resultado dessa filtragem substitui a amostra central da janela principal. Os autores examinam diversos esquemas de sub-divisão de janelas. É feita uma comparação entre a média tradicional e a abordagem proposta pelos autores, mostrando que a segunda apresenta melhores resultados na preservação de bordas para atributos de mergulho e curvatura.

\subsection{2}

\section{Derivada da função gaussiana}

Neste trabalho optou-se pela convolução das amostras do atributo identificador de horizontes com um filtro que já forneça uma estimativa suavizada das derivadas de primeira e segunda ordem. Tal escolha tem a vantagem de permitir a eliminação de uma etapa no fluxo do método proposto (Figura 4.1), na medida em que os gradientes do atributo identificador de horizontes são suavizados à medida em que são estimados. 
Nesse caso, investigou-se o uso da derivada da função gaussiana, a qual apresenta as vantagens de ser tratável analiticamente e ter a propriedade de separabilidade, tornando sua convolução mais eficiente do ponto de vista computacional. Além disso, a variância $\sigma^{2}$ da gaussiana permite um maior controle sobre o processo de suavização das amostras.

O filtro gaussiano e sua derivada podem ser aproximados através das seguintes expressões:

$$
\begin{gathered}
G(x)=\exp \left(-\frac{x^{2}}{2 \sigma^{2}}\right) \\
G^{\prime}(x)=-\frac{x}{\sigma^{2}} \exp \left(-\frac{x^{2}}{2 \sigma^{2}}\right)
\end{gathered}
$$

sendo $\sigma^{2}$ a variância da gaussiana. Em três dimensões, devido à propriedade de separabilidade do filtro gaussiano e suas derivadas, podemos reduzir bastante o tempo de processamento. Ao invés de realizarmos a convolução com a gaussiana 3D, podemos realizar três convoluções unidimensionais em cada direção usando o operador da derivada da guassiana descrito na Equação 4-18.

Na prática, a variação do tamanho do kernel do operador de derivada gaussiana permite obter atributos de curvatura em diferentes resoluções. Por exemplo, operadores menores irão considerar vizinhanças pequenas em torno da amostra, fornecendo maiores detalhes acerca da geometria local em torno da mesma, ao passo que operadores maiores são capazes de considerar um maior número de elementos em torno da amostra, reduzindo o nível de detalhamento. 


\section{5 \\ Resultados}

Neste capítulo serão examinados os resultados obtidos através do uso do método proposto, em dados sísmicos sintéticos e reais. A fim de avaliar numericamente o método proposto, foi gerado um dado sintético de curvatura conhecida, no caso, uma semi-esfera, com e sem ruído. Já o dado sísmico real de amplitudes usado nos experimentos foi o Bloco F3, localizado no Mar do Norte, e disponibilizado publicamente no repositório do software OpendTect (OPENDTECT, 2011).

\section{1 \\ Resultados em dados sintéticos}

Os dados sintéticos foram gerados de acordo com o modelo sísmico de convolução, o qual é um modelo matemático que descreve bem o efeito do processamento sísmico realizado sobre o dado (SILVA, 2004). O sinal de amplitude de cada traço é considerado o resultado da convolução de um impulso sísmico com uma função refletividade, a qual expressa a fração de energia refletida entre as camadas (Figura 5.1). A função refletividade é dada por

$$
R=\frac{V_{2} \rho_{2}-V_{1} \rho_{1}}{V_{2} \rho_{2}+V_{1} \rho_{1}}
$$

sendo $V_{n}$ e $\rho_{n}$ a velocidade e a densidade, respectivamente, do meio $n$. No processo de geração de dados sísmicos sintéticos, o impulso sísmico pode ser representado por uma wavelet, sendo que uma das mais usadas é a wavelet de Ricker (chapéu mexicano) (VIDAL et al., 2007). A frequência dominante da wavelet define a resolução da informação sísmica. Assim, neste trabalho foi usada a wavelet de Ricker, com frequência de $50 \mathrm{~Hz}$ para a geração dos dados sintéticos.

Dessa maneira, de acordo com o modelo de convolução, a amplitude $A(t)$ de cada traço é dada por

$$
A(t)=R(t) * w(t)
$$

sendo $R(t)$ a função refletividade do modelo geológico, $w(t)$ a wavelet escolhida, * o operador de convolução e $t$ o tempo.

A fim de validar a abordagem usada neste trabalho para a estimativa de atributos volumétricos de curvatura em dados sísmicos, foi gerado um dado 


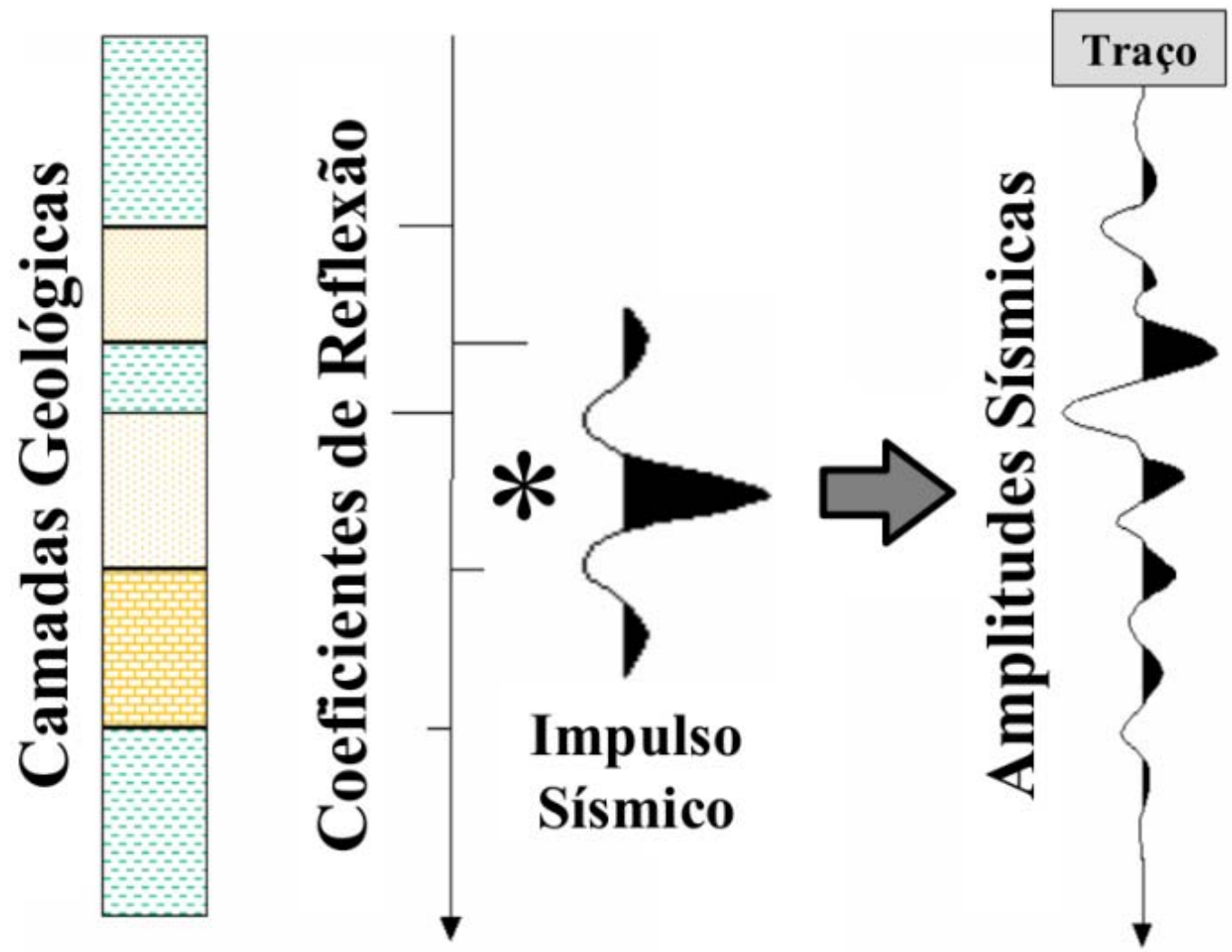

Figura 5.1: Modelo de convolução. Adaptado de Gerhardt (1998)

sintético com horizontes sísmicos em formato de semi-esfera (Figura 5.2). Isso porque, para uma esfera, a magnitude da curvatura média $k_{M}$ é constante para qualquer ponto, e seu valor é dado por $\left|k_{M}\right|=\frac{1}{R}$, sendo $R$ o raio da esfera (GOLDMAN, 2005). Para o presente experimento $R=50,0$, portanto a magnitude da curvatura média esperada ao longo dos horizontes é dada por $\left|k_{M}\right|=0,02$. Além disso, para a estimativa das derivadas usou-se o kernel da derivada da função gaussiana, com o tamanho da janela de análise de 5x5x5 amostras e $\sigma^{2}=1,5$.

Inicialmente, foi estimada a curvatura média obtida diretamente a partir da amplitude sísmica do dado, sem o uso de um atributo identificador de horizontes. Nesse caso, o atributo volumétrico $k_{M}$ ao longo do horizonte apresentou média igual a 0,0513 e desvio padrão de 0,0218, uma diferença significativa em relação ao valor esperado, que é de 0,02. Isto confirma experimentalmente o que foi discutido nos capítulos anteriores, ou seja, os horizontes não podem ser considerados iso-superfícies do campo escalar de amplitudes, devido a variações laterais de amplitude e à própria natureza oscilatória desse tipo de dado.

De acordo com o método proposto (Figura 4.1), diferentes atributos identificadores de horizontes produzem resultados distintos de atributos de 

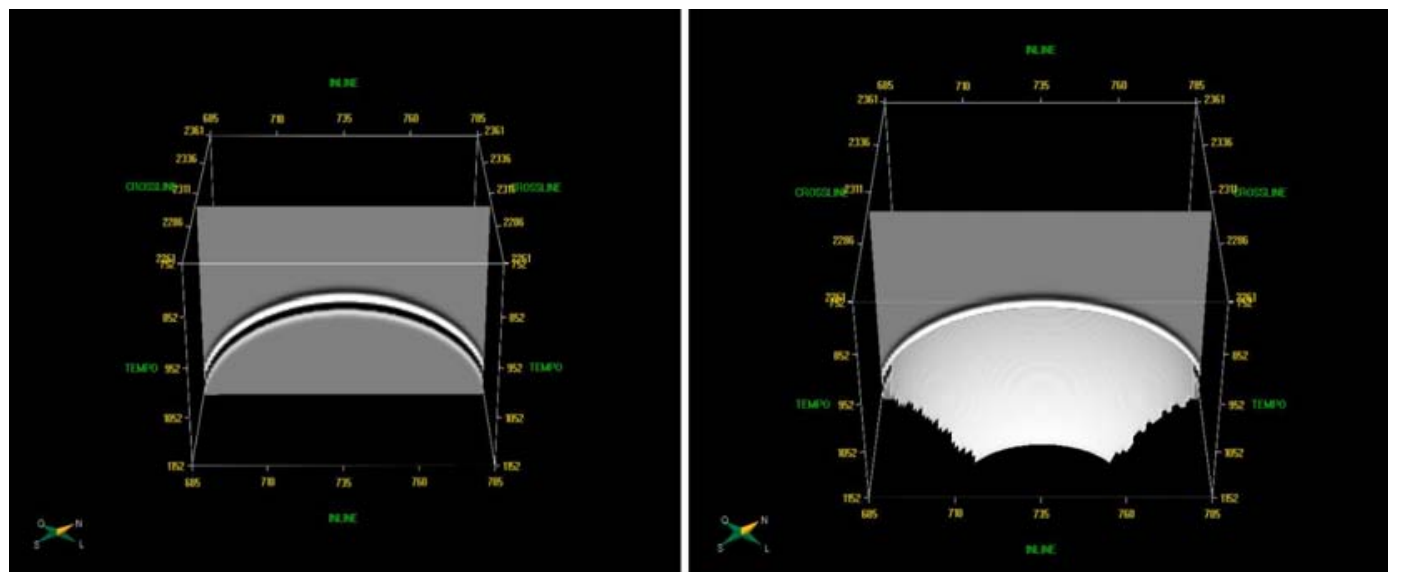

Figura 5.2: Seção vertical do dado sintético usado nos experimentos e um horizonte rastreado em formato de semi-esfera.

curvatura; consequentemente, podemos avaliar o quão eficaz é cada atributo na tarefa de fornecer a orientação local para cada ponto do volume, e, por conseguinte, o atributo de curvatura desejado neste experimento.

A Tabela 5.1 mostra as estimativas de $k_{M}$ usando o método proposto, para cada atributo identificador de horizontes. Os valores de $k_{M}$ são tomados ao longo de um horizonte semi-esférico, rastreado no dado volumétrico sintético, sendo consideradas a média e o desvio padrão ao longo desse horizonte.

Tabela 5.1: Curvatura média ao longo de um horizonte rastreado obtida através dos atributos propostos

\begin{tabular}{ccc}
\hline Atributo & Média & Desvio padrão \\
\hline \hline Fase instantânea & 0,0206 & 0,0043 \\
Derivada vertical & 0,0200 & 0,0046 \\
Atributo de ridges & 0,0207 & 0,0053 \\
\hline
\end{tabular}

Uma análise da Tabela 5.1 mostra que os três atributos propostos para a tarefa de representar horizontes sísmicos como superfícies de nível apresentam resultados bastante similares. Além disso, a média está bem próxima do valor esperado, $k_{M}=0,02$, e com um desvio padrão reduzido, o que indica uma oscilação pequena desse valor ao longo do horizonte. No entanto, podemos perceber que o atributo de ridges apresenta um desvio padrão levemente superior. Esse comportamento é, de certa forma, esperado, visto que esse atributo usa em sua estimativa derivadas de segunda ordem nas direções vertical e lateral.

Com o intuito de realizar uma comparação do método proposto neste trabalho com outra abordagem existente na literatura, calculou-se também o atributo volumétrico de curvatura $k_{M}$ usando a abordagem proposta por AlDossary e Marfurt (2006), citada no Capítulo 2. A Tabela 5.2 apresenta uma 
comparação entre o melhor resultado obtido pelo método proposto (usando o atributo de derivada vertical) e a abordagem de Al-Dossary e Marfurt (2006).

Tabela 5.2: Comparação entre o método proposto e o método de (AL-DOSSARY; MARFURT, 2006)

\begin{tabular}{ccc}
\hline Atributo & Média & Desvio padrão \\
\hline \hline Método proposto (derivada vertical) & 0,0200 & 0,0046 \\
(AL-DOSSARY; MARFURT, 2006) & 0,0200 & 0,0124 \\
\hline
\end{tabular}

Dessa forma, podemos ver que tanto o resultado obtido usando a estimativa proposta por Al-Dossary e Marfurt (2006) quanto aquele obtido através do método proposto apresentam um valor igual ao esperado, porém a abordagem proposta por Al-Dossary e Marfurt (2006) apresenta uma oscilação maior em torno da média. Esse resultado sugere que o método proposto é capaz de fornecer valores mais precisos de curvatura, em termos numéricos, ao longo dos horizontes sísmicos.
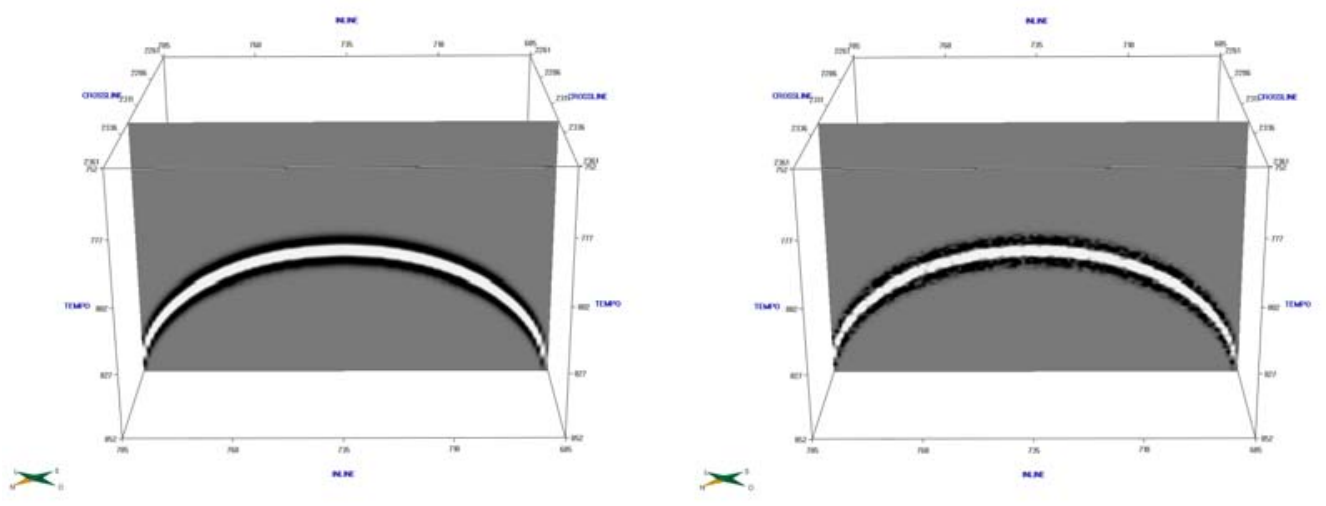

Figura 5.3: Seção vertical do dado sintético original e com acréscimo de ruído aleatório.

Com a finalidade de testar a robustez do método proposto na presença de ruídos, foi gerado um dado sintético com o mesmo formato anterior, mas com a adição de ruído aleatório (Figura 5.3). Outra vez, a fim de constatar experimentalmente o que foi discutido nos capítulos anteriores, foi realizada a estimativa da curvatura diretamente a partir da amplitude sísmica, sem o uso de um atributo identificador de horizontes. Nesse caso, $k_{M}$ apresentou média igual a 0,0411 e desvio padrão de 0,0201 ao longo do horizonte, um resultado que continua sendo diferente do valor esperado $k_{M}=0,02$. Mais uma vez, esse resultado corrobora o fato de que horizontes sísmicos não podem ser tratados como iso-superfícies.

A Tabela 5.3 mostra as estimativas de $k_{M}$ no mesmo dado sintético acrescido de ruído, usando o método proposto, para cada atributo identificador de horizontes. 
Tabela 5.3: Curvatura média ao longo de um horizonte rastreado (dado com ruído)

\begin{tabular}{ccc}
\hline Atributo & Média & Desvio padrão \\
\hline \hline Fase instantânea & 0,0203 & 0,0115 \\
Derivada vertical & 0,0198 & 0,0103 \\
Atributo de Ridges & 0,0200 & 0,0161 \\
\hline
\end{tabular}

Os resultados fornecidos pelo uso dos atributos identificadores de horizontes conservam a média em torno do valor esperado, porém percebe-se nitidamente que houve uma maior oscilação em torno da média nos três atributos. Apesar de fazer uso de derivadas de segunda ordem em sua computação, o atributo de ridges apresentou um resultado preciso, porém com o maior desvio padrão dentre os três atributos. A fase instantânea é conhecida na literatura por ser um atributo propagador de ruídos, mas nesse caso apresentou uma boa precisão e oscilação razoavelmente baixa em torno da média. A derivada vertical, entretanto, apresentou o resultado mais robusto, com média bastante próxima do esperado e menor desvio padrão dentre os três atributos.

Dessa forma, podemos concluir que os três atributos fornecem resultados de curvatura similares, porém a derivada vertical é capaz de fornecer o resultado mais preciso, em termos numéricos, frente a um dado ruidoso. Uma explicação para esse fato é que esse atributo é obtido da maneira mais simples, usando apenas uma derivada no eixo do tempo, propagando menos ruído para a estimativa da curvatura.

A Tabela 5.4 apresenta uma comparação entre o melhor resultado obtido pelo método proposto (usando o atributo de derivada vertical) e a abordagem de Al-Dossary e Marfurt (2006), no dado sintético acrescido de ruído.

Tabela 5.4: Comparação entre o método proposto e o método de Al-Dossary e Marfurt (2006) (dado com ruído)

\begin{tabular}{ccc}
\hline Atributo & Média & Desvio padrão \\
\hline \hline Método proposto (derivada vertical) & 0,0198 & 0,0103 \\
(AL-DOSSARY; MARFURT, 2006) & 0,0199 & 0,0202 \\
\hline
\end{tabular}

Analisando a Tabela 5.4 podemos constatar que as duas abordagens fornecem resultados similares para o dado com ruído. A estimativa proposta por Al-Dossary e Marfurt (2006) fornece o valor de média ligeiramente mais próximo do valor esperado, porém, com um maior desvio padrão ao longo do horizonte. O método proposto, através da derivada vertical, apresenta maior estabilidade por conta da menor oscilação em torno da média.

Dessa maneira, os experimentos realizados em dados sintéticos fornecem evidências de que a abordagem proposta é capaz de fornecer resultados coe- 
rentes da estimativa de atributos de curvatura em dados sísmicos volumétricos de amplitude, em termos numéricos, mesmo na presença de ruído aleatório.

\section{2}

\section{Resultados em um dado real}

O dado sísmico real usado para avaliar o método proposto foi o Bloco F3, disponibilizado publicamente no repositório do software OpendTect (OPENDTECT, 2011). O Bloco F3 é uma região marítima de exploração sísmica bastante conhecida, localizada na parte holandesa do Mar do Norte, contendo reservatórios de óleo e gás. Uma descrição mais detalhada dessa região, com interpretações estratigráficas, pode ser encontrada em Schroot e Schuttenhelm (2003). O volume de amplitudes tem dimensões 580 x 950 x 461, e ocupa cerca de 1,1 gigabytes de memória.

A Figura 5.4 mostra os atributos volumétricos de curvatura $k_{1}$ e $k_{2}$, usando a fase instantânea, a derivada vertical e o atributo de ridges, respectivamente, como atributos identificadores de horizontes. Cada atributo volumétrico de curvatura é visualizado ao longo de um horizonte rastreado no dado de amplitude. O tamanho da janela de análise usada para a estimativa das derivadas foi de $5 \times 5 \times 5$ amostras, com variância $\sigma^{2}=0,5$.

Os atributos volumétricos de curvatura são visualizados ao longo do mesmo horizonte rastreado, o que faz com que as características geométricas locais do horizonte sejam realçadas de acordo com o atributo visualizado. Por exemplo, o atributo $k_{1}$ enfatiza anticlinais (cristas e domos) positivamente, enquanto sinclinais (vales e depressões) são mostrados com valores negativos. Por outro lado, o atributo $k_{2}$ enfatiza regiões sinclinais com valores negativos e anticlinais de maneira positiva.

Uma análise visual das imagens mostra que os atributos de curvatura fornecidos pelos atributos identificadores de horizontes oferecem resultados similares no realce de dobras, descontinuidades, vales e outras feições. Entretanto, percebe-se que a derivada vertical oferece um resultado menos detalhado, em relação aos outros dois atributos. Tal característica pode ser útil em determinadas situações, quando o intérprete está interessado em realçar apenas as feições mais proeminentes do dado de entrada. Para o realce de feições mais sutis, entretanto, a fase instantânea e o atributo de ridges provêem os melhores resultados.

A Figura 5.5, mostra os atributos volumétricos de curvatura média e gaussiana, usando a fase instantânea, a derivada vertical e o atributo de ridges, respectivamente, como atributos identificadores de horizontes, e sendo visualizados ao longo de um horizonte rastreado no dado de amplitude. 
Novamente, o tamanho da janela de análise usada para a estimativa das derivadas foi de $5 \times 5 \times 5$ amostras, com variância $\sigma^{2}=0,5$.

Nota-se que a curvatura gaussiana é um atributo que não fornece muitas informações acerca da morfologia local em dados sísmicos, fato esse já verificado em outros trabalhos e discutido na Seção 3.3. A curvatura média tende a ser dominada pelos extremos de $k_{1}$ e $k_{2}$, não fornecendo muitas informações adicionais acerca da morfologia local do dado sísmico.

O índice de forma e a curvicidade podem ser vistos na Figura 5.6, ao longo do mesmo horizonte, usando a fase instantânea, a derivada vertical e o atributo de ridges. O índice de forma classifica as feições locais de acordo com o código de cores adotado. Neste caso, a classificação varia desde domos (vermelho) até depressões (azul escuro). Como a vizinhança examinada não é extensa, o atributo muda rapidamente, fornecendo muitas vezes informação em excesso. Já a curvicidade considera a magnitude das curvaturas principais, e revelou-se, um bom detector de feições nas quais tanto $k_{1}$ quanto $k_{2}$ apresentam valores mais intensos, como dobras, vales e algumas descontinuidades, fato corroborado pelo intérprete. Novamente, percebe-se que a derivada vertical oferece um resultado menos detalhado, em relação aos outros dois atributos.

A Figura 5.7 mostra a interseção de um horizonte com uma seção inline do dado sísmico e a resposta fornecida pelos atributos $k_{1}$ e $k_{2}$. Para o caso do atributo $k_{1}$, percebe-se que existe uma forte correlação entre o realce de dobras no atributo visualizado ao longo do horizonte e o comportamento da sísmica, o que sugere a corretude do atributo estimado. O atributo $k_{2}$ realça os vales e depressões com valores negativos e domos e picos com valores positivos. Novamente, observa-se uma relação coerente entre a sísmica original e a resposta do atributo estimado pelo método.

A Figura 5.8 mostra uma fatia de tempo do volume de amplitudes e suas correspondentes fatias de tempo do atributo $k_{2}$ obtido através da fase instantânea, derivada vertical e atributo de ridges. As curvaturas geradas através dos três atributos identificadores de horizontes apresentam diversas semelhanças entre si. As setas indicam feições estruturais bastante semelhantes que são realçadas pelas curvaturas fornecidas pelos três atributos. Podemos perceber que os atributos de curvatura são capazes de realçar características não evidentes no dado de amplitude.

A Figura 5.9 mostra a influência do tamanho da vizinhança considerada na computação de derivadas no resultado da curvatura, considerando, como exemplo, o atributo curvicidade. Percebe-se que um operador de derivada menor é capaz de fornecer um nível maior de detalhamento, ao passo que um aumento do tamanho do operador é capaz de suprimir detalhes que podem 
ocasionar excesso de informação visual ao intérprete.

A influência da variância $\sigma^{2}$ da derivada da gaussiana pode ser vista na Figura 5.10. A Figura mostra os atributos volumétricos $k_{1}$ e $k_{2}$, visualizados ao longo de um horizonte rastreado, e obtidos usando a derivada vertical como atributo identificador de horizontes. Podemos perceber que uma variância mais larga gera resultados mais suaves, e com menor nível de detalhamento. Tal fato pode ser bastante interessante para o intérprete, que pode estar interessado em gerar um resultado bastante detalhado, ou, ao contrátrio, realçar apenas as feições mais relevantes. Dessa maneira, ao usarmos a derivada da função gaussiana como método de estimativa das derivadas, além do tamanho do operador de derivada, a variância $\sigma^{2}$ também pode ser usado para controlar o nível de detalhamento desejado no resultado final dos atributos de curvatura.

O resultado do índice de forma volumétrico ao longo de um horizonte rastreado pode ser visto na Figura 5.11. Observa-se que cada região do dado é classificada de acordo com sua morfologia local, com valores que variam de -1 a 1., conforme visto na Seção 3.2. Visualmente, a classificação é feita usando uma tabela de cores. Neste exemplo, regiões que se aproximam de um domo recebem cor vermelha, ao passo que regiões correspondentes a cavidades (buracos) recebem cor azul escuro.

\subsection{1}

\section{Comparação com outra abordagem existente na literatura}

Com o propósito de validar os resultados obtidos por nosso método em dados reais, foi realizada uma comparação da mesma com a estimativa de curvatura volumétrica proposta por Al-Dossary e Marfurt (2006). Tal abordagem baseia-se na estimativa dos volumes de dip e azimuth a partir buscas locais pelos ângulos de mergulho, tendo como entrada um volume de coerência obtido pela técnica de semblance (MARFURT, 2006). Uma vez que esses volumes estão estimados, os atributos volumétricos de curvatura são obtidos a partir das derivadas dos mesmos.

Essa etapa da pesquisa contou com a participação de um intérprete, de modo que foi possível confirmar a existência das feições geológicas realçadas pelos dois métodos. No caso das falhas e fraturas foram examinadas a continuidade das feições delineadas como critério de avaliação visual, pois quanto mais contínuo for o realce de uma falha ou fratura, mais fácil para o intérprete reconhecer esse tipo de feição. Outro critério avaliado foi a sensibilidade a ruído, particularmente o ruído de aquisição ou footprint, cuja presença pode dificultar o reconhecimento de estruturas mais sutis nos volumes de curvaturas. Finalmente, o tempo de processamento das duas abordagens também foi 
comparado.

A Figura 5.12 mostra uma comparação do método proposto neste trabalho com a abordagem proposta por Al-Dossary e Marfurt (2006). Em 5.12-(a) temos o atributo volumétrico $k_{1}$ obtido através de uma implementação do trabalho de Al-Dossary e Marfurt (2006) sendo exibido ao longo de um horizonte rastreado. Em 5.12-(b), 5.12-(c) e 5.12-(d) temos o mesmo atributo volumétrico obtido através da fase instantânea, derivada vertical e atributo de ridges, ao longo do mesmo horizonte. As imagens indicam que os atributos realçam as mesmas feições presentes no dado de entrada (setas azuis e roxas) e confirmadas pelo intérprete. Entretanto, na implementação do método de Al-Dossary e Marfurt (2006) as setas verdes indicam a presença de artefatos causados por ruído de aquisição, confirmados pelo intérprete, que não aparecem nos atributos obtidos de acordo com o método proposto. Esse resultado sugere que, para o dado sísmico real usado nos experimentos deste trabalho, a abordagem proposta é capaz de prover maior robustez frente a ruído de aquisição.

Outra comparação do método proposto neste trabalho com a abordagem proposta por Al-Dossary e Marfurt (2006) pode ser vista na Figura 5.13. Novamente, em 5.13-(a) temos o atributo volumétrico $k_{1}$ obtido através da implementação da estimativa volumétrica de curvaturas proposta por AlDossary e Marfurt (2006) sendo exibido ao longo de um horizonte rastreado. Em 5.13-(b), 5.13-(c) e 5.13-(d) temos o mesmo atributo volumétrico obtido através da fase instantânea, derivada vertical e atributo de ridges, ao longo do mesmo horizonte. A análise das imagens indica que os atributos obtidos através do método proposto apresentam menor sensibilidade a ruído de aquisição. Podemos observar que, de uma maneira geral, o resultado é mais "limpo", o que facilita a identificação das estruturas geológicas. Além disso, as setas indicam que o método proposto é capaz de gerar maior continuidade no delineamento de falhas e fraturas, as quais foram confirmadas pelo intérprete. Nota-se também que os três atributos identificadores de horizontes fornecem resultados bastante semelhantes entre si.

A Figura 5.14 mostra mais uma comparação do método proposto com a abordagem proposta por Al-Dossary e Marfurt (2006). Em 5.14-(a) temos a intersecção da sísmica original com uma fatia de tempo (horizontal) do atributo volumétrico $k_{1}$ obtido através da abordagem de Al-Dossary e Marfurt (2006). Em 5.14-(b), 5.14-(c) e 5.14-(d) temos o mesmo resultado usando os atributos de fase instantânea, derivada vertical e atributo de ridges, respectivamente, através da abordagem proposta. Novamente, os resultados mostram que os atributos obtidos através de nosso método apresentam menor sensibilidade a ruído de aquisição e maior continuidade no delineamento de falhas e fraturas 
confirmadas pelo intérprete. As setas roxas indicam uma falha geológica capturada pelo método proposto mas ausente no atributo obtido através da implementação da estimativa de Al-Dossary e Marfurt (2006).

Dessa forma, as comparações entre o método proposto neste trabalho e outra abordagem existente na literatura indicam que, para o dado real usado nestes experimentos, nossa abordagem é capaz de realçar feições relevantes do dado sísmico de entrada com um razoável grau de continuidade, e com baixa sensibilidade a ruídos periódicos na direção de aquisição, o que resulta em um atributo final que facilita o trabalho do intérprete em identificar as feições presentes no dado de entrada. É importante frisar que as comparações entre os métodos foram feitas usando tamanhos de janela de análise equivalentes, para a estimativa das derivadas.

A Tabela 5.5 mostra a influência do tamanho do operador de derivada no desempenho computacional do método proposto.

Tabela 5.5: Tempo de processamento do método proposto variando o tamanho do operador de derivada

\begin{tabular}{cc}
\hline Tamanho do operador & Tempo \\
\hline \hline $3 \times 3 \times 3$ & $16 \mathrm{~min}$. e $51 \mathrm{seg}$. \\
$5 \times 5 \times 5$ & $20 \mathrm{~min}$. e $15 \mathrm{seg}$. \\
$7 \times 7 \times 7$ & $26 \mathrm{~min}$. e $12 \mathrm{seg}$. \\
$9 \times 9 \times 9$ & $34 \mathrm{~min}$. e $48 \mathrm{seg}$. \\
\hline
\end{tabular}

Assim, podemos ver que, mesmo sem o uso de paralelismo, nossa abordagem pode fornecer um tempo de processamento dentro do aceitável para o tamanho do dado usado nos experimentos.

A Tabela 5.6 mostra uma comparação de performance entre a abordagem apresentada neste trabalho e o método de Al-Dossary e Marfurt (2006) na estimativa de atributos volumétricos de curvatura em dados sísmicos. Para tanto, foi medido o tempo médio de processamento para a obtenção dos atributos de curvatura usando a fase instantânea, a derivada vertical e o atributo de ridges. O tamanho da vizinhança para o cálculo das derivadas foi de 5x5x5 amostras. As implementações usadas na comparação não fizeram uso de paralelismo.

Tabela 5.6: Comparação entre o tempo de processamento do método proposto e o da abordagem de (AL-DOSSARY; MARFURT, 2006)

\begin{tabular}{cc}
\hline Abordagem & Tempo \\
\hline \hline Método proposto & $20 \mathrm{~min} . \mathrm{e} 15 \mathrm{seg}$. \\
(AL-DOSSARY; MARFURT, 2006) & 3h e 30 min. \\
\hline
\end{tabular}


Comparando a abordagem proposta neste trabalho com outra existente na literatura, verifica-se que a mesma apresenta melhor performance computacional, com um tempo de processamento bastante inferior. Além disso, a paralelização dos algoritmos usados na implementação do método proposto certamente fornecerá um tempo de processamento mais aceitável ao usuário final.

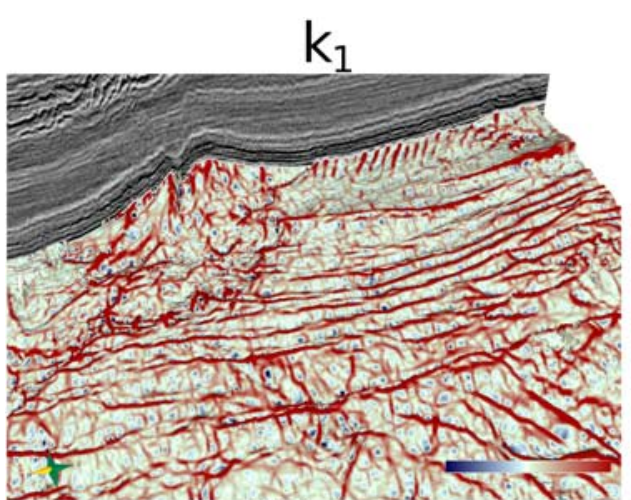

(a)

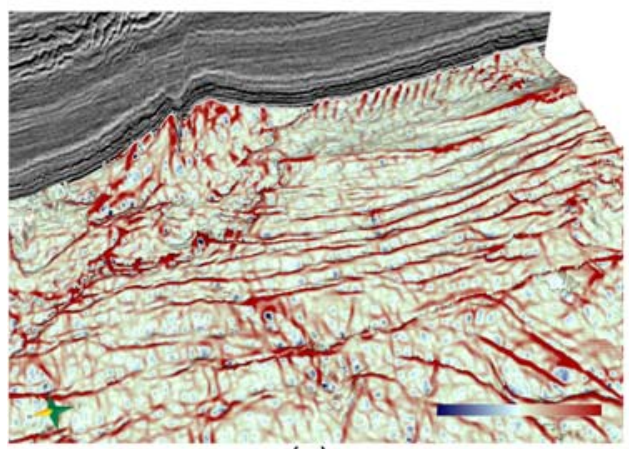

(c)

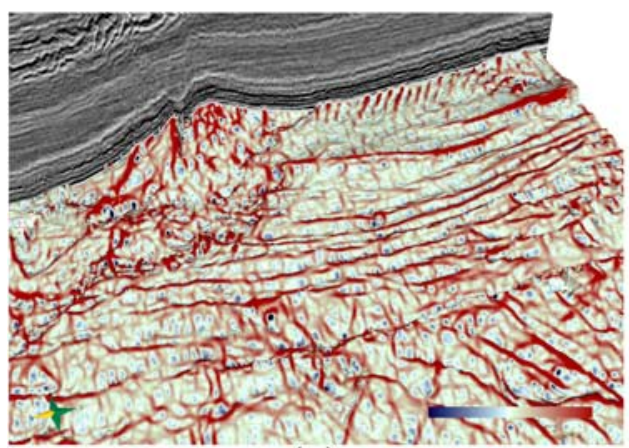

(e)

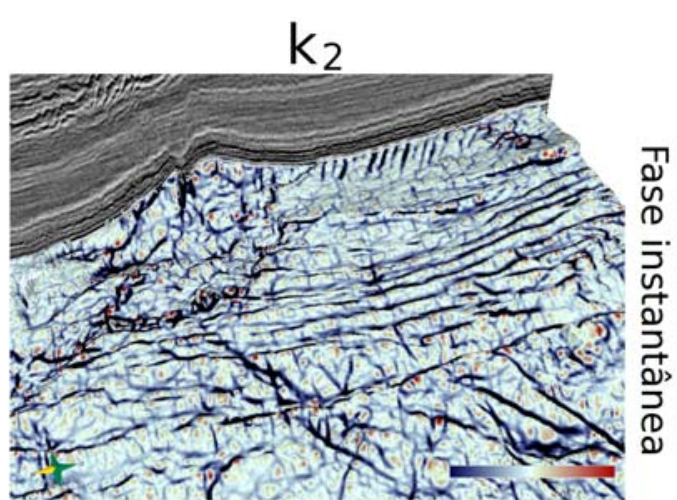

(b)

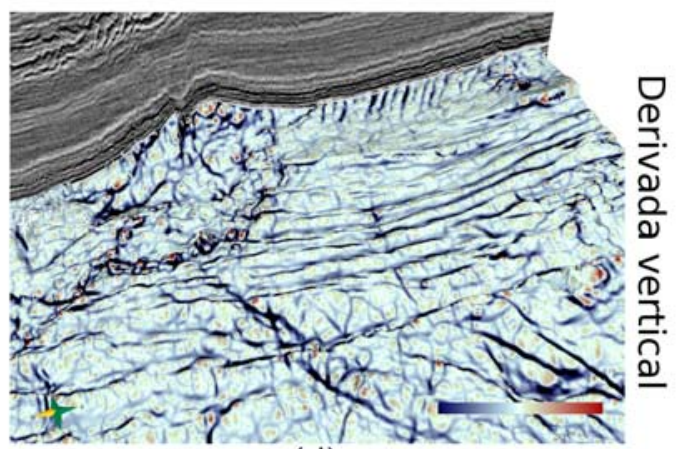

(d)

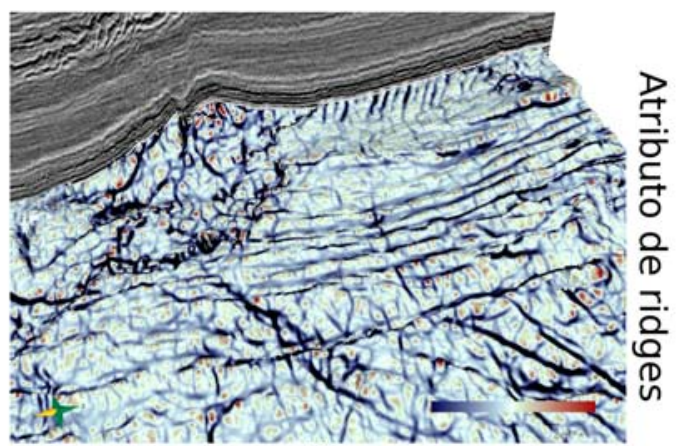

(f)

Figura 5.4: Atributos volumétricos $k_{1}$ e $k_{2}$ (curvaturas principais), obtidos tendo a fase instantânea (a), a derivada vertical (b) e o atributo de ridges (c) como atributos identificadores de horizontes. Os atributos estão sendo visualizados ao longo de um horizonte rastreado a partir do volume de amplitudes. O operador de derivada considera uma vizinhança de $5 \times 5 \times 5$ amostras e uma variância $\sigma^{2}=0,5$ para a derivada da função gaussiana. 


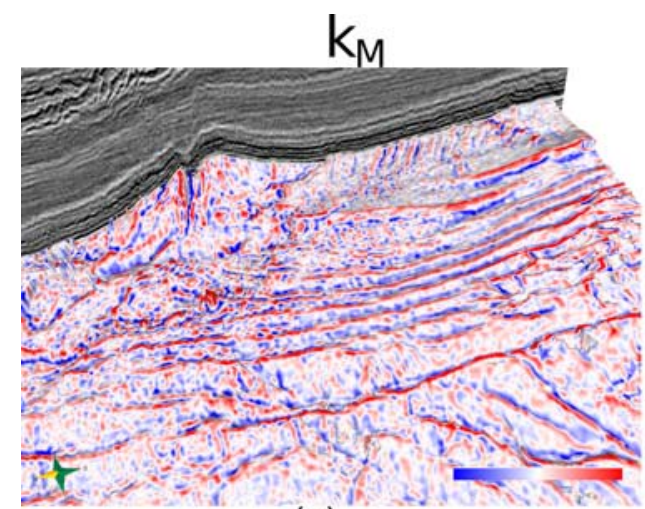

(a)

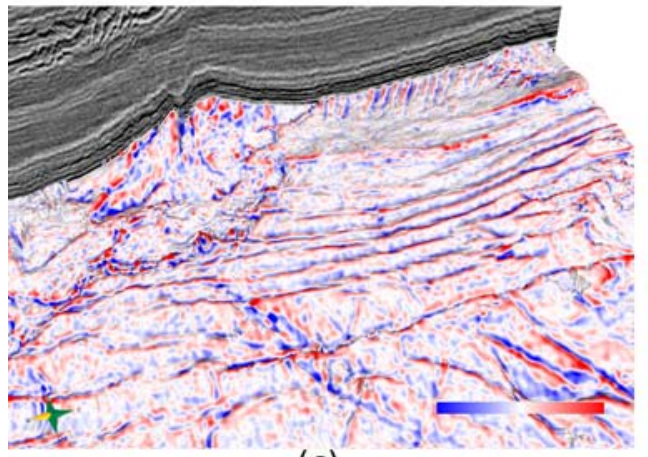

(c)

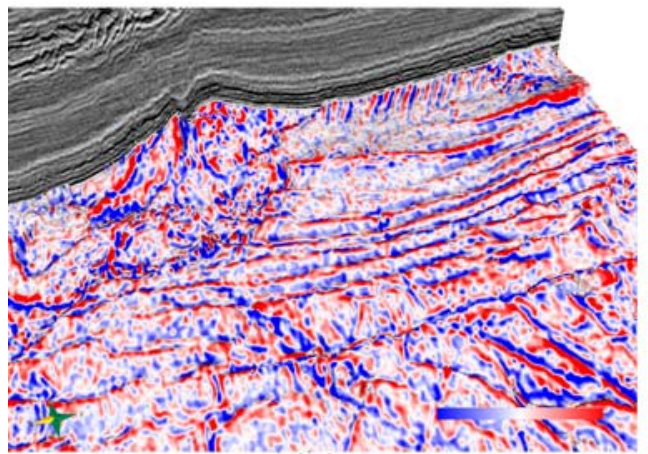

(e)

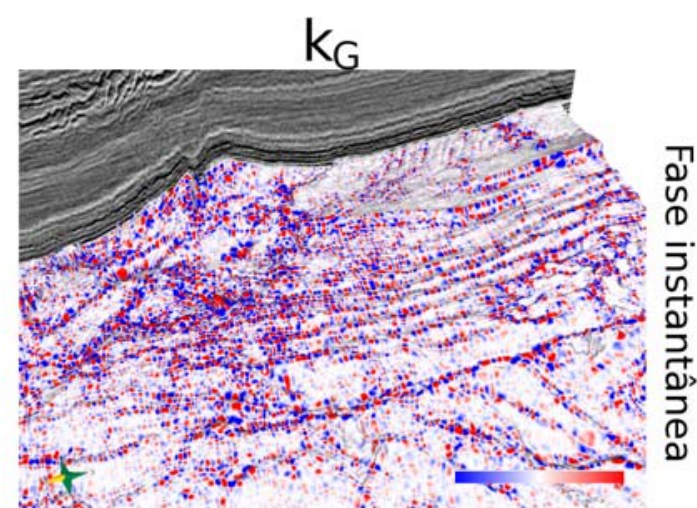

(b)

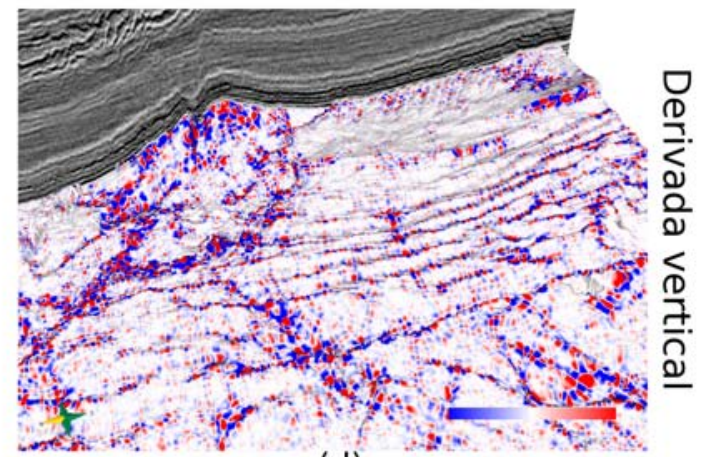

(d)

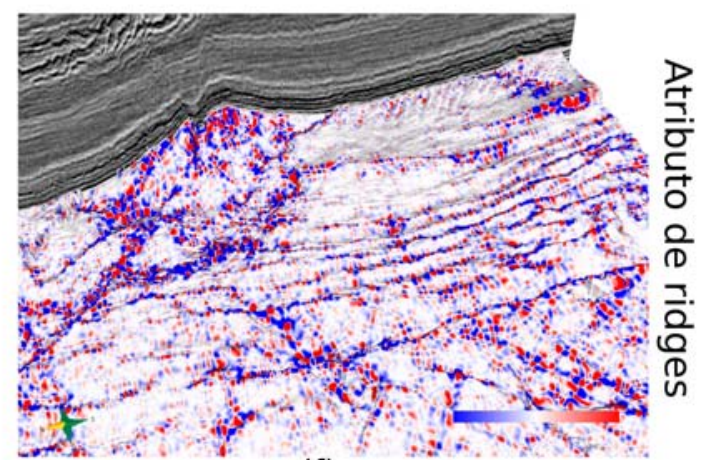

(f)

Figura 5.5: Curvaturas volumétricas média $\left(k_{M}\right)$ e gaussiana $\left(k_{G}\right)$ computadas tendo a fase instantânea (a), a derivada vertical (b) e o atributo de ridges (c) como atributos identificadores de horizontes. Os atributos estão sendo visualizados ao longo de um horizonte rastreado a partir do volume de amplitudes. O operador de derivada considera uma vizinhança de $5 \times 5 \times 5$ amostras e uma variância $\sigma^{2}=0,5$ para a derivada da função gaussiana. 


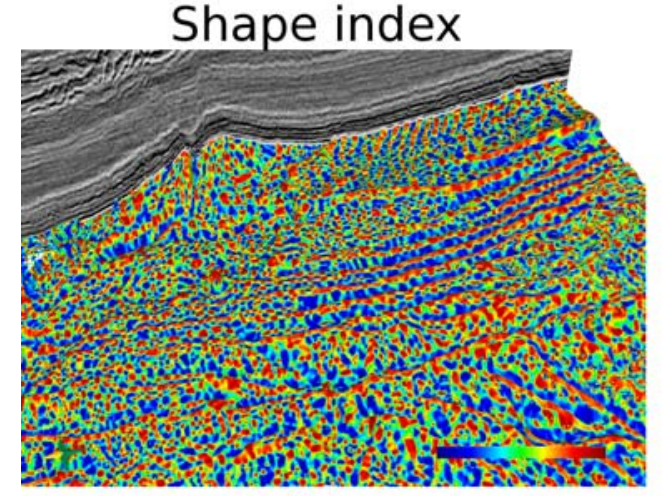

(a)

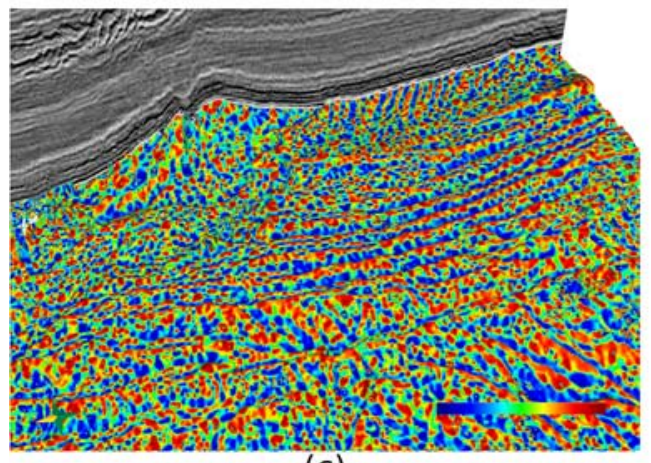

(c)

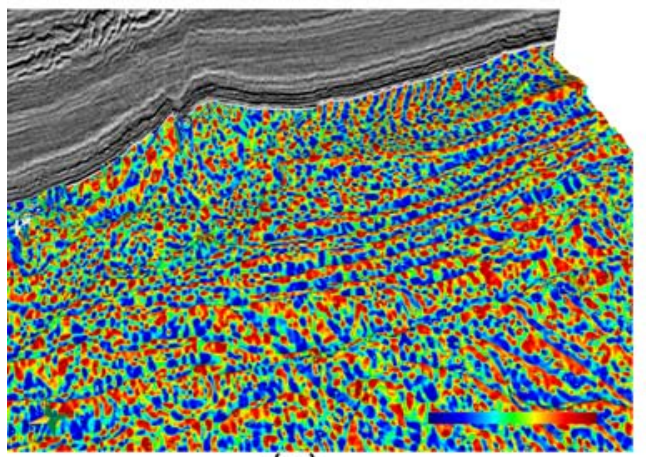

(e)

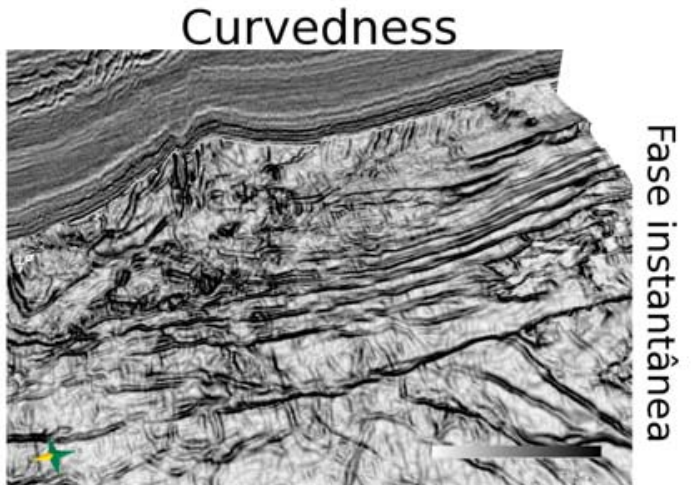

(b)

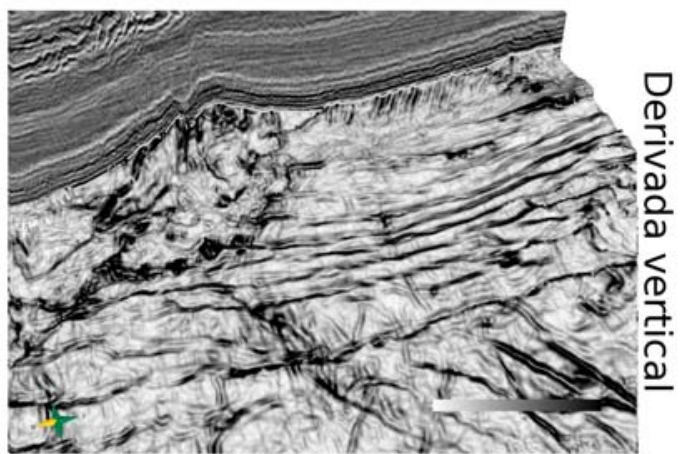

(d)

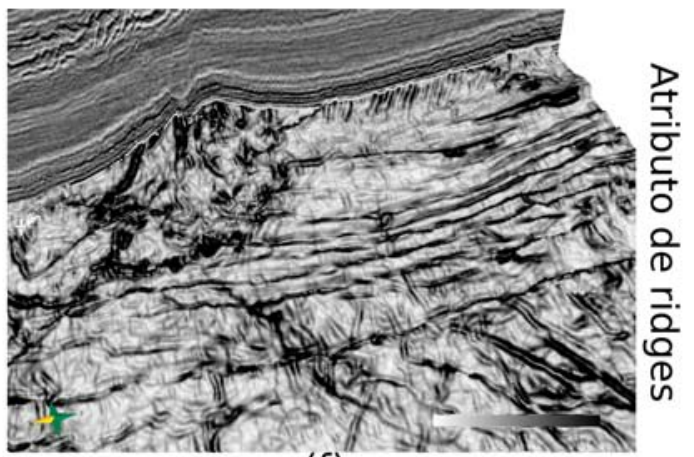

(f)

Figura 5.6: Atributos volumétricos de índice de forma e curvicidade, tendo a fase instantânea (a), a derivada vertical (b) e o atributo de ridges (c) como atributos identificadores de horizontes. Os atributos estão sendo visualizados ao longo de um horizonte rastreado a partir do volume de amplitudes. O operador de derivada considera uma vizinhança de 5x5x5 amostras e uma variância $\sigma^{2}=0,5$ para a derivada da função gaussiana. 


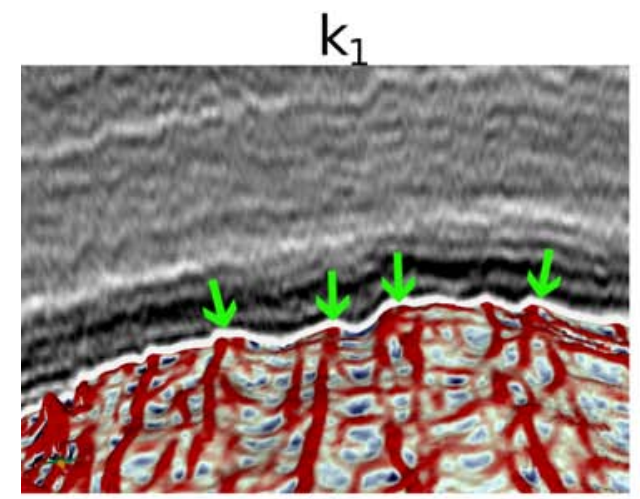

(a)

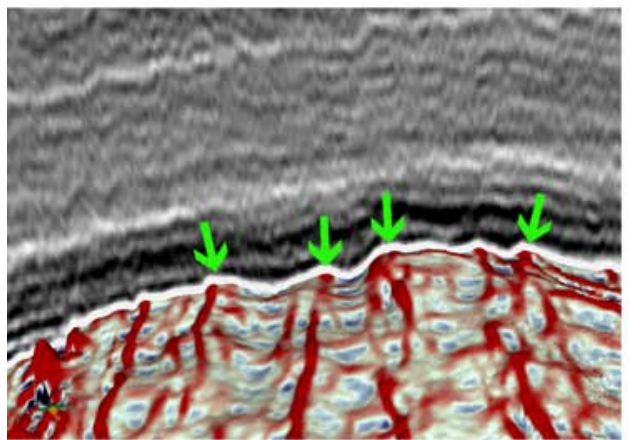

(c)

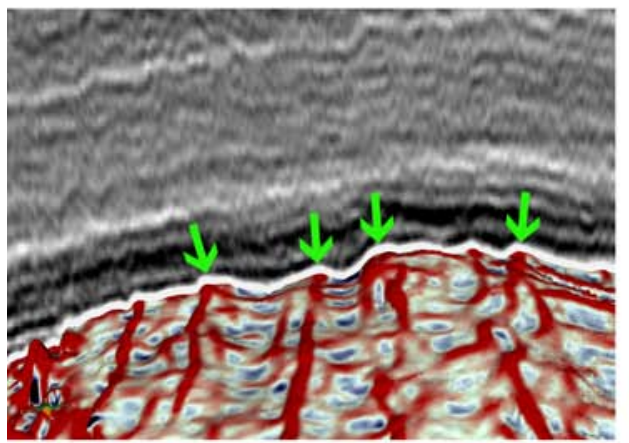

(e)

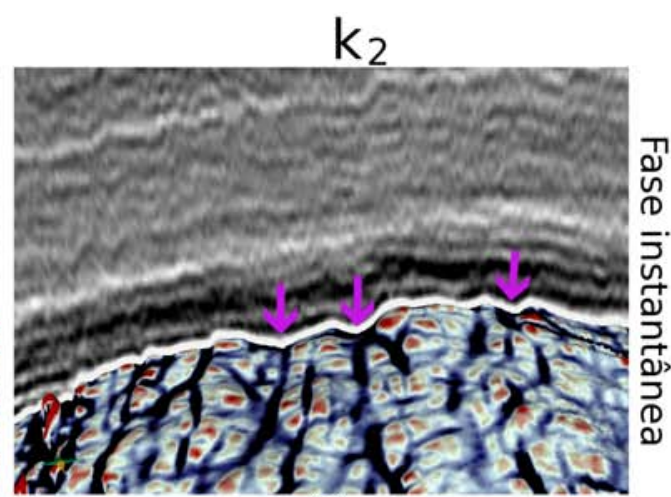

(b)

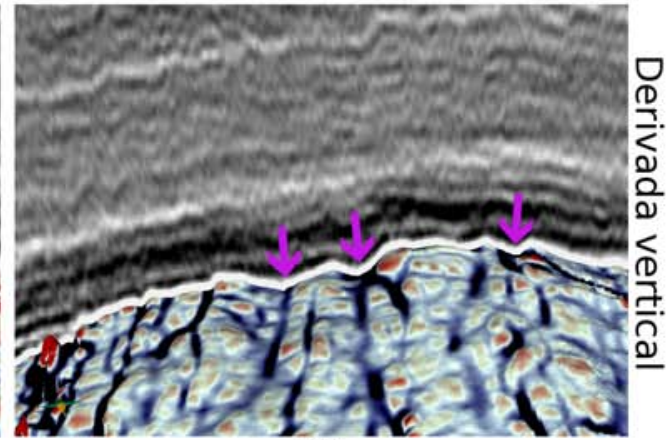

(d)

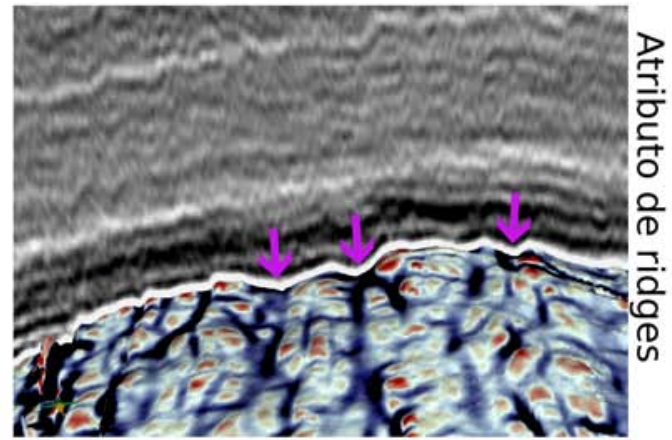

(f)

Figura 5.7: Comportamento dos atributos de curvatura em relação à sísmica original. Os atributos volumétricos de curvatura $k_{1}$ e $k_{2}$ estão sendo visualizados ao longo de um horizonte rastreado a partir do dado de amplitude e foram obtidos através do uso da fase instantânea ( $a$ e $b$ ), derivada vertical ( $c$ e $d$ ) e atributo de ridges ( $e$ e $f$ ) como atributos identificadores de horizontes. As setas indicam que existe uma correspondência entre os picos e vales do horizonte na sísmica e a resposta dos atributos volumétricos de curvatura. O operador de derivada considera uma vizinhanạ de $5 \times 5 \times 5$ amostras e uma variância $\sigma^{2}=0,5$ para a derivada da função gaussiana. 


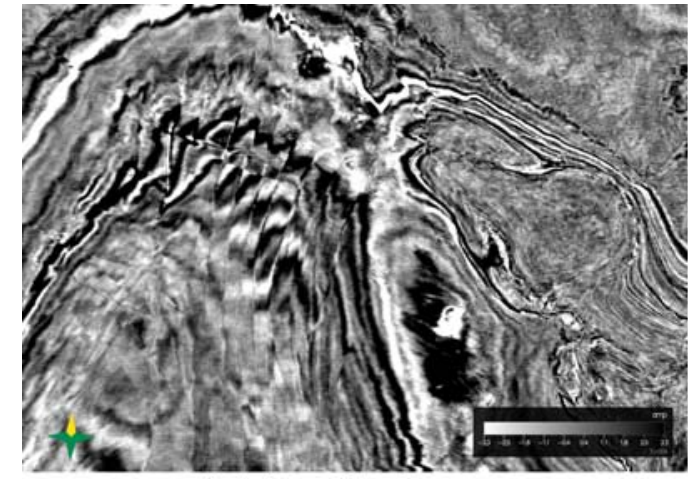

(a) Amplitude

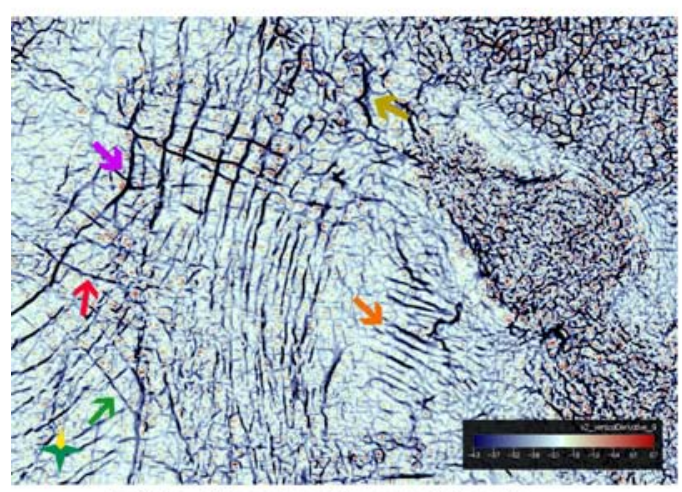

(c) $k_{2}$ (derivada vertical)

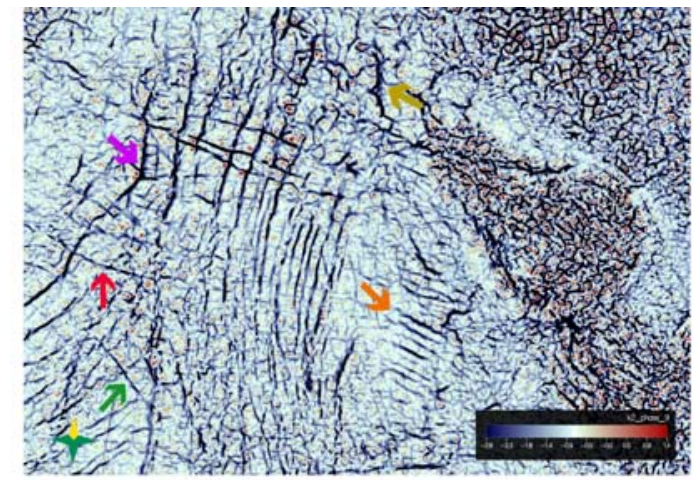

(b) $k_{2}$ (fase instantânea)

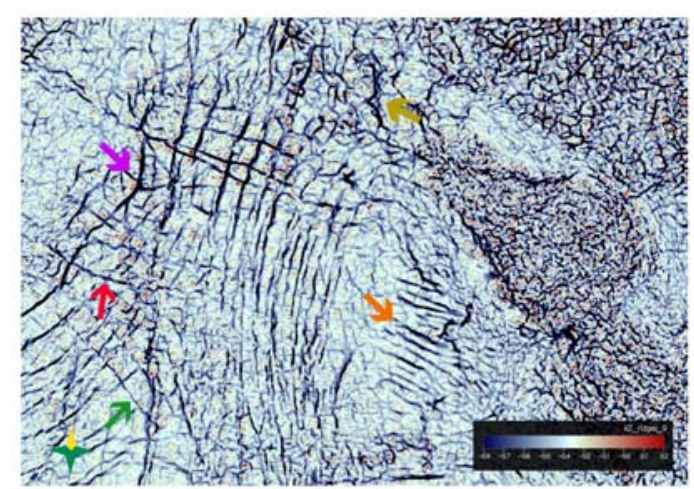

(d) $k_{2}$ (atributo de ridges)

Figura 5.8: Fatia de tempo da sísmica original e fatias correspondentes do atributo $k_{2}$ obtidas através da fase instantânea (a), derivada vertical (b) e atributo de ridges (c). O operador de derivada considera uma vizinhaną de 9x9x9 amostras e uma variância $\sigma^{2}=0,9$.

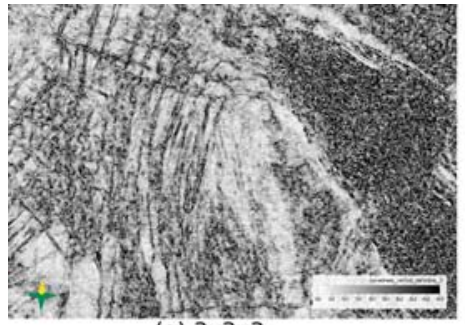

(a) $3 \times 3 \times 3$

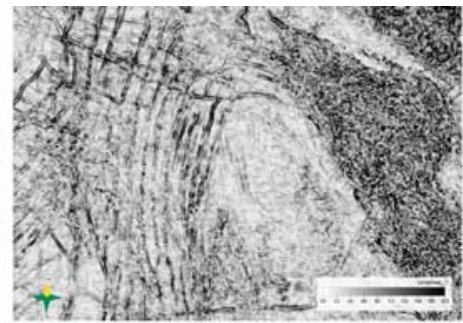

(b) $7 \times 7 \times 7$

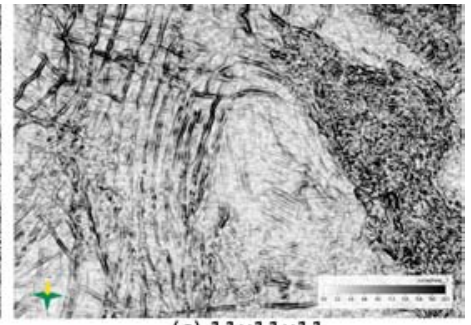

(c) $11 \times 11 \times 11$

Figura 5.9: Variação dos atributos de curvatura ocasionada pela pela mundança no tamanho do operador de derivada. Atributo de curvedness obtido a partir da derivada vertical, em uma fatia de tempo, considerando uma vizinhança de 3x3x3 (a), 7x7x7 (b) e 11x11x11 (c) amostras. 

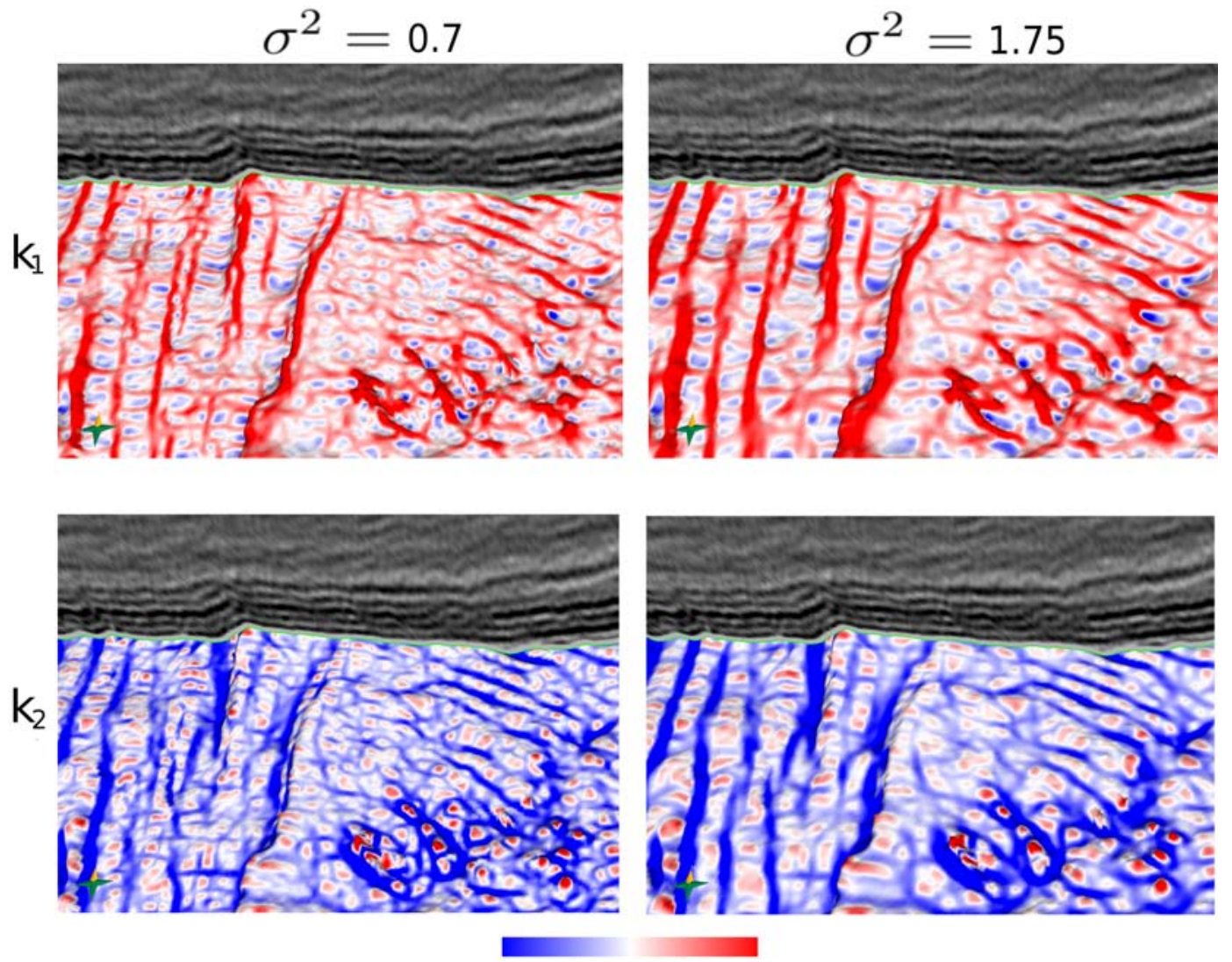

Figura 5.10: Influência da variância $\sigma^{2}$ no resultado do atributo de curvatura. São mostrados os atributos volumétricos $k_{1}$ e $k_{2}$, obtidos usando o atributo de derivada vertical, e visualizados ao longo de um horizonte rastreado. O tamanho do operador de derivada é de $7 \times 7 \times 7$ amostras. Podemos ver que o aumento de $\sigma^{2}$ é capaz de reduzir o detalhamento do resultado final dos atributos.

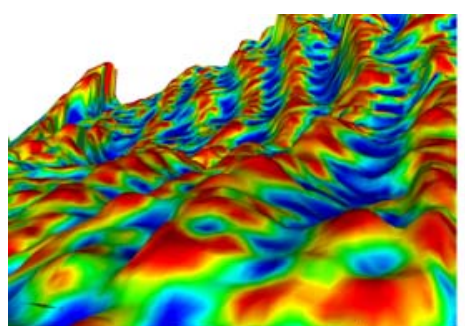

(a) Shape index (fase instantânea)

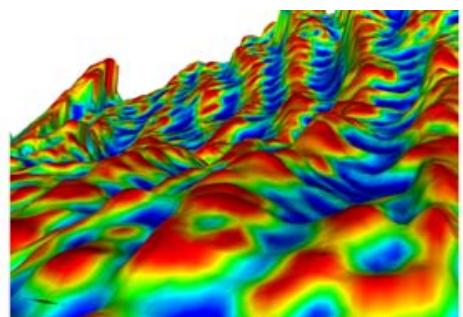

(b) Shape index (atributo de ridges) $0+1$

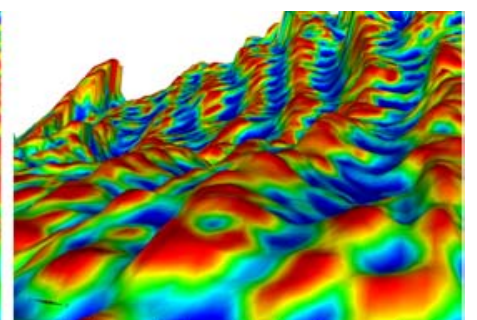

(c) Shape index (derivada vertical)

Figura 5.11: Comparação entre o atributo de índice de forma gerado usando a fase instantânea (a), a derivada vertical (b) e o atributo de ridges (c) como atributos identificadores de horizontes, considerando uma vizinhança de $11 \times 11 x 11$ amostras, para o operador de derivada. $O$ valor da variância $\sigma^{2}$ da derivada da gaussiana é $\sigma^{2}=1,1$. 


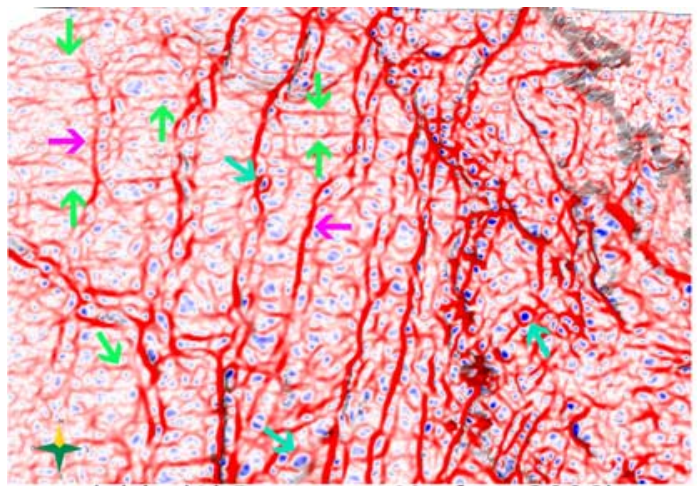

(a) $k_{1}$ (Al-Dossary e Marfurt, 2006)

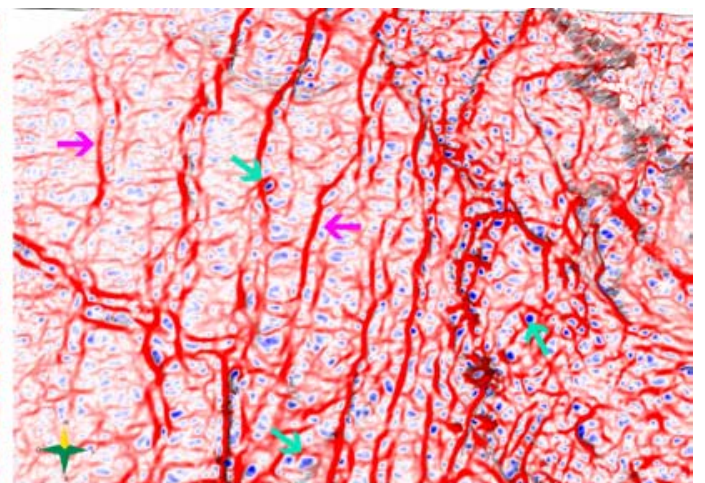

(b) $k_{1}$ (fase instantânea)

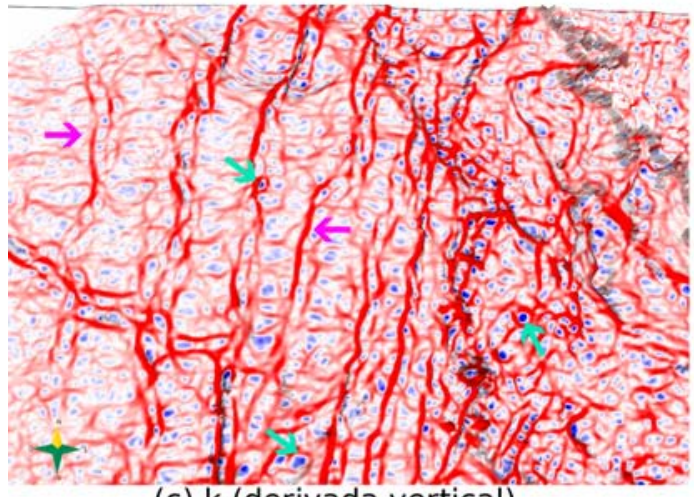

(c) $k_{1}$ (derivada vertical)

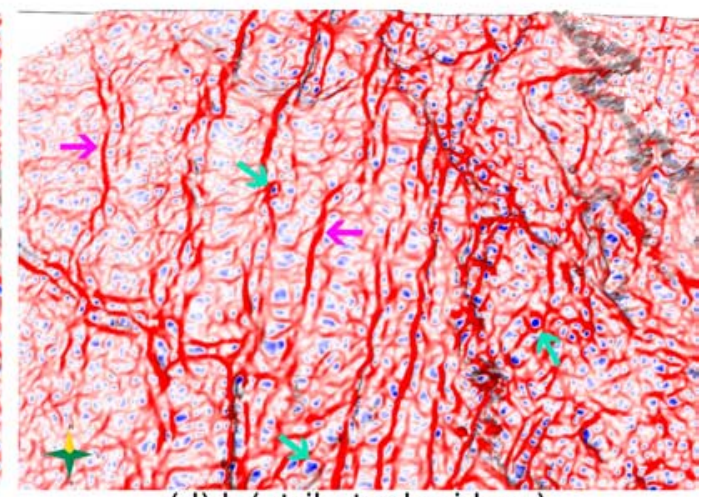

(d) $\mathrm{k}_{1}$ (atributo de ridges)

Figura 5.12: Comparação do método proposto com a abordagem proposta por Al-Dossary e Marfurt (2006). Em (a) temos o atributo volumétrico $k_{1}$ obtido através de uma implementação do trabalho de Al-Dossary e Marfurt (2006) sendo exibido ao longo de um horizonte rastreado. Em (b), (c) e (d) temos o mesmo atributo volumétrico obtido através da fase instantânea (b), derivada vertical (c) e atributo de ridges (d), ao longo do mesmo horizonte. Considerouse o tamanho do operador de derivada de $7 \times 7 \times 7$ amostras e a variância da derivada da gaussiana $\sigma^{2}=0,7$. Percebe-se nitidamente a presença das mesmas estr uturas principais nos atributos obtidos através das abordagens. Entretanto, na implementação do método de Al-Dossary e Marfurt (2006) as setas verdes indicam a presença de artefatos causados por ruído de aquisição, confirmados pelo intérprete, que não aparecem nos atributos obtidos de acordo com o método proposto. 


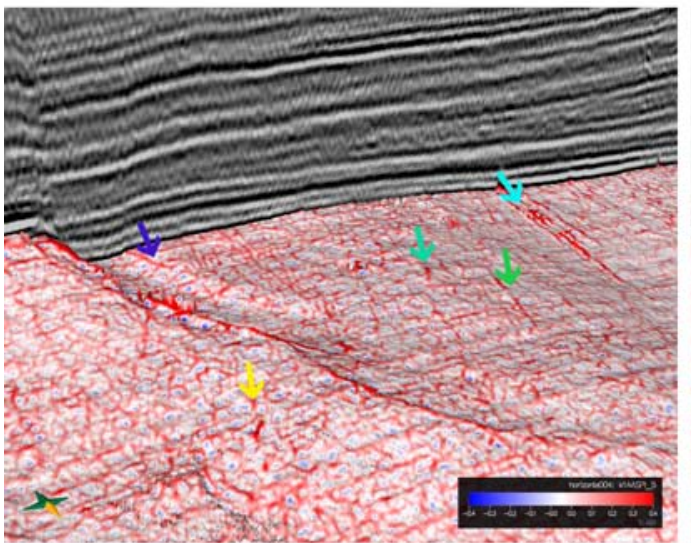

(a) $k_{1}$ (Al-Dossary e Marfurt, 2006)

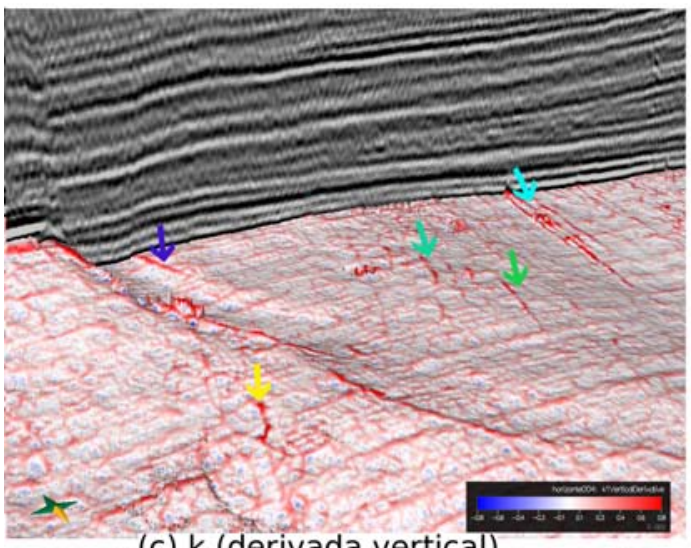

(c) $k_{1}$ (derivada vertical)

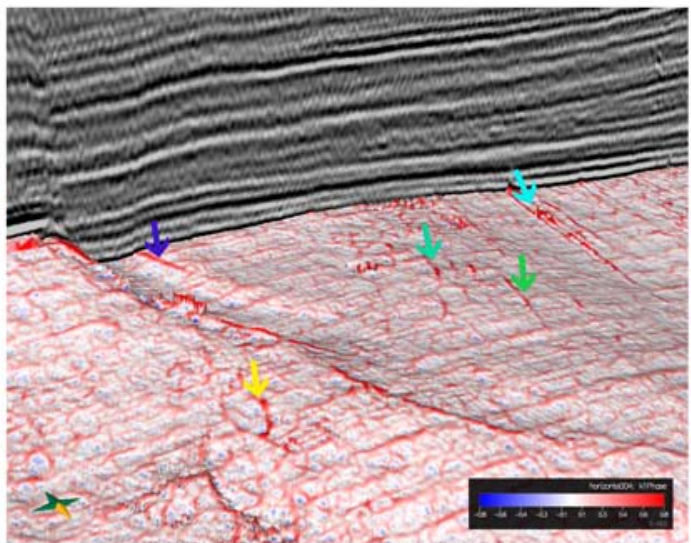

(b) $k_{1}$ (fase instantânea)

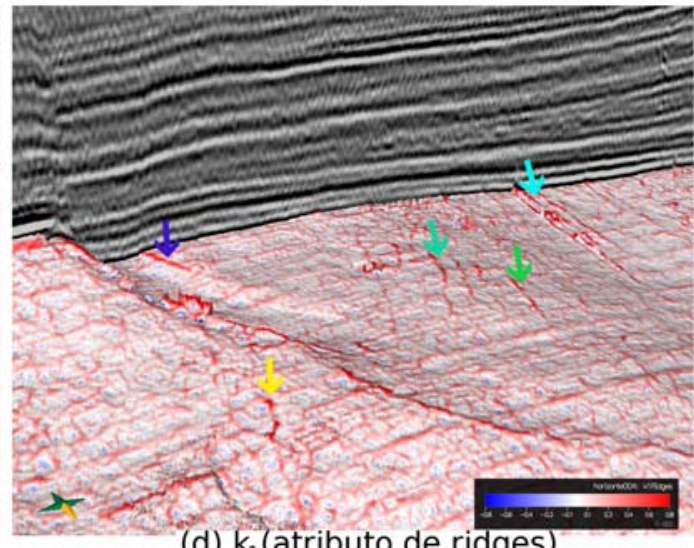

(d) $k_{1}$ (atributo de ridges)

Figura 5.13: Comparação do método proposto com a abordagem proposta por Al-Dossary e Marfurt (2006), mostrando a intersecção de uma seção vertical da sísmica original com um horizonte rastreado. Ao longo desse horizonte são exibidos os valores do atributo volumétrico $k_{1}$ obtido através da estimativa de Al-Dossary e Marfurt (2006) (a), e usando os atributos de fase instantânea (b), derivada vertical (c) e atributo de ridges (d) através do método proposto. Considerou-se o tamanho do operador de derivada de $5 \times 5 \times 5$ amostras e a variância da derivada da gaussiana $\sigma^{2}=0,5$. Uma inspeção visual mostra que os atributos obtidos através do método proposto apresentam menor sensibilidade a ruído de aquisição para o dado real usado nos experimentos. Além disso, as setas indicam que o método proposto é capaz de gerar maior continuidade no delineamento de falhas e fraturas confirmadas pelo intérprete. 


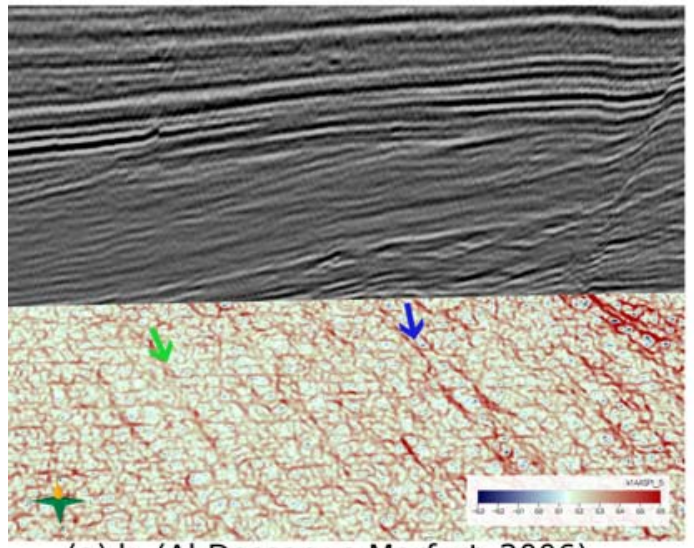

(a) $k_{1}$ (Al-Dossary e Marfurt, 2006)

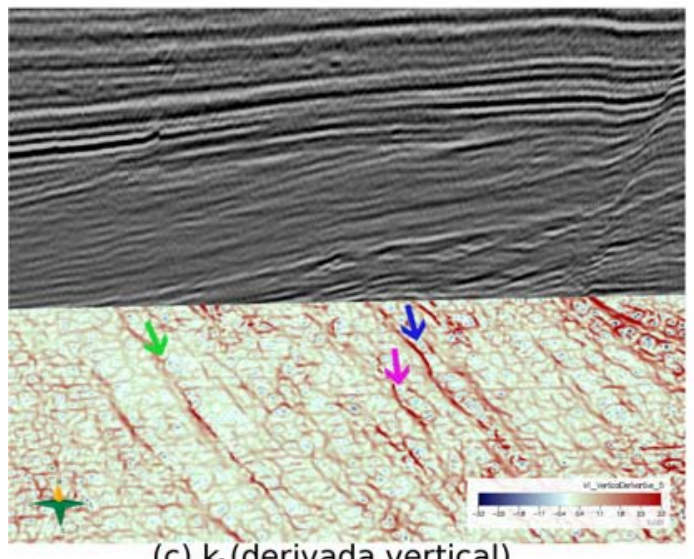

(c) $k_{1}$ (derivada vertical)

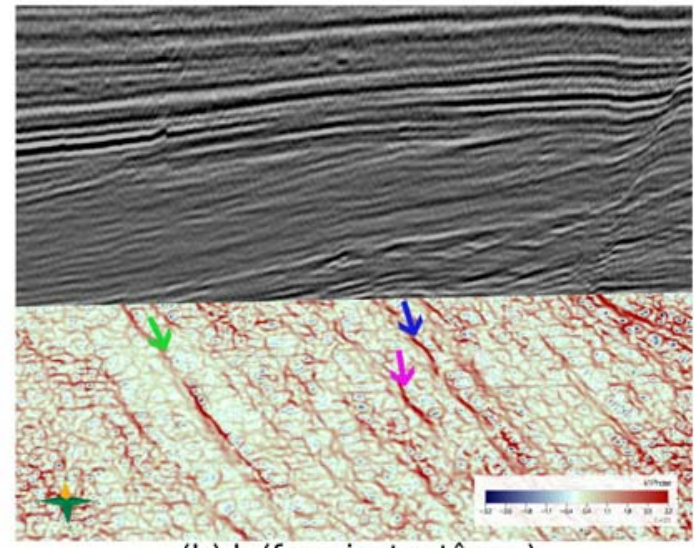

(b) $k_{1}$ (fase instantânea)

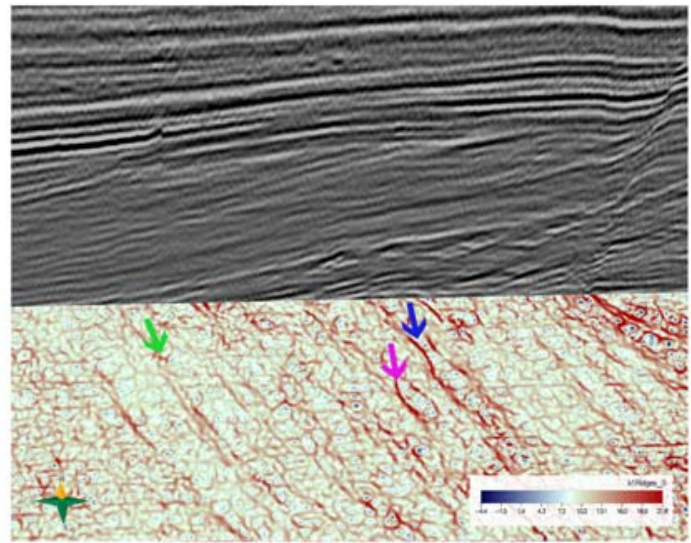

(d) $\mathrm{k}_{1}$ (atributo de ridges)

Figura 5.14: Comparação do método proposto com a abordagem proposta por Al-Dossary e Marfurt (2006). Em (a) temos a intersecção da sísmica original com uma fatia de tempo (horizontal) do atributo volumétrico $k_{1}$ obtido através do método de Al-Dossary e Marfurt (2006). Em (b), (c) e (d) temos o mesmo resultado usando os atributos de fase instantânea, derivada vertical e atributo de ridges, respectivamente, através do método proposto. Considerouse o tamanho do operador de derivada de $5 \times 5 \times 5$ amostras e a variância da derivada da gaussiana $\sigma^{2}=0,5$. Os resultados mostram que os atributos obtidos através do método proposto apresentam menor sensibilidade a ruído de aquisição para o dado real usado nos experimentos e maior continuidade no delineamento de falhas e fraturas confirmadas pelo intérprete. As setas roxas indicam uma falha geológica capturada pelo método proposto mas ausente no atributo obtido através da implementação da abordagem de Al-Dossary e Marfurt (2006) 


\section{6 \\ Conclusões e trabalhos futuros}

Este capítulo apresenta algumas conclusões obtidas a partir dos experimentos realizados, bem como algumas sugestões de trabalhos para dar continuidade à presente linha de pesquisa.

O presente trabalho apresentou uma nova abordagem para estimar, a partir de dados sísmicos de amplitude, atributos volumétricos de curvatura através da aplicação de geometria diferencial. Entretanto, a natureza oscilatória deste tipo de dado sísmico e variações laterais de amplitude não permitem tratar horizontes sísmicos como superfícies de nível, ou iso-superfícies. Portanto, este trabalho buscou representar adequadamente os horizontes como superfícies de nível através do cálculo de atributos cujos gradientes fornecessem uma representação mais coerente da orientação local de cada amostra. Para essa tarefa, foram analisados três atributos: fase instantânea, derivada vertical e atributo de ridges.

Uma vez que os horizontes sísmicos estejam adequadamente representados como iso-superfícies, através do cálculo de um atributo identificador de horizontes, o método usado neste trabalho propôs o uso de fórmulas que permitem estimar de maneira eficiente de diversos atributos de curvatura, tais como curvatura média, gaussiana e as curvaturas principais.

Os experimentos com dados sintéticos mostraram que a abordagem proposta nesta tese apresenta um razoável grau de robustez, sendo capaz de fornecer resultados numéricos próximos aos valores esperados de curvatura, mesmo na presença de ruído. Em particular, os resultados obtidos mostram o potencial da derivada vertical e do atributo de ridges como atributos identificadores de horizontes, capazes de representar, de maneira aproximada, horizontes como superfícies de nível.

Os resultados obtidos com o uso de um dado sísmico real mostraram o potencial do método proposto como ferramenta de auxílio à interpretação geológica. Foi verificado que os três atributos propostos neste trabalho fornecem resultados de atributos de curvatura visualmente semelhantes. Além disso, os resultados mostram que o método proposto é capaz de delinear feições sísmicas tais como falhas e fraturas com razoável grau de continuidade e sensibilidade ao ruído de aquisição menor em comparação com a abordagem proposta por Al-Dossary e Marfurt (2006), uma das mais citadas na literatura. As feições realçadas pelos atributos gerados através do método proposto foram 
confirmadas pelo intérprete.

Em relação ao tempo de processamento, o método proposto mostrouse mais eficaz em comparação com a abordagem proposta por Al-Dossary e Marfurt (2006). Futuramente, a paralelização dos algoritmos usados na implementação do método proposto certamente irá acelerar ainda mais o tempo de processamento.

Dentre as contribuições apresentadas por este trabalho pode-se citar uma nova abordagem para a estimativa de atributos volumétricos de curvatura em dados sísmicos, a qual, fundamentada inteiramente na teoria da geometria diferencial, é capaz de prover uma estimativa razoável dos principais atributos de curvaturas usados na interpretação e predição de diversas feições estratigráficas, a um tempo de processamento aceitável ao usuário final.

É um fato conhecido que a estimativa da curvatura, por fazer uso de derivadas de segunda ordem, é bastante sensível à presença de ruído no dado de entrada. Este trabalho buscou contornar este problema suavizando as estimativas de derivadas através da convolução com a derivada da função gaussiana. Apesar de fornecer razoável eficácia frente a ruído aleatório, esta abordagem não contempla a presença de ruído coerente, ou de aquisição, comumente encontrado no dado sísmico de amplitude. Os resultados mostraram que a presença de ruídos de aquisição introduz alguns artefatos no resultado final dos atributos. Isso é confirmado por Chopra et al. (2011a), que fornecem diversos exemplos de como o processamento de atributos sísmicos, como curvatura e coerência, em dados de entrada ruidosos pode fornecer estimativas equivocadas dos mesmos. Portanto, como trabalho futuro, propõe-se a inserção de uma etapa de pré-processamento do dado sísmico, com o uso de técnicas de filtragem orientada e balanceamento espectral para suprimir o máximo possível os diversos tipos de ruídos comumente encontrados nesse tipo de dado.

Uma aplicação dos resultados desta tese encontra-se no uso do campo de normais provido pelos gradientes dos atributos identificadores de horizontes propostos em aplicações de visualização volumétrica. Além disso, os atributos propostos podem ser usados em funções de transferência $2 \mathrm{D}$ como forma de realçar os horizontes e fornecer uma melhor representação visual do volume de amplitudes.

O uso do tensor de estrutura do gradiente nos atributos identificadores de horizonte pode fornecer uma orientação local mais suavizada e, por conseguinte, uma curvatura menos sensível a ruídos, assim como a suavizacão do atributo identificador de horizontes através de filtros direcionais. Nesse contexto, a aplicação da suavização da fase instantânea proposta por Solberg et al. (2012) pode remover eventuais ruídos introduzidos por esse atributo no 
processo de estimativa dos atributos de curvatura.

Finalmente, devido à flexibilidade do método proposto neste trabalho, podemos considerar a investigação de outros atributos identificadores de horizonte, bem como outras técnicas de suavização de campos vetoriais, com intuito de gerar atributos de curvatura livres de ruídos mas sem deixar de realçar as feições mais sutis do volume de amplitudes sísmicas. 


\section{Referências Bibliográficas}

AL-DOSSARY, S.; MARFURT, K. J. 3d volumetric multispectral estimates of reflector curvature and rotation. Geophysics, v. 71, n. 5, p. 41-51, 2006.

BARNES, A. E. Coherence and dispersion as complex seismic trace attributes. In: Proceedings of the 1997 SEG Annual Meeting. Dallas: [s.n.], 1997.

CHOPRA, S.; MARFURT, K. J. Curvature attribute applications to $3 \mathrm{~d}$ surface seismic data. CSEG Recorder, p. 44-56, set. 2006.

CHOPRA, S.; MARFURT, K. J. Seismic curvature attributes for mapping faults/fractures, and other stratigraphic features. CSEG Recorder, p. 37-41, nov. 2007.

CHOPRA, S.; MARFURT, K. J. Volumetric curvature attributes add value to $3 d$ seismic data interpretation. The Leading Edge, p. 856-867, jul. 2007.

CHOPRA, S.; MARFURT, K. J. Interesting pursuits in seismic curvature attribute analysis. CSEG Recorder, p. 41-51, abr. 2011.

CHOPRA, S.; MISRA, S.; MARFURT, K. J. Emerging and future trends in seismic attributes. The Leading Edge, p. 298-318, mar. 2008.

CHOPRA, S.; MISRA, S.; MARFURT, K. J. Coherence and curvature attributes on preconditioned seismic data. The Leading Edge, p. 260-266, abr. 2011.

CHOPRA, S.; MISRA, S.; MARFURT, K. J. Integration of coherence and volumetric curvature images. In: Proceedings of Recovery 2011 - CSPG CSEG CWLS Convention. [S.I.: s.n.], 2011.

DONIAS, M.; BAYLOU, P.; KESKES, N. Curvature of oriented patterns: 2-d and 3-d estimation from differential geometry. IEEE International Conference on Image Processing, v. 1, p. 236-240, 1998.

ERICSSON, J. B.; MCKEON, H. C.; HOOPER, R. J. Facies and curvature controlled 3-d fracture models in a cretaceous carbonate reservoir, arabian gulf. Faulting, Fault Sealing and Fluid Flow in Hydrocarbon Reservoirs, Geological Society Special Publication, v. 147, p. 299-312, 1988.

FIGUEIREDO, A. M. Mapeamento Automático de Horizontes e Falhas em Dados Sísmicos 3D baseado no algoritmo de Gás Neural Evolutivo. Dissertação (Mestrado) - Departamento de Informática , PUC-Rio, 2007. 
FRANCIS, J. J.; JAGER, G. de. The bilateral median filter. Transactions of the South African Institute of Electrical Engineers, v. 96, n. 2, p. 106-111, 2005.

GAUSS, C. F. Disquisitiones generales circa superficies curvas. [S.I.]: Typis Dieterichianis, 1828.

GERHARDT, A. Aspectos da Visualização Volumétrica de Dados Sísmicos. Dissertação (Mestrado) — Departamento de Informática , PUC-Rio, 1998.

GOLDMAN, R. Curvature formulas for implicit curves and surfaces. Computer aided geometric design, Elsevier, v. 22, p. 632-658, 2005.

KINDLMANN, G.; WHITAKER, R.; TASDIZEN, T.; MOLLER, T. Curvaturebased transfer functions for direct volume rendering: methods and applications. In: Proceedings of the IEEE Visualization 2003. [S.I.: s.n.], 2003. p. 512-520.

KLEIN, P.; RICHARD, L.; JAMES, H. 3d curvature attributes: a new approach for seismic interpretation. First Break, v. 26, p. 105-111, 2008.

KOENDERINK, J. J.; DOORN, A. J. van. Surface shape and curvature scales. Image and Vision Computing, v. 10, n. 8, p. 557 - 564, 1992. ISSN 0262-8856.

LINDEBERG, T. Scale-space theory: A basic tool for analysing structures at different scales. Journal of Applied Statistics, v. 21, n. 2, p. 225-270, 1994.

LISLE, R. J. Detection of zones of abnormal strains in structures using gaussian curvature analysis. AAPG Bulletin, v. 78, n. 12, p. 1811-1819, 1994.

LUO, Y.; HIGGS, W. G.; S.KOWALIK, W. Edge detection and stratigraphic analysis using 3d seismic data. In: Proceedings of the 1996 SEG Annual Meeting. Denver: [s.n.], 1996.

MAI, H.; MARFURT, K. J.; TAN, M. T. Multi-attributes display and rose diagrams for interpretation of seismic fracture lineaments, example from cuu long basin, vietnam. In: Proceedings of the 9th SEGJ International Symposium Imaging and Interpretation - Science and Technology for Sustainable Development. [S.I.: s.n.], 2009. Paper 1D93.

MARFURT, K. J. Robust estimates of 3d reflector dip and azimuth. Geophysics, v. 71 , n. 4 , p. $29-40,2006$.

MARFURT, K. J.; SUDHAKER, V.; GERSZTENKORN, A.; CRAWFORD, K. D.; NISSEN, S. Coherency calculations in the presence of structural dip. Geophysics, v. 64, n. 1, p. 104-111, 1999. 
MARTINS, L. de O.; SILVA, P. M. C.; GATTASS, M. A method to estimate volumetric curvature attributes in $3 \mathrm{~d}$ seismic data. In: Proceedings of 74th EAGE Conference \& Exhibition incorporating SPE EUROPEC 2012. Copenhagen: [s.n.], 2012. Paper E023.

MYNATT, I.; BERGBAUER, S.; POLLARD, D. Using differential geometry to describe 3-d folds. Journal of structural geology, Elsevier, v. 29, p. 1256-1266, 2007.

OPENDTECT. Open Seismic Repository. set. 2011. http:

//www . opendtect.org/osr/Main/HomePage.

PHILLIPS, F.; TODD, J. T. Perception of local three-dimensional shape. Journal of Experimental Psychology: Human Perception and Performance, v. 22, n. 4, p. 930-944, 1996.

ROBERTS, A. Curvature attributes and their application to $3 \mathrm{~d}$ interpreted horizons. First Break, v. 19, p. 85-99, 2001.

SCHROOT, B. M.; SCHUTTENHELM, R. T. E. Expression of shallow gas in the netherlands north sea. Geologie \& Mijnbouw, v. 82, n. 1, p. 91-105, 2003.

SIGISMONDI, E. M.; SOLDO, C. J. Curvature attributes and seismic interpretation: Case studies from argentina basins. The Leading Edge, v. 22, p. 1122-1126, 2003.

SILVA, P. M. C. Visualização volumétrica de horizontes em dados sísmicos 3D. Tese (Doutorado) - Departamento de Informática , PUC-Rio, 2004.

SILVA, P. M. C.; MACHADO, M.; GATTASS, M. 3d seismic volume rendering. In: Proceedings of the Eight International Congress of the Brasilian Geophysical Society. Rio de Janeiro: [s.n.], 2003.

SOLBERG, A.; JENSEN, A.; GELIUS, L. J. Robust 2d hilbert atributes of local amplitude and phase. In: Proceedings of 74th EAGE Conference \& Exhibition incorporating SPE EUROPEC 2012. Copenhagen: [s.n.], 2012. Paper E022.

VIDAL, A. C.; SANCEVERO, S. S.; ReMACRE, A. Z.; COSTANZO, C. P. Modelagem geoestatística $3 \mathrm{~d}$ da impedância acústica para a caracterização do campo de namorado. Revista Brasileira de Geofísica, v. 25, n. 3, 2007.

WANG, W.; GAO, J.; ZHENG, H.; CHEN, W.; ZHANG, E. Edge preserving vector filter for smoothing reflector dip and azimuth. In: Proceedings of the 2010 SEG Annual Meeting. Denver, Colorado: [s.n.], 2010. p. 1488-1493. 
WEN, R.; TOWNSEND, C. Seismic attributes for mapping small scale faults in reservoirs. In: Proceedings of the 59th EAGE Conference. Geneva: [s.n.], 1997. Presentation C010.

YOSHIDA, H.; NAPPI, J.; MACENEANEY, P.; RUBIN, D. T.; DACHMAN, A. H. Computer-aided diagnosis scheme for detection of polyps at ct colonography. RadioGraphics, v. 22, n. 4, p. 963-979, 2002. 